\title{
ENEERGY
}

DOE/ET/29355-T7

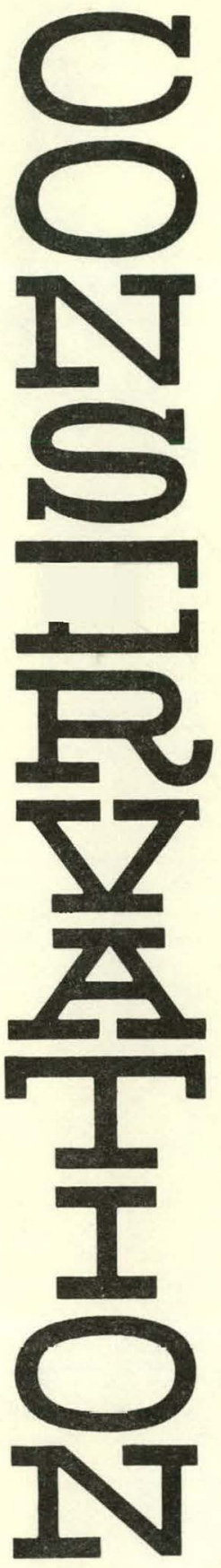

\section{PERFORMANCE OF A TECHNICAL AND ECONOMICAL FEASIBILITY STUDY OF AN HVDC COMPRESSED GAS INSULATED TRANSMISSION LINE}

Third Quarterly Progress Report for April 1-June 30, 1980

By
R. L. LaBarge

July 15,1980

Work Performed Under Contract No. AC01-79ET29355

Aluminum Company of America

Alcoa Center, Pennsylvania

\section{U. S. DEPARTMENT OF ENERGY}

Division of Electric Energy Systems 


\section{DISCLAIMER}

This report was prepared as an account of work sponsored by an agency of the United States Government. Neither the United States Government nor any agency Thereof, nor any of their employees, makes any warranty, express or implied, or assumes any legal liability or responsibility for the accuracy, completeness, or usefulness of any information, apparatus, product, or process disclosed, or represents that its use would not infringe privately owned rights. Reference herein to any specific commercial product, process, or service by trade name, trademark, manufacturer, or otherwise does not necessarily constitute or imply its endorsement, recommendation, or favoring by the United States Government or any agency thereof. The views and opinions of authors expressed herein do not necessarily state or reflect those of the United States Government or any agency thereof. 


\section{DISCLAIMER}

Portions of this document may be illegible in electronic image products. Images are produced from the best available original document. 


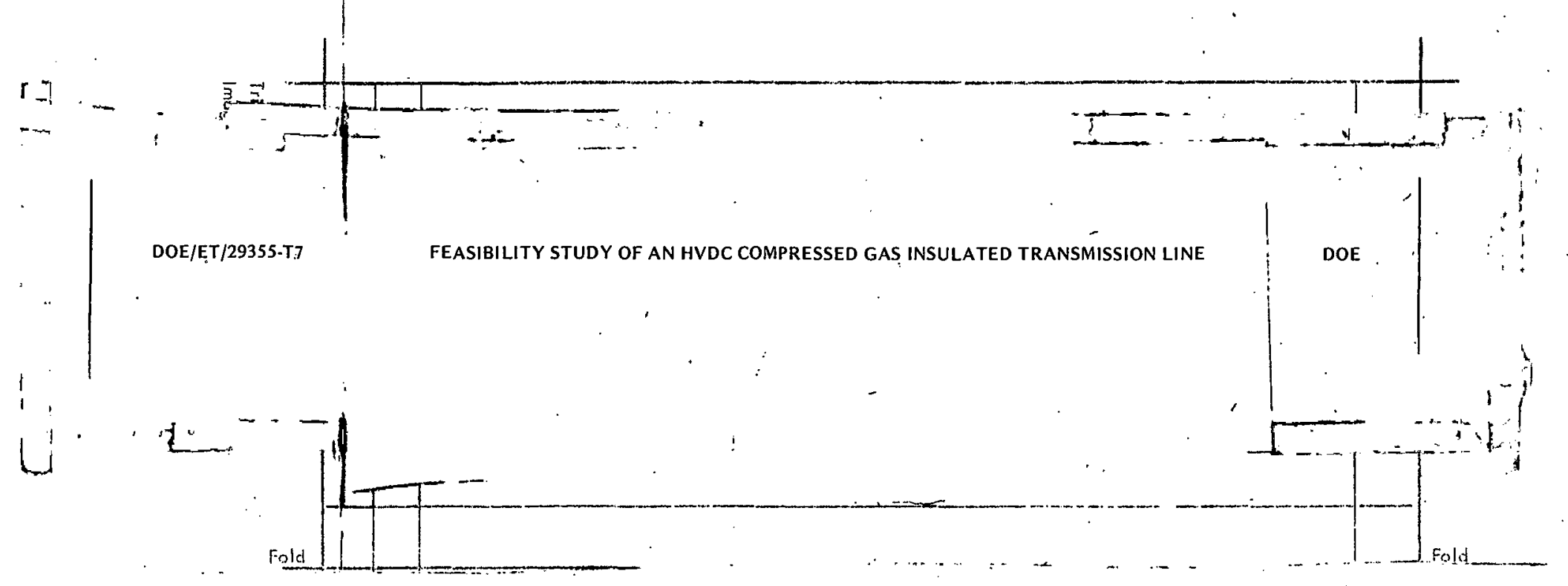




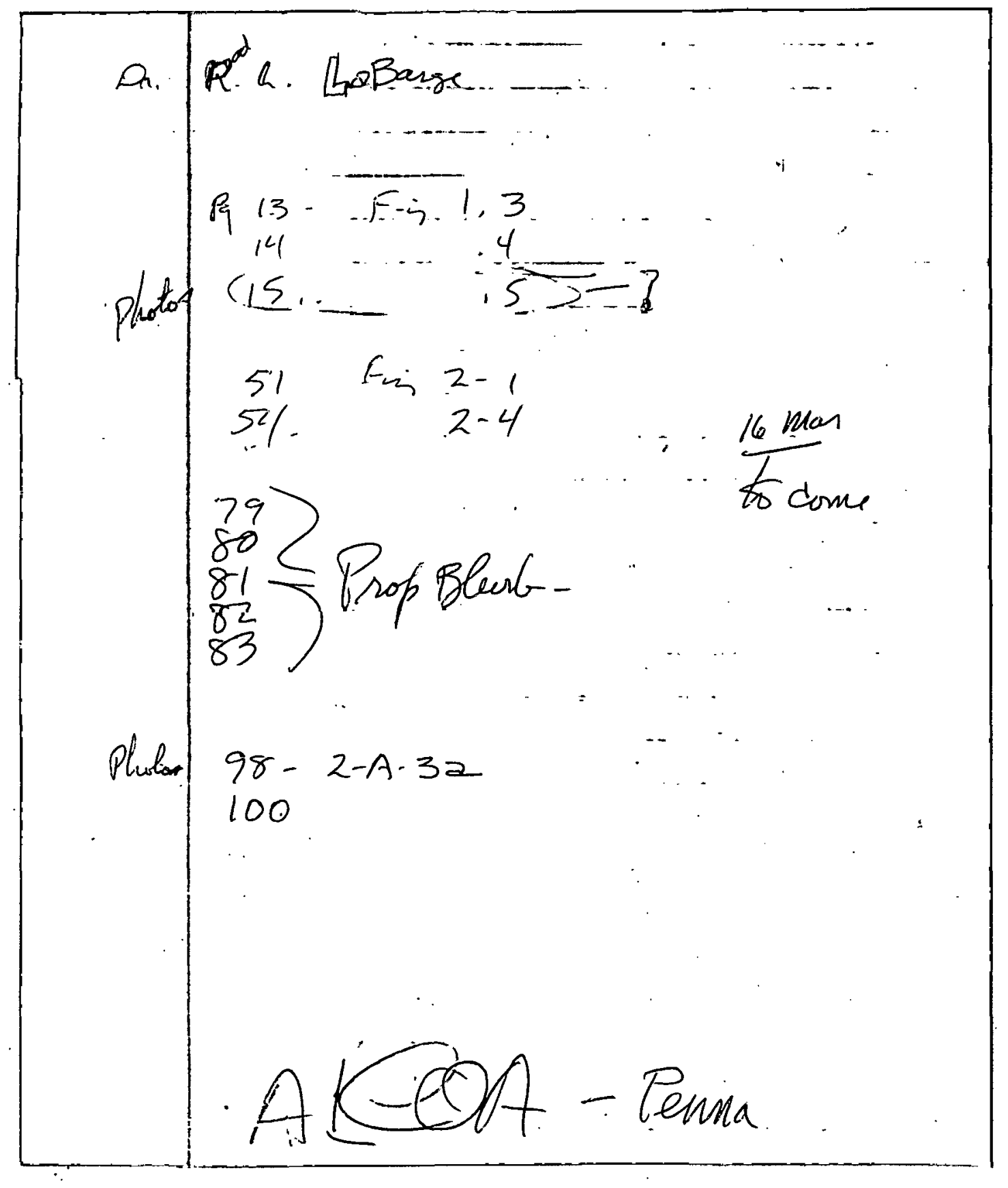



PERFORMANCE OF A TECHNICAL AND ECONOMICAL FEASIBILITY STUDY

OF AN HVDC COMPRESSED GAS INSULATED TRANSMISSION LINE

THIRD QUARTERLY PROGRESS REPORT

FOR PERIOD 1980 APRIL 01 - 1980 JUNE 30

R. L. LA BARGE

ALUMINUM COMPANY OF AMERICA

ALCOA TECHNICAL CENTER

ALCOA CENTER, PA 15069

PREPARED FOR THE

DEPARTMENT OF ENERGY

UNDER CONTRACT DE-AC01-79ET 29355 
TABLE OF CONTENTS

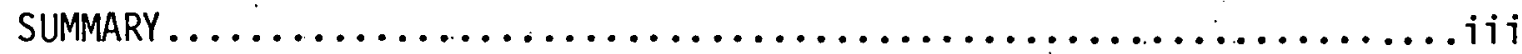

TASK 1 CABLE SYSTEM DEFINITION......................... 1

TASK 2 GAS DIELECTRIC INVESTIGATION. .......................41

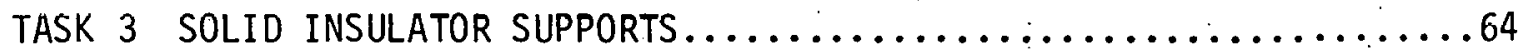

TASK 4 ENCLOSURE AND CONDUCTOR...........................66

APPENDIX 2-A PARTICLE MOTION.................................

APPENDIX 4.1 COMPUTER PROGRAM........................... 112

APPENDIX 4.2 COMPUTER PROGRAM............................. 115

APPENDIX 4.3 COMPUTER PROGRAM............................ 118 


\section{EXECUTIVE SUMMARY}

\section{A. Progress Made During the Third Quarter}

1. HVDC commissioning procedure has been successfully demonstrated with model cables. Particles of all types and in large numbers never found in a practical cable are placed in the middle of the model cable at the beginning but are trapped at the end of the commissioning procedure.

The procedure consists of a series of raising-holding-lowering voltage cycles. Axial motion of particles is caused by bouncing; hovering particles are forced to bounce during the raising and lowering period while other types of particles during the holding period as well.

The concepts of protecting the insulators have been successfully realized. Small particles are confined in the lower half of the cable and bounced into traps in the bulge. Large particles invading Into the tup half of the cable are captured hovering around the ends and along the lower edge of the expansion-joint shield; they are subsequently bounced into the trap below the expansion-joint shield. None of the particles can contaminate the insulators, even when the insulators are placed as low as at the $20^{\prime}$ clock or $100^{\prime \prime}$ clock position.

Trapped particles are not pulled out of the improved traps on polarity reversals. 
2. Simulation of particle path is done with a microcomputer. The very simple simulation model predicts the effect of the enclosure profile and agrees with test observations.

3. Both test observations and the simulations lead to the expectation that a successful HVDC commissioning procedure can be applied to the total length of an installed cable.

4. Overvoltages within the cable due to lightning surge have been analyzed. The most severe switching overvoltages were analyzed previously. A $1300 \mathrm{kV}$ BIL and a $1050 \mathrm{kV}$ BSIL are independently shown to be feasible. This is a conservative conclusion. Lower BIL and BSIL could be feasible if the improvement of arrester technology is projected for longer term and/or if more elaborate protection schemes are introduced.

5. Thermal expansion of the insulator is shown to be compatible with the metal inserts.

6. "As-cast" conductor can be used to achieve equal, if not better, utilization of the gas dielectric strength with respect to lightning impulse. Other types of voltage are still to be assessed.

7. Work has been started for the report on the effect of material selection as well as processing into insulators on the long-term dielectric performance of the insulator. 
8. Computer programs have been written to calculate conductor stress and deflection and mechanical loads on the insulators for any desired conductor size.

9. The design of a prototype expansion joint has been completed and is being assembled for mechanical and electrical testing.

10. A field joining concept has been outlined that minimizes the possibility of contaminating the system. 
B. Work PIanned for the Next Quarter

1. Tests will be made to determine fully the dielectric strength of gas with "as-cast" conductor.

2. Improvement in HVDC commissioning procedure will be sought during the above tests.

3. Further tests will be made on the property of insulator affecting its strength during polarity reversals.

4. In view of the concern about particles which could possibly be on the insulator before the HVDC commissioning, additional tests will be proposed to DOE to resolve this concern.

5. Complete the mechanical and electrical tests on the expansion joint prototype.

6. Continue the field installation study. 


\subsection{Introduction}

The emphasis of the dielectric program is to obtain by tests the probabilistic design data for a cable so that the cable can be optimized to match the arrester characteristics then available. However, it is necessary to demonstrate by tests the technical feasibility of the novel design concepts and for the test purpose the BIL and the BSIL have to be fixed. In the following sections, the reasons and the supporting data are reviewed for the conclusion that a $1300 \mathrm{kV}$ BIL and a $1050 \mathrm{kV}$ BSIL are feasible. More precise analysis or longer term projection of arrester characteristics may lead to lower BIL and BSIL.

\subsection{Arrester Characteristics}

The selection of arrester rating has been discussed in the Second Quarterly Report. The arrester characteristics used assume some modest improvement over the near-term future as compared to present commercially available arresters. Each arrester consists of two columns of MOV discs. The number of discs are selected to withstand normal system voltage $( \pm 600 \mathrm{kV})$ indefinitely. To lower the protective level, $15 \%$ of the discs are shunted by a gap which, at appropriate overvoltage, will spark over and bypass the shunted discs. The characteristics are shown in Fig. 1.1 (Fig. 1.1 of the Second Quarterly Report). Some numerical values are given in Table 1.1.

\subsection{Switching Surge Protective Level *}

Based on past analyses, the disturbances causing the most severe overvoltages are listed in Table 1.2 (Table 1.2 of the Second Quarterly Report). For a well-designed station, the most severe switching surges are items 4 and 6 . Simulator tests were made of these items.

\footnotetext{
* The work was carried out by J. Hudson of EUSED, G.E. Co., Schenectady.
} 
Item 4 (referred to as Case 1 in the Second Quarterly Report) is defined in Fig. 1.2 with oscillograms shown in Figs. 1.3 and 1.4 (Figs. 1.3, 1.4 and 1.5 of the Second Quarterly. Report).

Item 6 (referred to as Case 2 in the Second Quarterly Report) is defined in Fig. 1.5, in which are also shown the test results (Fig. 1.6 of the Second Quarterly Report).

In both cases, the arrester currents are well below $3 \mathrm{kA}$. Using conservatively $3 \mathrm{kA}$ as the base for switching surge coordination, the protective level is $854 \mathrm{kV}$. Adding $15 \%$ safety margin leads to $982 \mathrm{kV}$. 


\section{$1.4 \quad$ Lightning-Surge Protective Level}

\subsubsection{Introduction}

Investigations have been made to assess the feasibility of a $1300 \mathrm{kV}$ BIL with respect to lightning surges. Section 1.4 .2 gives an outline of the mechanism by which overvoltages within the cable can exceed the protective level of the arresters at the cable terminals. Section 1.4.3 outlines the parameters of lightning currents, based on recent work done by CIGRE WG 33-01. These parameters and the design of the overhead line are the controlling factors on the shape and the magnitude of lightning surges. Section 1.4 .4 gives the results of computed overvoltages within the cable. The results illustrate the benefits of two protective schemes. One scheme is used to lengthen the front and to slow down the rate of rise of the surge into the cable. The other scheme is used to do likewise to the reflected surge at the station-end of the cable. These preliminary results indicate that a $1300 \mathrm{kV}$ BIL is feasible with additional arresters on the overhead line or with additional capacitors at the station.

\subsubsection{Overvoltage Within the Cable}

As stated earlier, MOV arresters are installed at both ends of the cable, each arrester consisting of two columns with $15 \%$ of each column shunted with an appropriately set sparking gap. The scheme is depicted at the top of Fig. $1-6$.

Against lightning surges, these arresters will limit the voltage at the cable terminals to a certain voltage (considered as 1 per unit, without loss of generality). However, the peak overvoltage could be higher within the cable. 
Fig. 1-6 depicts the overvoltage, assuming conventional arresters with series gap, which spark over at 1 p.u. voltage. The small initial drop of discharge voltage is ignored to simplify the diagram. It is seen that the peak voltage at $A$ within. the cable could reach 1.5 p.u.

Fig. 1-7 depicts similar conditions but using MOV arresters without series gap. The peak voltage at $A$ is now only 1.13. Comparison of Fig. 1-6 with Fig. 1-7 illustrates that the "protective effect" of a MOV arrester extends further into the cable than a conventional arrester, more so for surges with slower rate of rise.

If the incident surge has an infinite tail, the peak overvoltage within the cable would be 1.26 for locations at least $t_{f} / 2$ (traveling time) from the station $S$. This overall peak overvoltage could be smaller than 1.26 p.u. for incident surges having finite tails.

The peak overvoltage within the cable thus depends on the shape of the incident surge. The shape of the incident surge is controlled by the shape of the lightning current and the characteristics of the arresters. Also, various schemes can be devised to modify the rate of rise of the incident surge into the cable or the reflected surge at the station end of the cable due to successive reflections. The most severe surge is the full wave, of which the peak voltage equals the flashover voltage of the line insulation. (Ref.1-1

\subsubsection{Parameters of Lightning Currents *}

As the result of a comprehensive critical review of directly rernried 7ightning-r.urrent. nscillngrams, magnetic-7ink measurements and

* Based on private communication from Dr. R. B. Anderson, Chairman of CIGRE Working Group 33-01 (Lightning). 
field-change measurements, statistical data have been established for various characteristic parameters of lightning strokes. Those relevant to this project can be summarized as follows.

The downward negative strokes have more engineering significance because they are far more frequent and are associated with larger currents than positive strokes. Just over half of lightning flashes have more than one stroke. The statistics of the first stroke are compared with those of the subsequent strokes in Fig. 1-3 to Fig.1-12. Figures bearing subscript a are for the first stroke and those bearing subscript b the subsequent strokes.

It is seen that the currents of subsequent strokes have shorter fronts, higher rate of rise but smaller peak magnitudes.

\subsubsection{Computer Analysis}

A. Characteristics of Overhead Line

While the BIL of an apparatus can and should be standardized, that of an overhead line cannot and could not be standardized. For the present purpose of establishing the feasible BIL of our cable, we have assumed an impulse withstand voltage of $1800 \mathrm{kV}$ for the line insulation under combined $D C$ and impulse stresses. We assume that the hardwares of insulators have been optimized to eliminate effectively the polarity effect. The effective surge impedance of the line, for strokes to one conductor, is assumed to be 300 ohins. The surge impedance of the cable is assumed to be 80 ohms.

Within a mile of the HVDC station, the overhead line is assumed to have $100 \%$ shielding and the towers are assumed to have sufficiently

* This is a gross simplification, ignoring the $V$ - $t$ curve of air insulation, but is a reasonable value for a $3 \mathrm{~m}$ string. 
low footing resistance. In other words, all lightning surges are assumed to reach the cable after having traveled at least over a mile on the overhead line.

\section{B. Types of Lightning Surges}

(a) Shielding Failures

With these assumed values, $90 \%$ of the first stroke but only $50 \%$ of subsequent strokes would cause line flashovers. From the cable-protection point of view, the most severe lightning surges are those which just fail to cause flashovers, viz., the full-wave surge having peak voltages equal to the withstand voltage of the line insulation (Ref 1-1). Fig.1-13 indicates a weak correlation between the peak current and the maximum rate of rise. Using the upper boundary of the data points, the most severe surges due to the first stroke can be estimated to have a rate of rise of $2 \mathrm{kA} / \mu \mathrm{s}$, or a time-topeak of $6 \mu \mathrm{s}$. * The corresponding values for the subsequent strokes are $100 \mathrm{kA} / \mu \mathrm{s}$ and $0.12 \mu \mathrm{s}$.

The $6 \mu$ s - front stroke can cause a voltage surge of similar front but a $0.12 \mu$ - front voltage surge cannot occur on a line well-shielded near the station.

Fưr surges having front durations Innger than a few microseconds, line corona does not alter the time to peak appreciably over the first few miles of travel. However, for front durations shorter than 1 microsecond, the front could be lengthened at a rate of about $1 \mu \mathrm{s} / \mathrm{mile}$ (Ref, 1-? and 1-3). It is considered. more realistic to use a front of about $0.5 \mu \mathrm{s}$ instead of $0.12 \mu \mathrm{s}$ to compare with a front of about $6 \mu \mathrm{sec}$ ( $5 \mu \mathrm{sec}$ actually used) in the computer study. 
(b) Back Flashovers

With present knowledge and experience, it is technically feasible to eliminate shielding failures completely. if footing resistance can be reduced to 18 ohms or lower, the overhead line can be inmune to lightning surges, provided that the maximum lightning current is below $90 \mathrm{kA}$ as depicted.in. Fig. 1-8a. 0therwise, back flashover could occur. The front of the surge due to back flashover is extremely short. However, it is feasible to reduce the footing resistances at the towers within a mile from the station. The corona effect would then lengthen the front of the incident surge to $0.5 \mu \mathrm{s}$ or longer, as discussed before.

Comprehensive information on the tail of the lightning current is lacking. It is generally regarded as around $50 \mu \mathrm{s}$. The tail of the surges due to back flashover would be shorter than the parent stroke current as the effective footing resistance is successively reduced by surges reflected from other towers.

\section{Results}

The computations were made by Mr. Wendell Neugebauer of EUSED, General Electric Co., using the EMTP program developed by BPA. The circuit representation is shown at the top of Table 1-3, which shows the result. Lightning current, having peak value to cause a $1800 \mathrm{kV}$ surge, is injected at location 2.

The discharge voltage of a MOV arrester is a function of the discharge current and also of the rate of rise of the current. 
Typical functions are plotted in Fig. 1-14. The $0.6 \times 1.5 \mu$ s curve is used for cases $3-9$ and the $8 \times 20 \mu$ s curve is used for cases $10-11$.

Each arrester consists of two columns with $15 \%$ shunt-gap. Arresters are installed at both cable ends for cases 3, 4, 6 and 7. For all other cases, an arrester is also installed on the overhead line $2000 \mathrm{ft}$. from the cable, for the purpose of lengthening the front of the incident surge. In cases 9 and 11, a $1-\mu \mathrm{F}$ capacitor is also installed at the station-end of the cable to lengthen the reflected surge. The conductor resistance is included as lumped resistors in cases 8 and 9.

Voltages at locations $3-8$ were computed. Their peak values are given in Table 1-3, The highest voltages in the cable for each case is estimated. For example, Fig. 1-15 gives the voltage for case 7. At location 7 (Fig. 1-15f)) the peaks of the incident and the reflected surges do not coincide. The highest voltage occurs at a location between locations 7 and 8 . Its magnitude can be estimated as the sum of the peaks of the incident and the reflected surges, both of which can be measured from Fig. 1-15f.

The estimated highest voltages are given in Table 1-3.

\subsubsection{Discussion and Conclusions}

The highest surge voltages in cases $3-8$ are overestimated because the characteristics of the arrester are based on the vary shurt current of $0.6 \times 1.5 \mu \mathrm{s}$. The arrester protective levels would be lower for longer discharge current as indicated in Fig. 1-14.

In addition, the actual distortion and attenuation within the cable are probably more than those shown by the computer results, which show hardly any distortion and attenuation over a 20-mile travel (compare Fig. $1-15 \mathrm{c}, \mathrm{d}$ and $\mathrm{e})$. 
Comparison of cases 4-7 indicates that the highest surge voltage within the cable is little influenced by the dc component; the extreme values being 1150 and $1200 \mathrm{kV}$ with $4 \%$ difference between them. The rest of the cases were therefore all made with $+600 \mathrm{kV} \mathrm{dc}$ component.

Cases 5 and 10 show that the highest surge voltages within the cable are $1115 \mathrm{kV}$ and $1035 \mathrm{kV}$ respectively, the latter being a better estimate because the arrester characteristics are based on a discharge-current shape closer to the shape of the injected current. An estimate of $1100 \mathrm{kV}$ can thus be made.

The highest surge voltage can be further reduced by an additional capacitor at the station, as indicated by cases 9 and 11 .

1.5 Feasible BIL and BSIL

With an arrester at the first tower from the cable, in addition to the arresters at both ends of the cable, the lightning-surge protective level is estimated at $1100 \mathrm{kV}$. A BIL of $1300 \mathrm{kV}$ is considered feasible, corresponding to a safety margin of $18 \%$.

With the additional arrester at the first tower, the switching-surge protective level will be lower than $854 \mathrm{kV}$, previous.ly deduced without the additional arrester. Even with $854 \mathrm{kV}$ and a $15 \%$ safety margin, the protective level is only $980 \mathrm{kV}$. Therefore, a BSIL of $1050 \mathrm{kV}$ is considered feasible. 


\subsection{References}

Reference 1-1. M. Ouyang, "Lightning Protection of Cable-Connected High-Voltage Distribution Substations by Surge Diverters," Proc. IEE, Vol. 117, No. 8, Aug. 1970, pp. 1693-1702.

Reference 1-2. N. Hylten Cavaliius and S. Annestrand, "Distortion of Traveling Waves in Cables and on Power Lines," CIGRE Report No. 1962-325, Appendix III, 1962.

Reference 1-3. M. Ouyang and P. G. Kende11, "Tests on Disturlion and Attenuation of Waves on Overhead Line," Trans. 1ttt, PAS-94, No. 2, March/April 1975, pp. 498-507. 


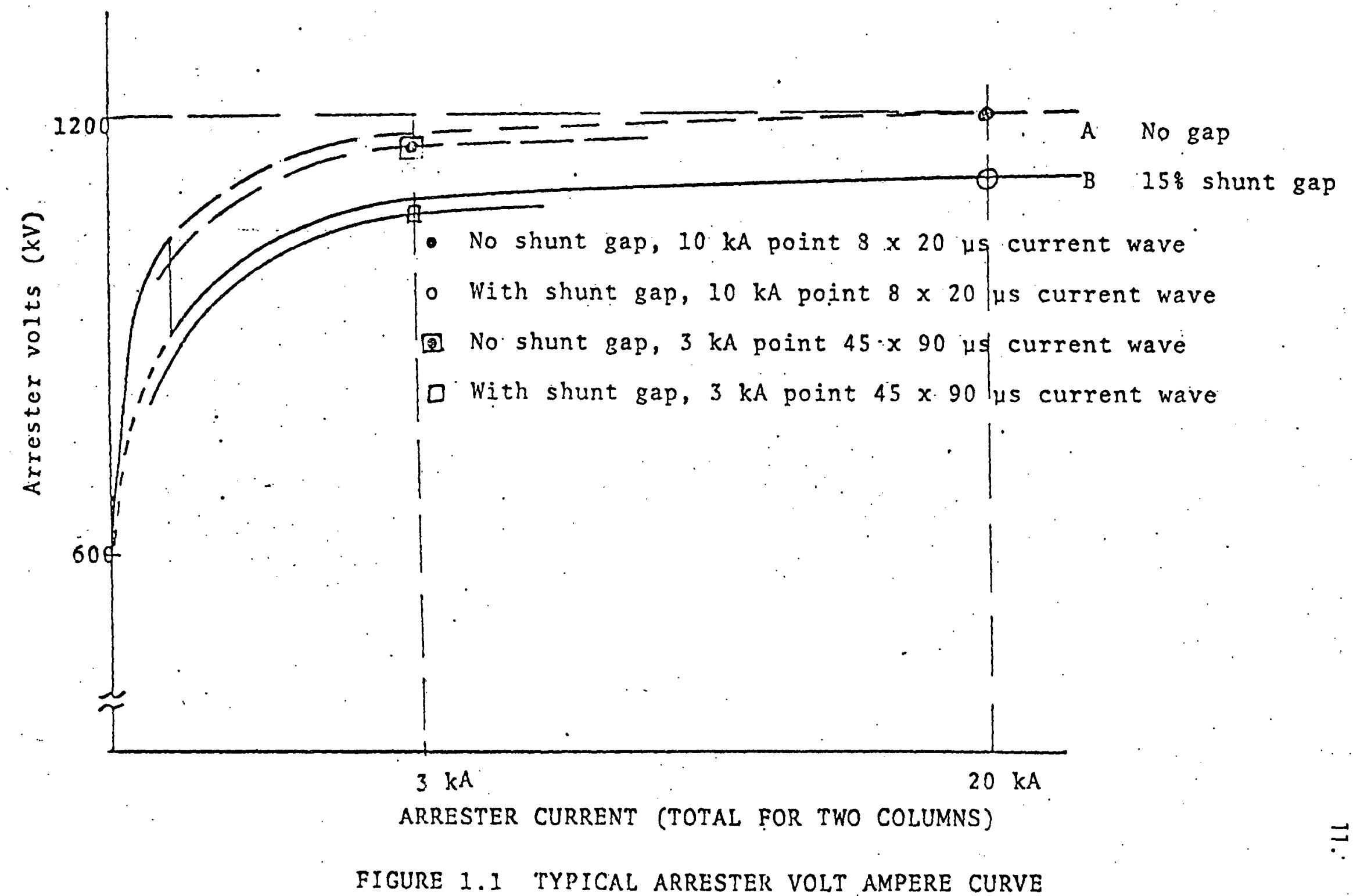




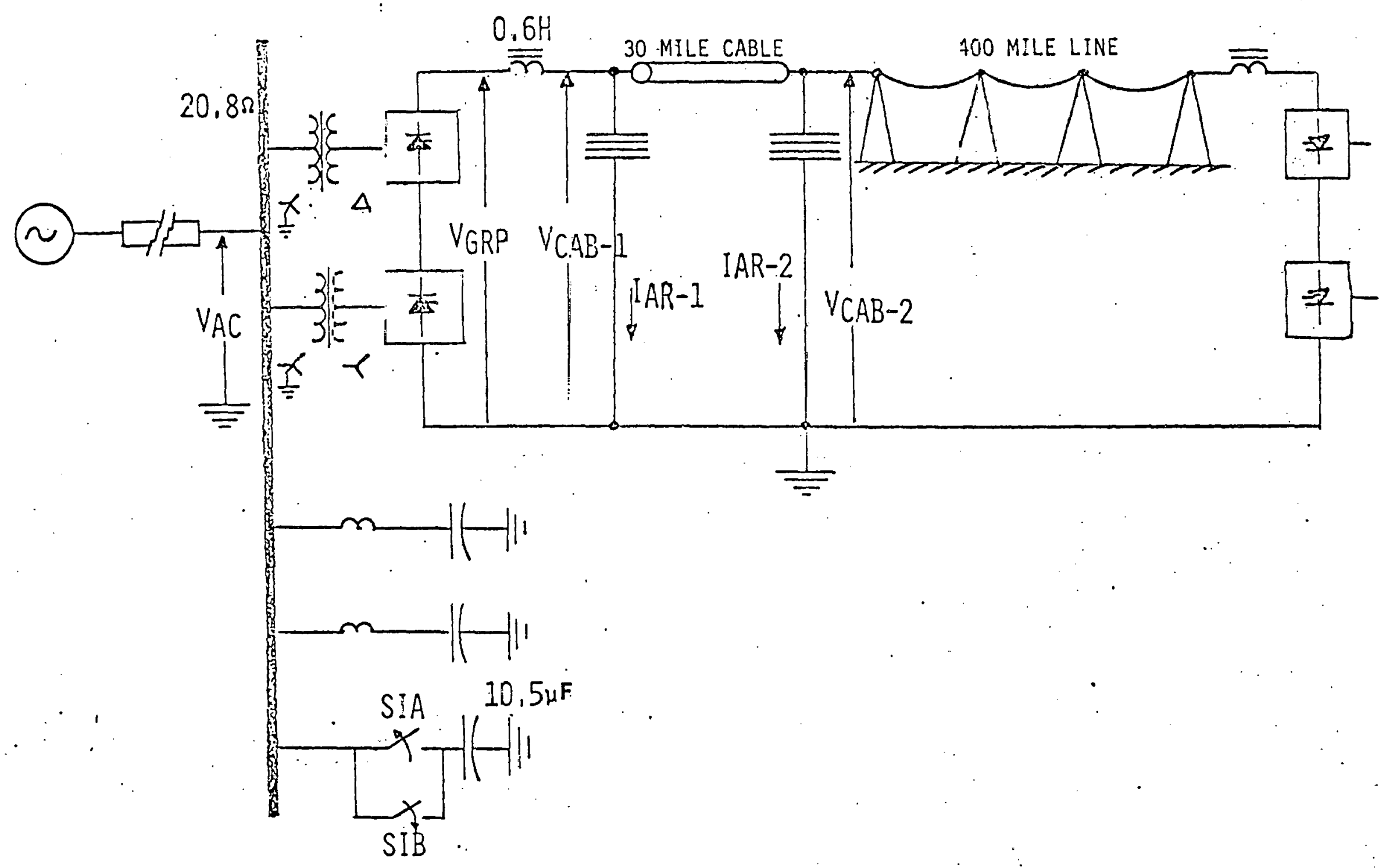

CASE 1 RESTRIKE ON VAR BANK

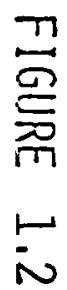




\section{RESTRIKE ON VAR BANK}

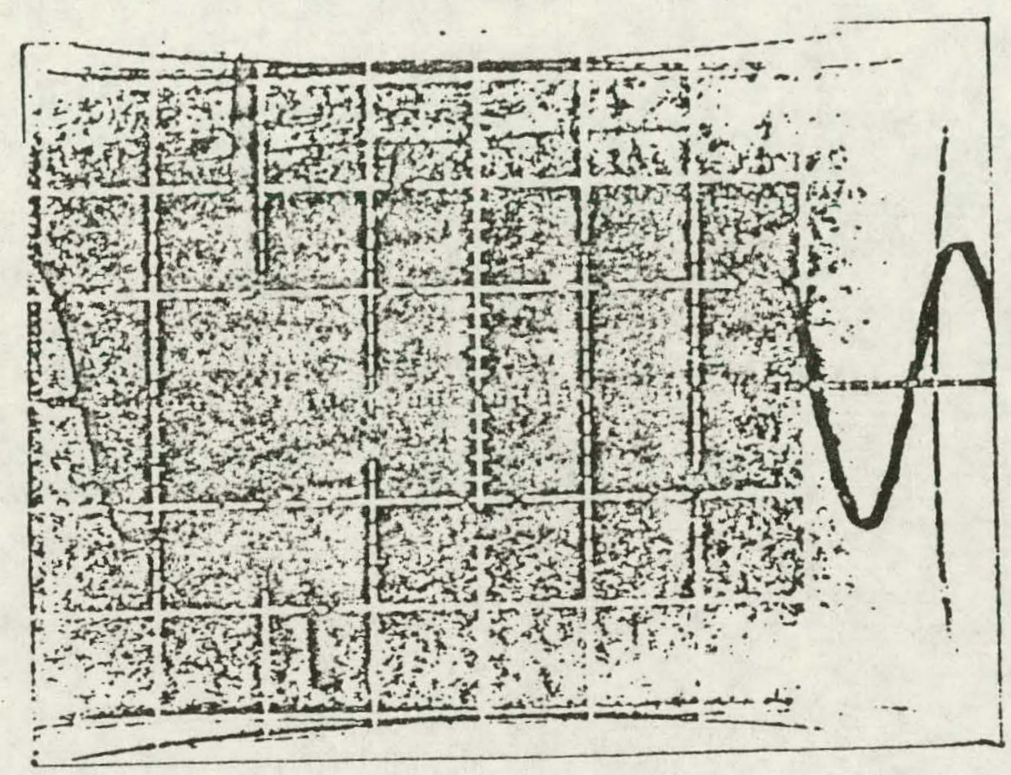

- VAR-BÄKK VOLTS

$10 \mathrm{MS} / \mathrm{DIV}$

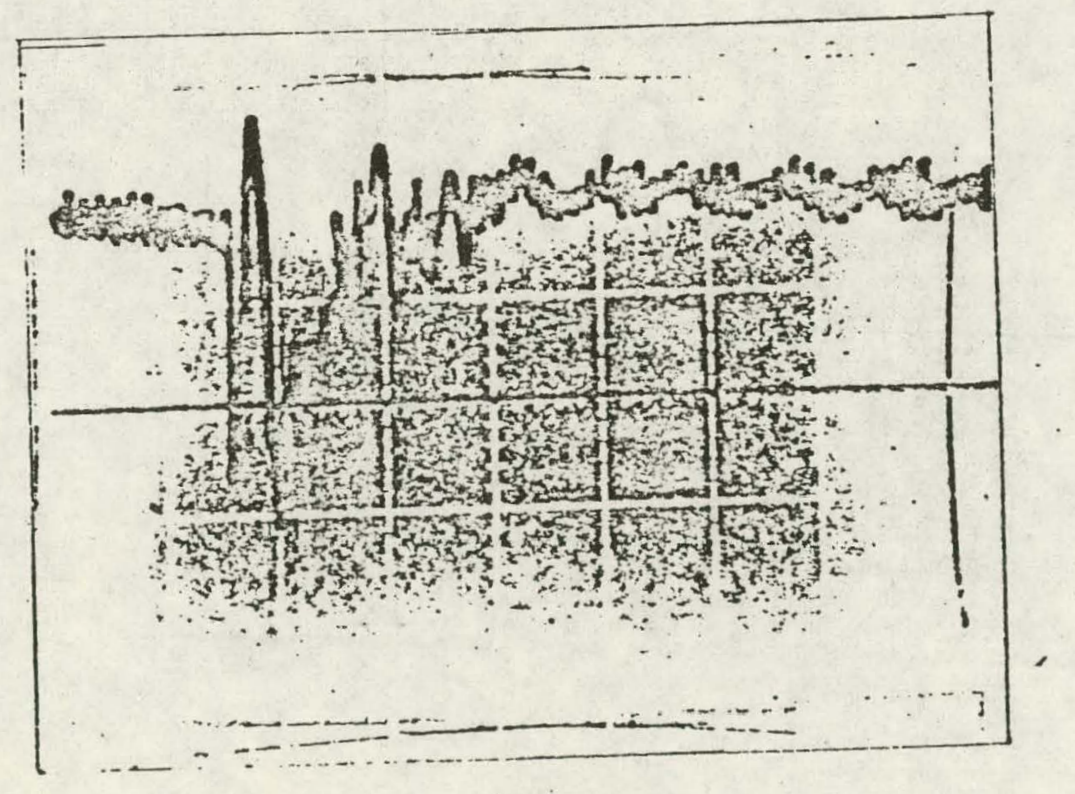

CONVERTER GROUP DC VOLTS

$333 \mathrm{kV} / \mathrm{DIV}$

$10 \mathrm{MS} / \mathrm{DIV}$

FIGIRE 1.3 


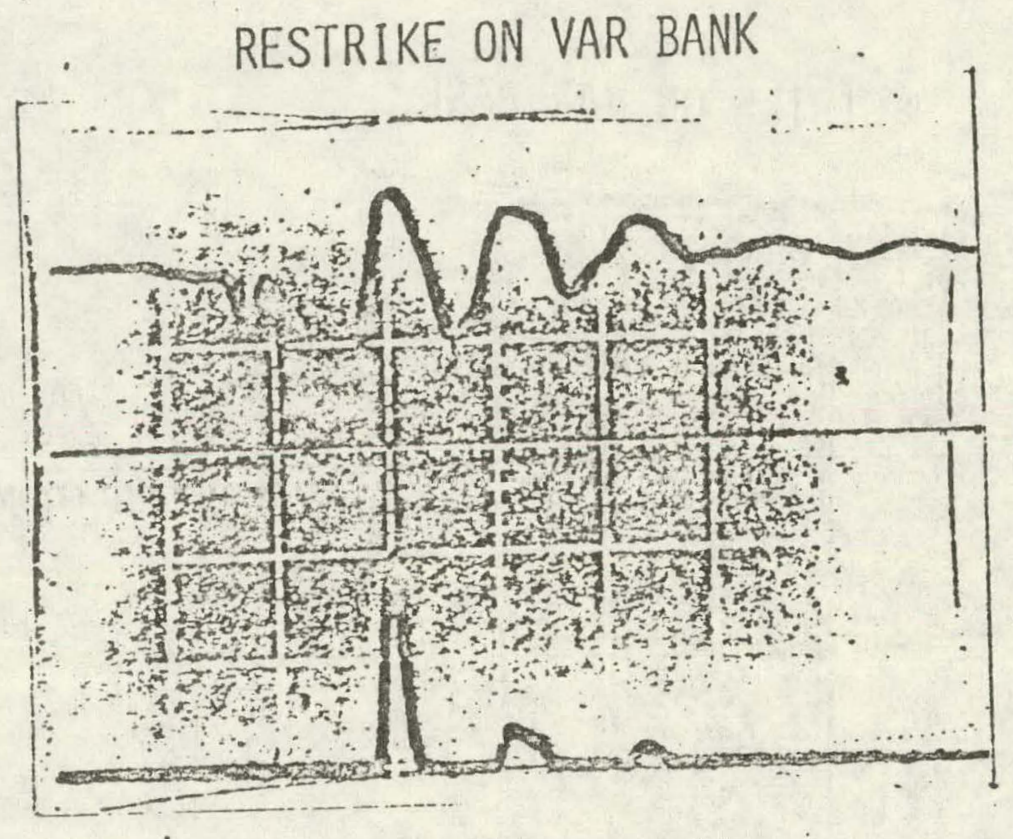

$V_{C A B-1}$

CABLE VOLTS

333 kV/DIV

IAR-1

ARRESTER CURRENT

IFT A/DIV

10 MS/DIV

VCAB-2

CABLE VOLTS

$333 \mathrm{kV} / \mathrm{DIV}$

IAR-2

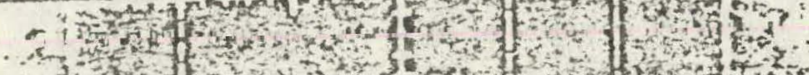
की

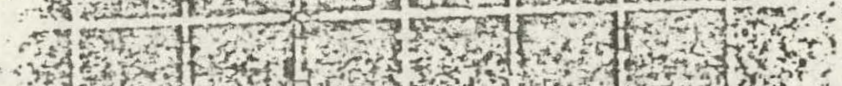

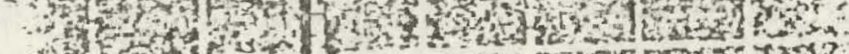
is

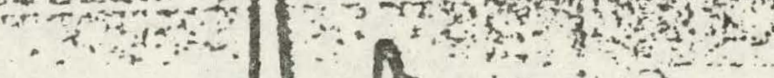


IMPROPER START AT $\alpha=0$
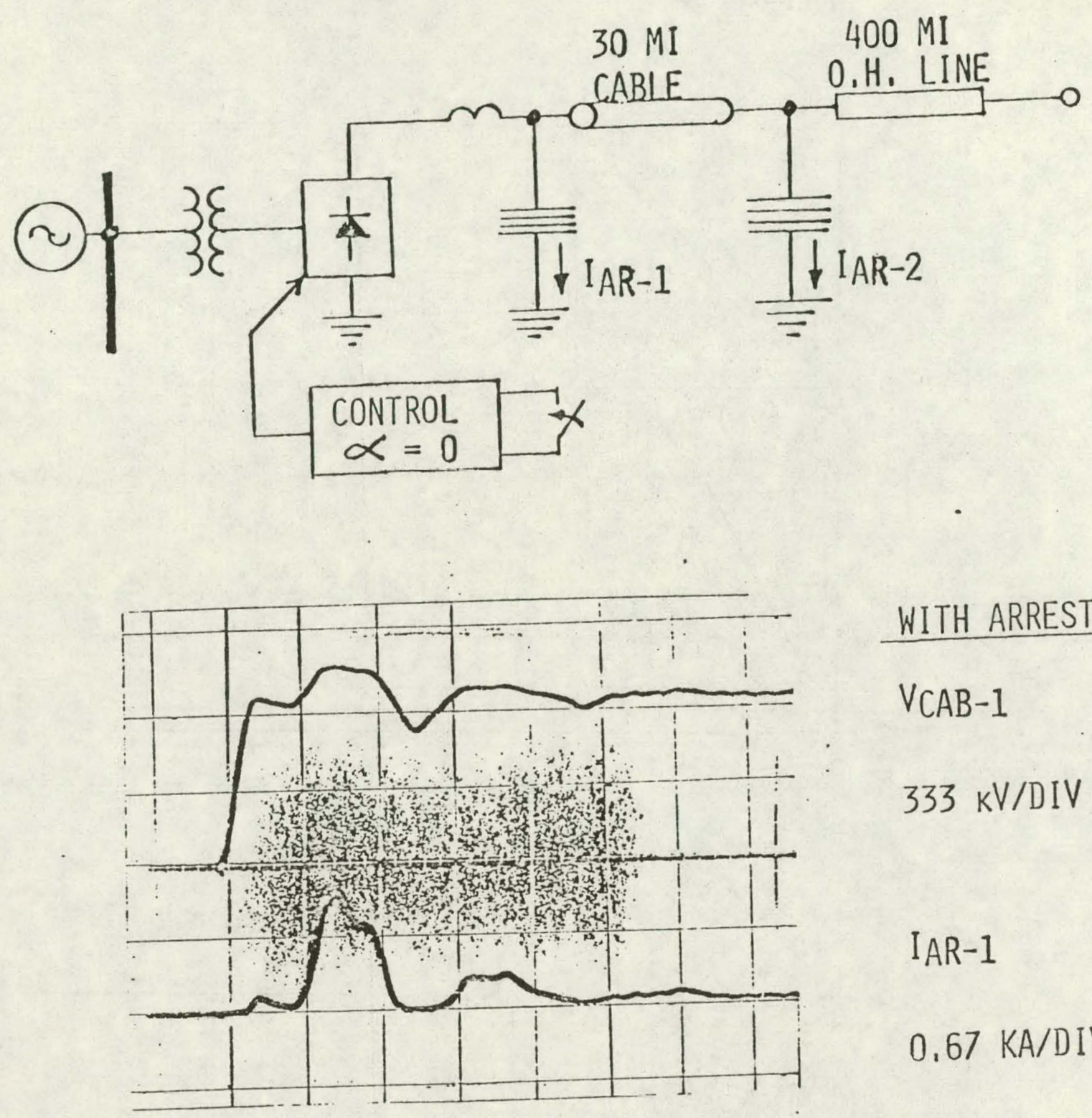

WITH ARRESTERS

VCAB-1

$333 \mathrm{kV} / \mathrm{DIV}$

IAR-1

$0.67 \mathrm{KA} / \mathrm{DIV}$

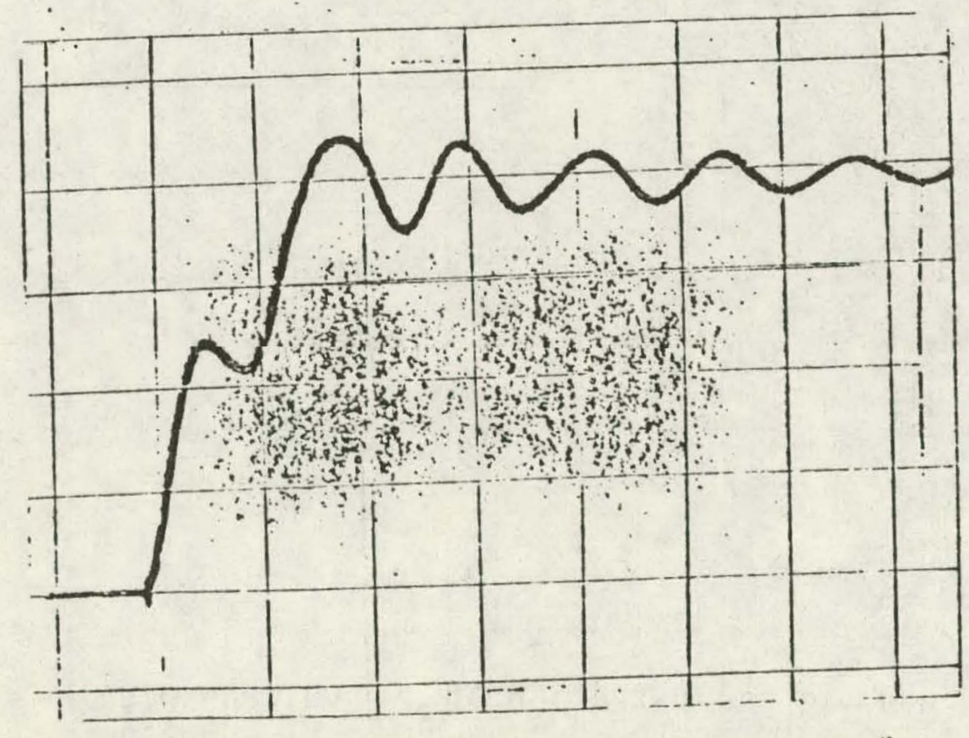

\section{$\because$ \\ NO ARRESTERS \\ VCAB-1}

333 KV/DIV

$5 \mathrm{MS} / \mathrm{DIV}$

FIGURE 1.5 

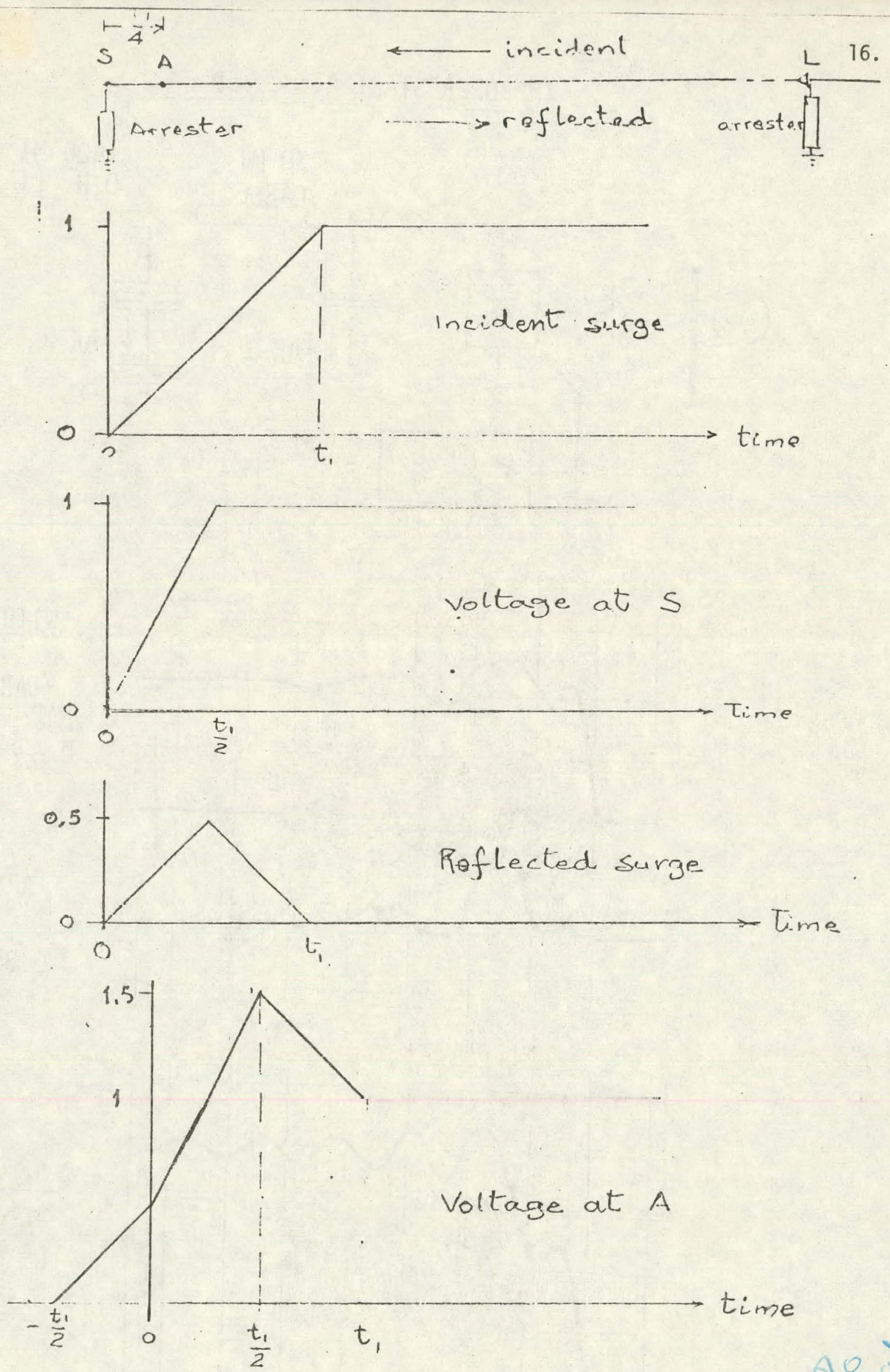

Fig. 1-6. Schematic illustration of overvoltage within a cable protected by conventional arresters. 

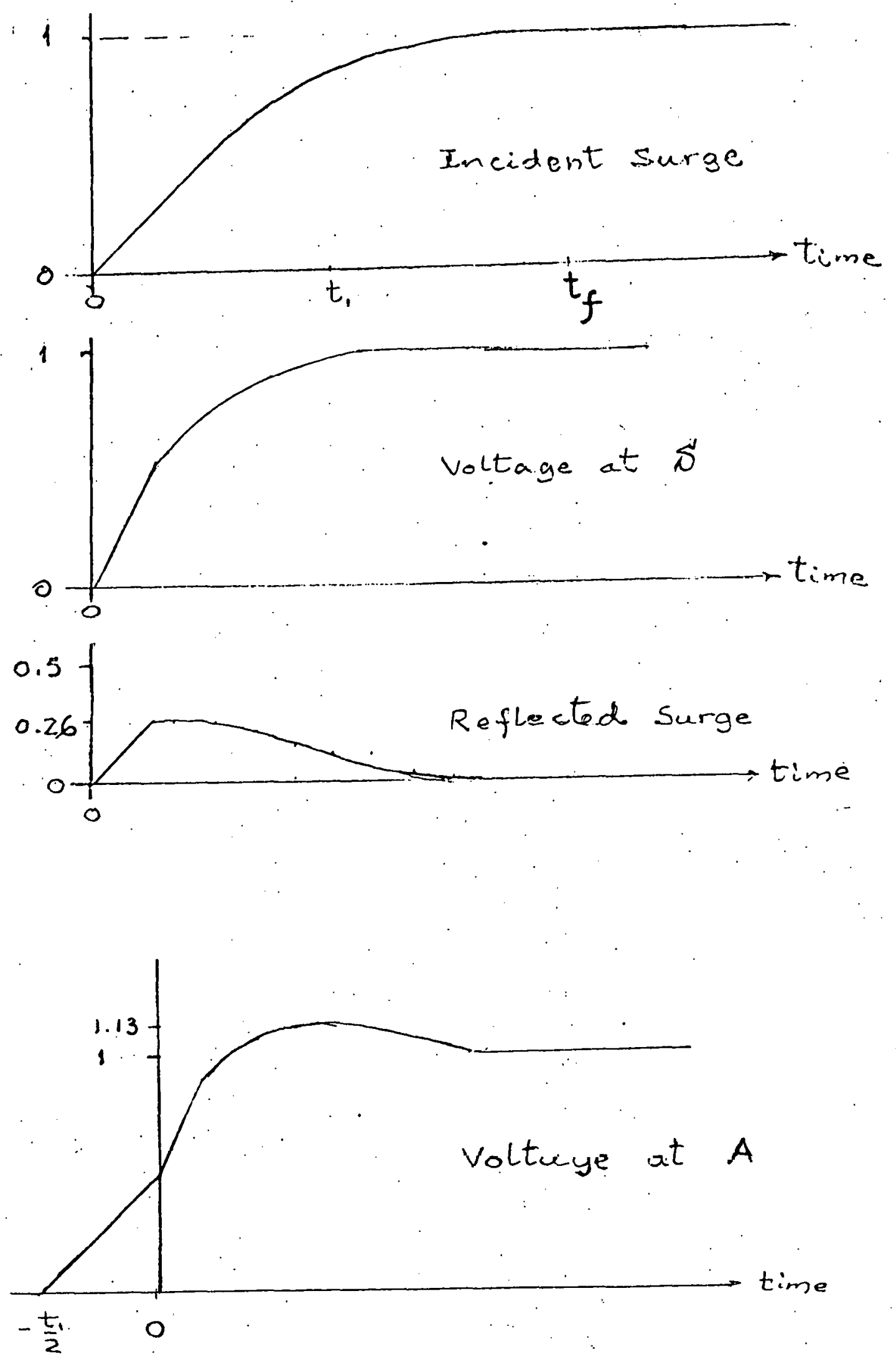

Fig. 1-7 Schematic illustration of overvoltage within a cable protected by MOV arresters. 


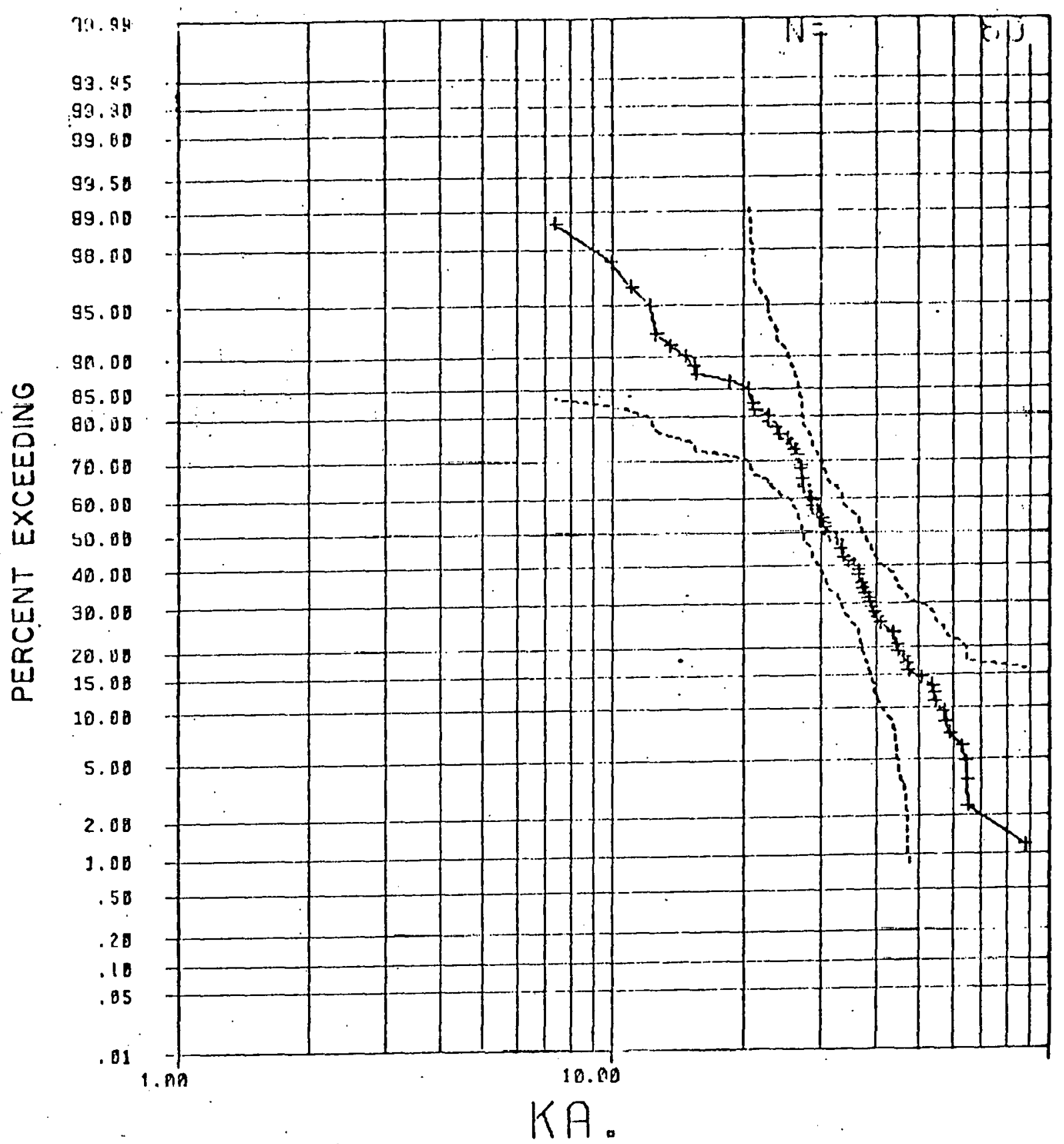

Figure 1-8a

Cumulative Frequency Distributions of First-Stroke Wavefront Parameters

Amplitude of Maximum Current Peak 


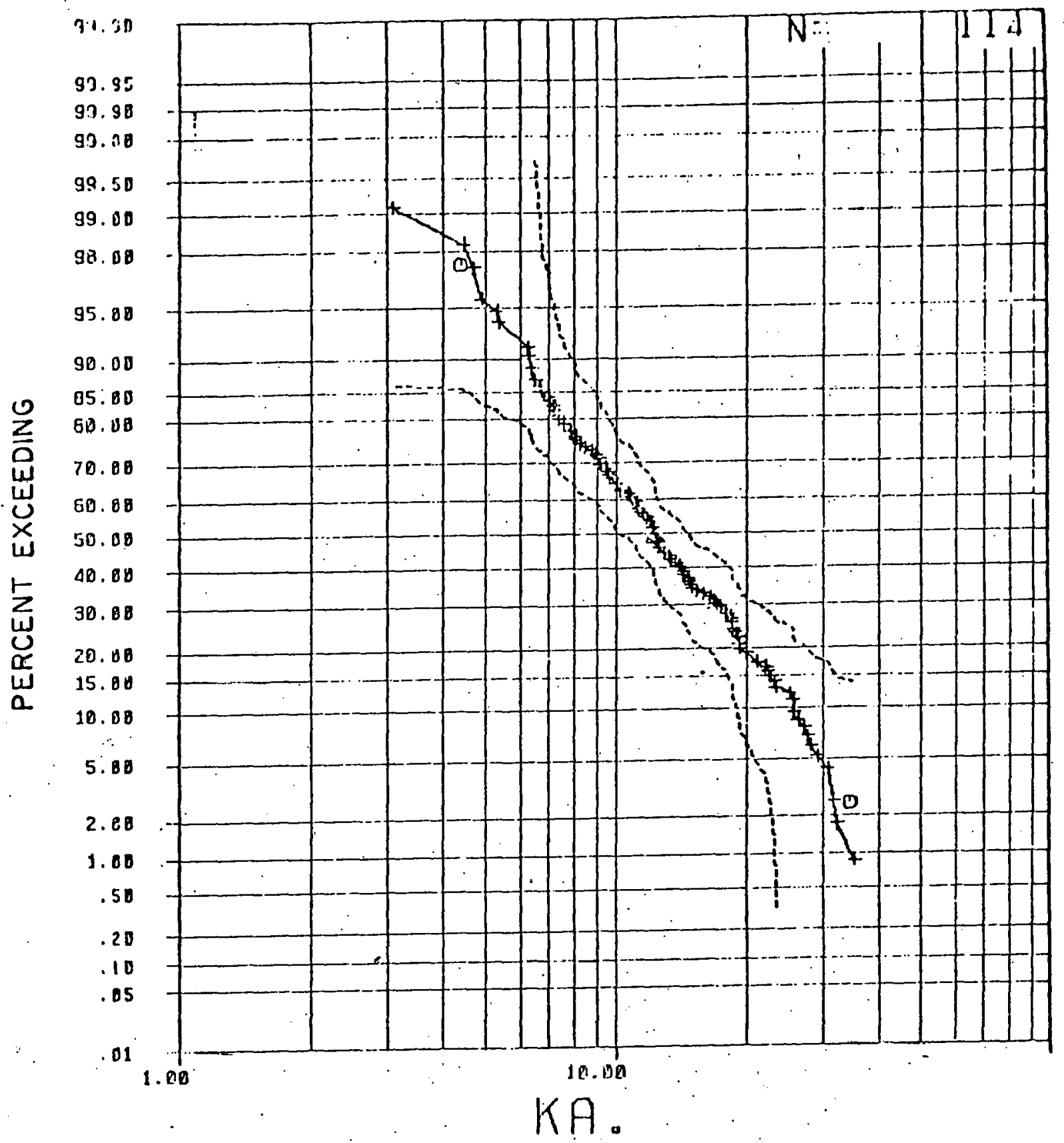

PEAK

Figure $1-8 b$

Cumulative Frequency Distributions of Subsequent. Stroke Wavefront Parameters Amplitude of Maximum Current Peak 



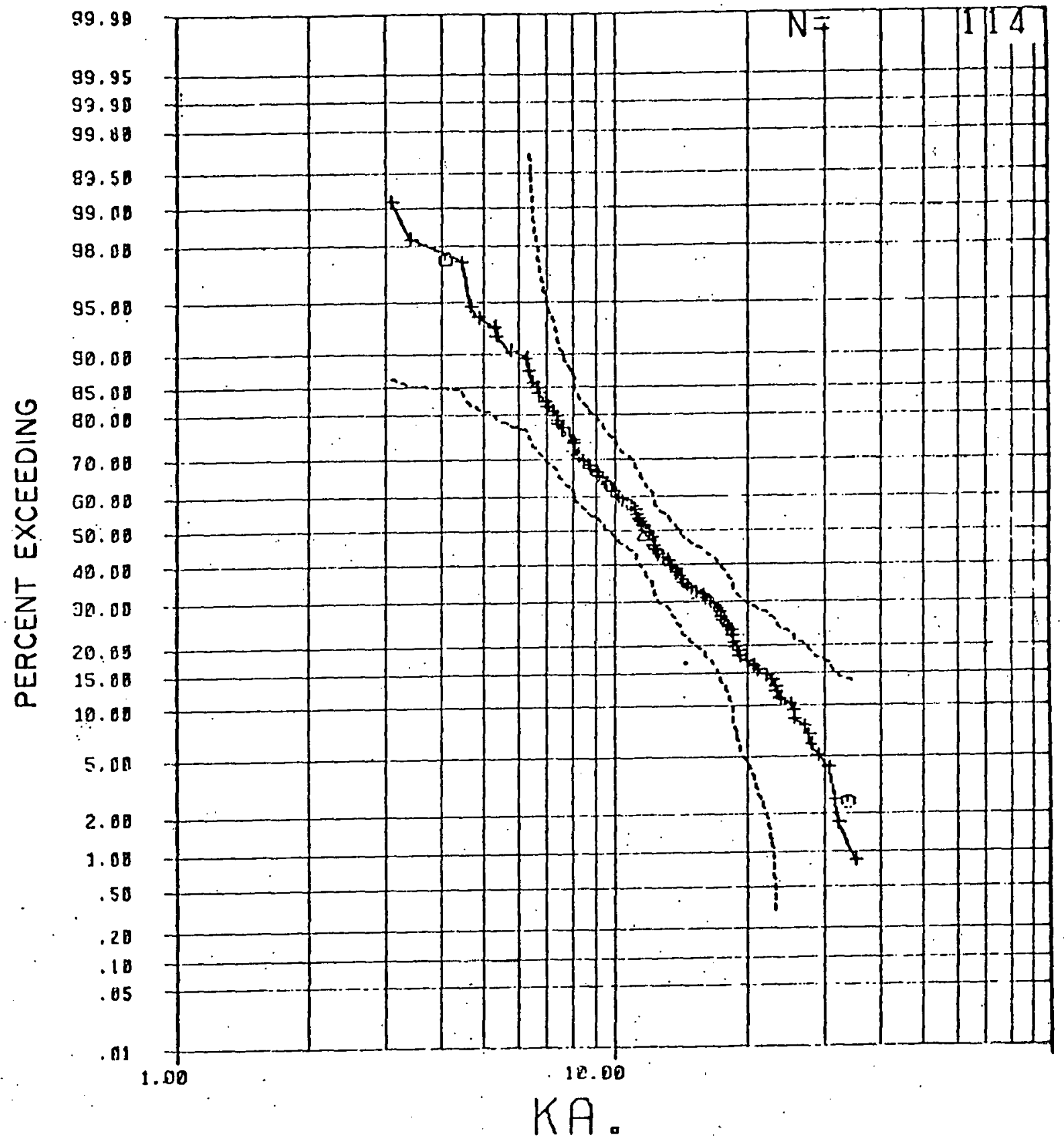

PEAK 1

Figure 1-9b

Cumulative Frequency Distributions of Subsequent Stroke Wavefront Parameters

Anplitude of First Current Peak 


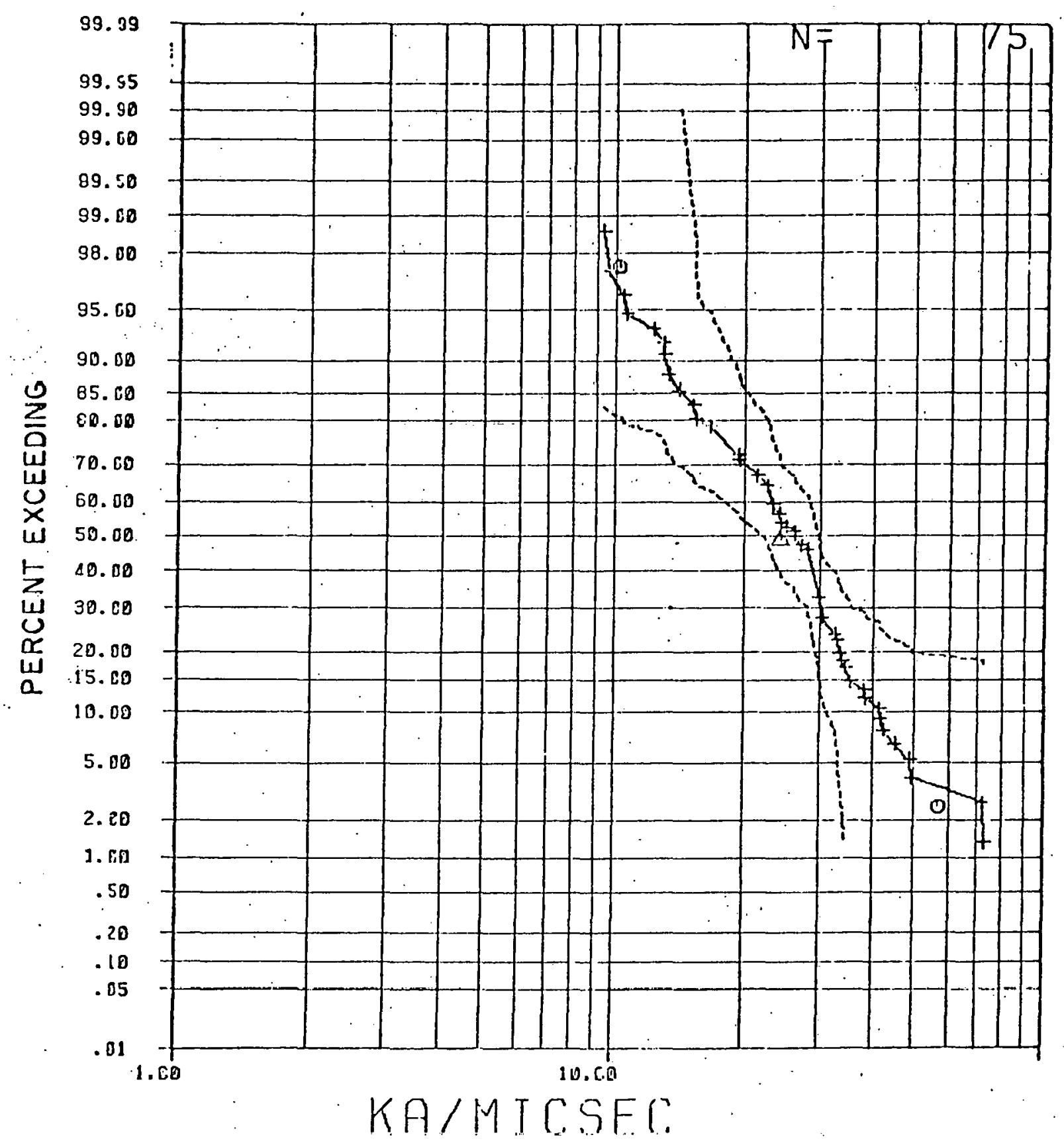

Figure 1-10a

Cumulative Frequency Distributions of First-Stroke Wavefront Parameters

Maximum Rate-of-Rise 


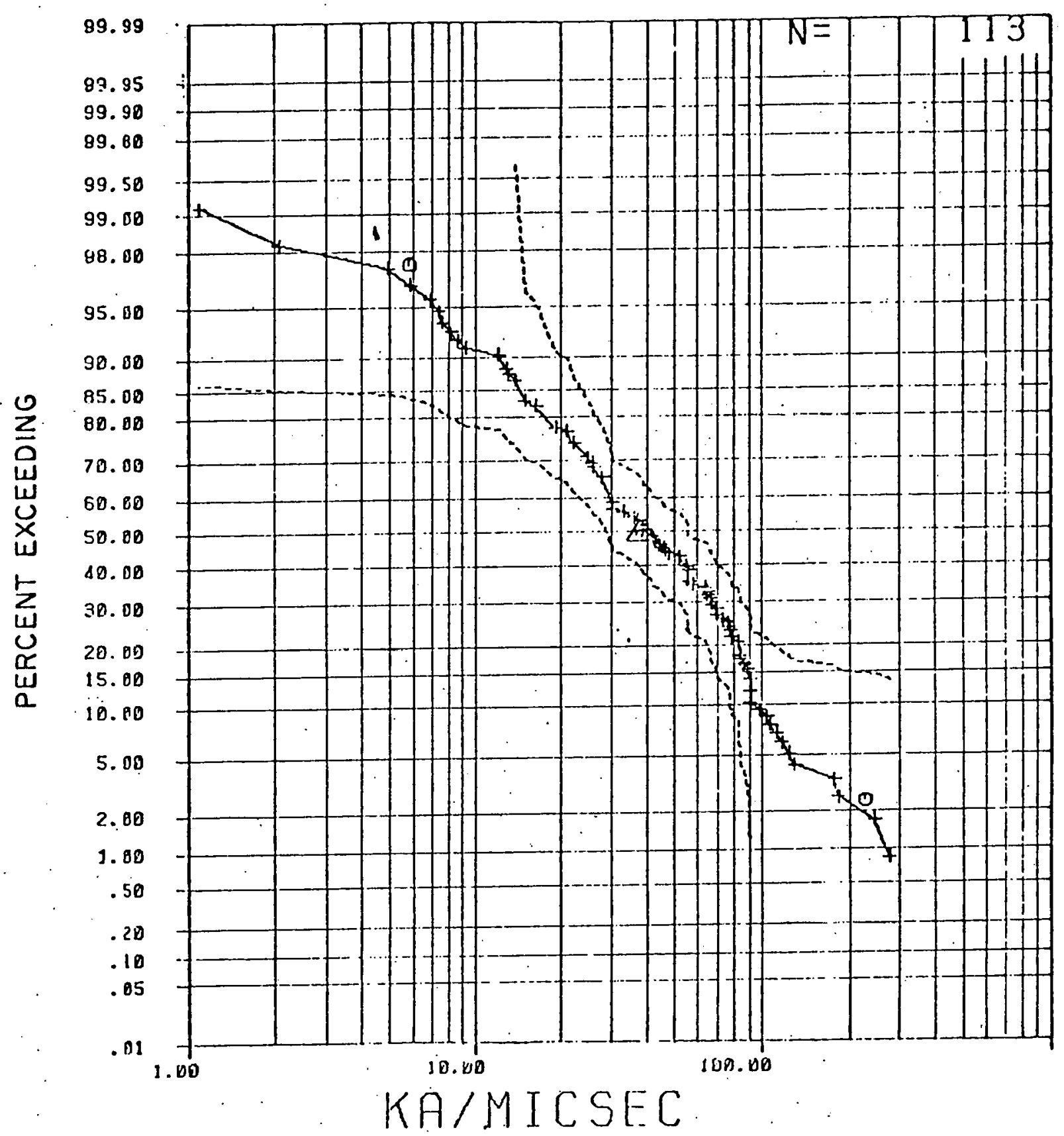

Figure 1-10b

Cumulative Frequency Distributions of Subsequent Stroke Wavefront Parameters

Maximuni Rate-of-Rise 


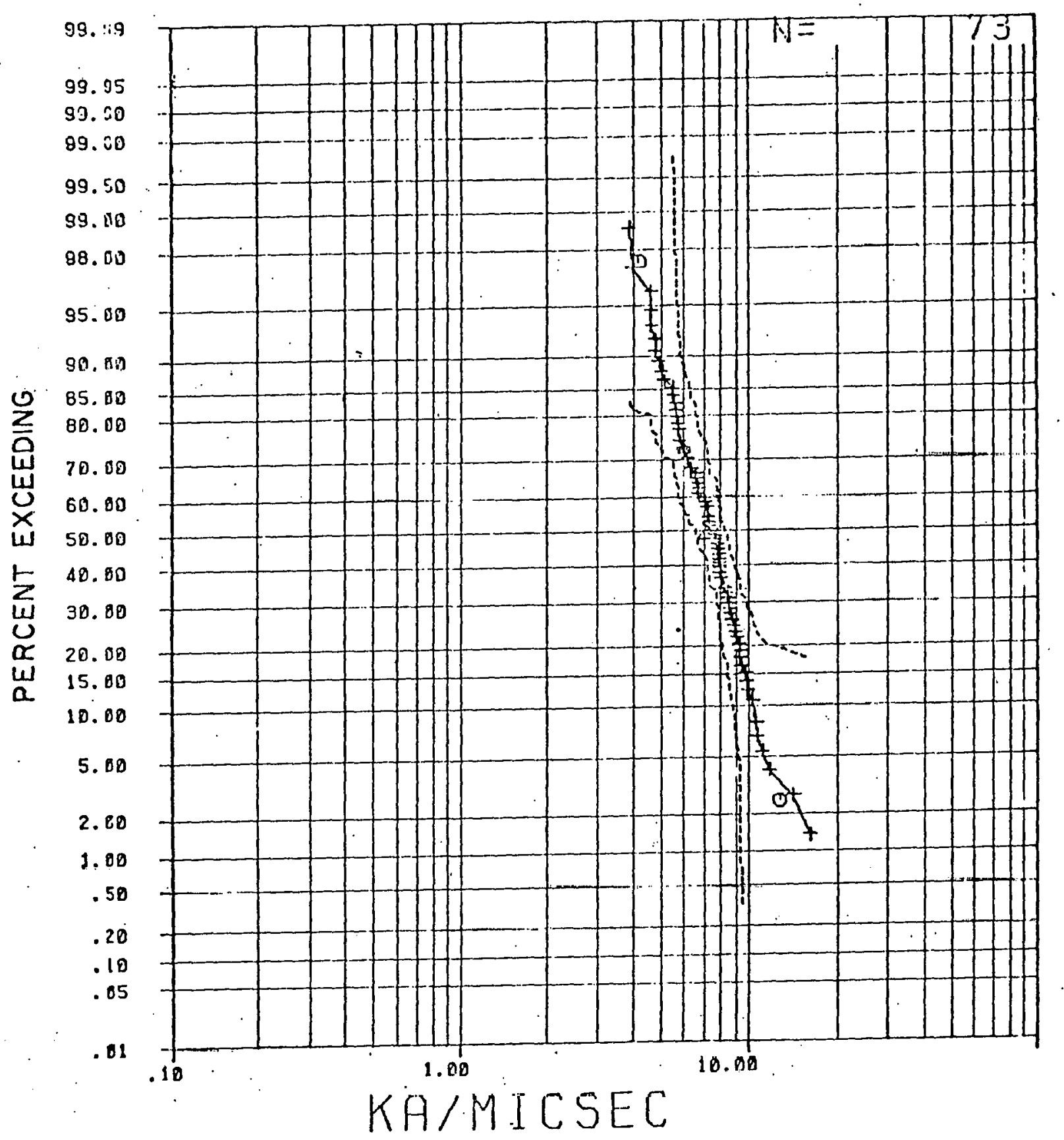

Figure 1-11a

Cunulative Frequency Distributions of First-Stroke Wavefront Parameters Average Steepness $30-90 \%$ 


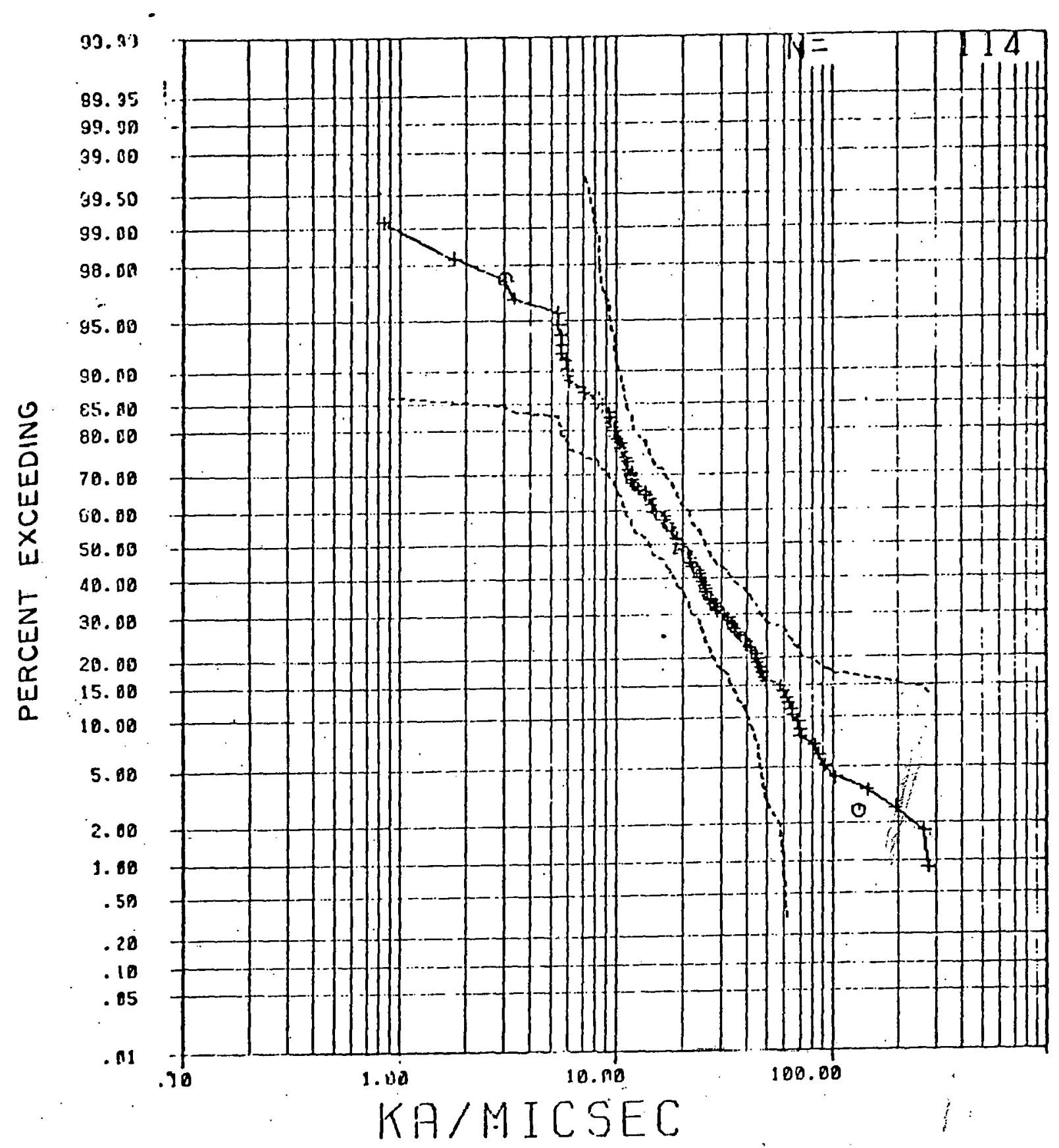

Figure 1-11b

Cumulative Frequency Distributions of Subsequent Stroke Wavefront Parameters 


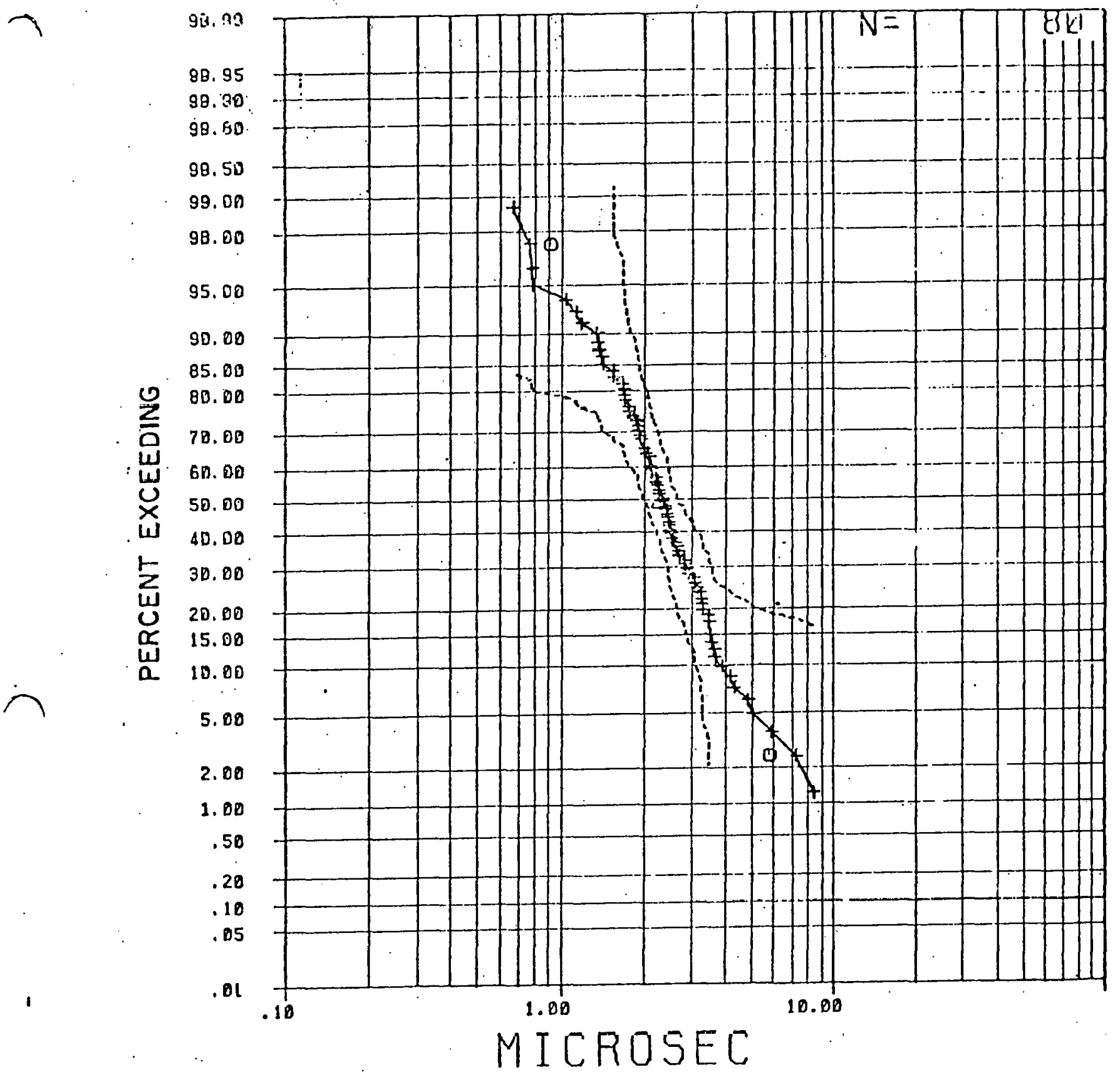

Figure 1-12a

Cumulative Frequency Distributions of First-Stroke Wavefront Parameters 


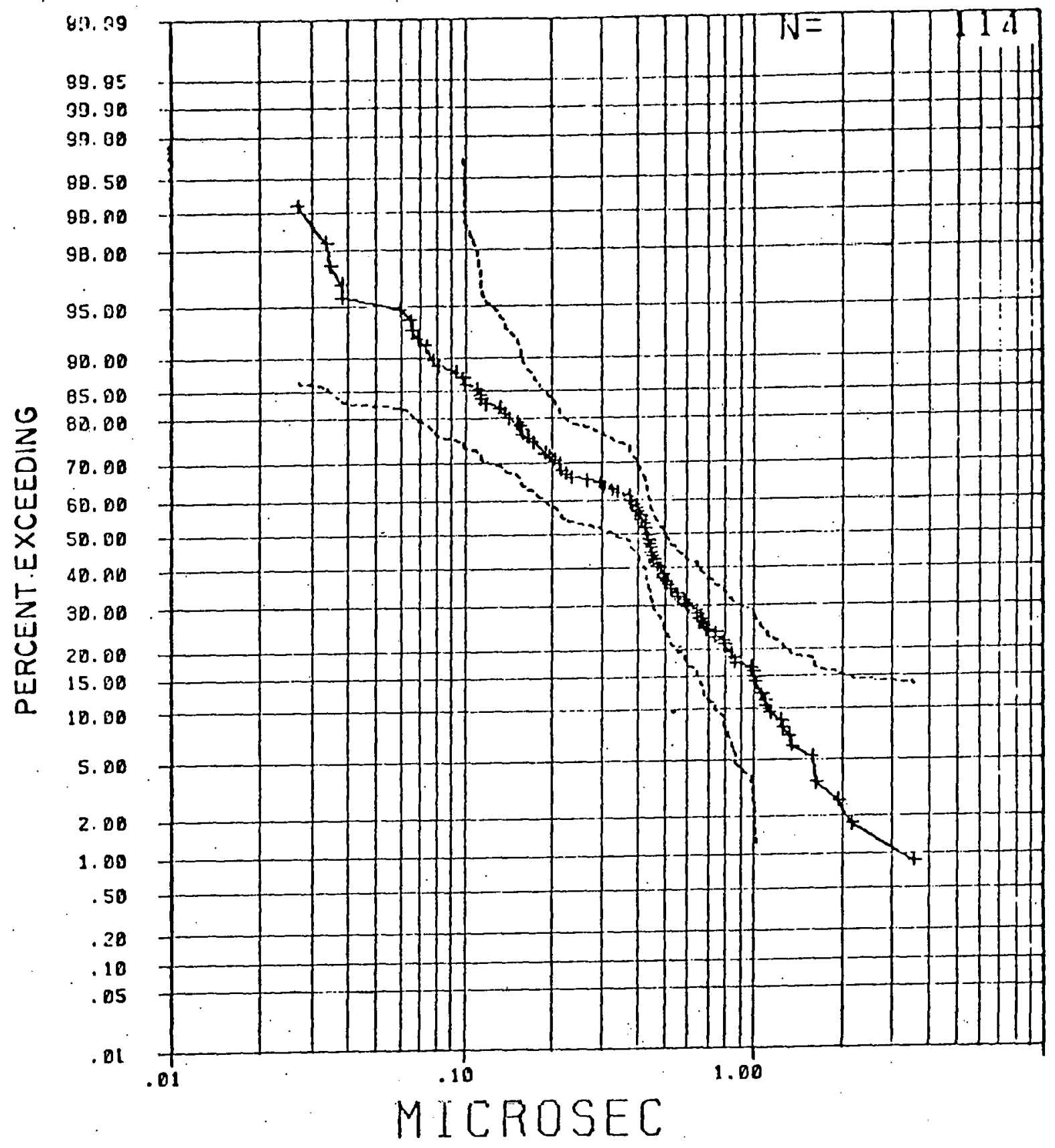

T3D

Figure $1-12 b$

Cumulative Frequency Distributions of Subsequent Stroke Wavefront Parameters

Front Duration 30-90\% 


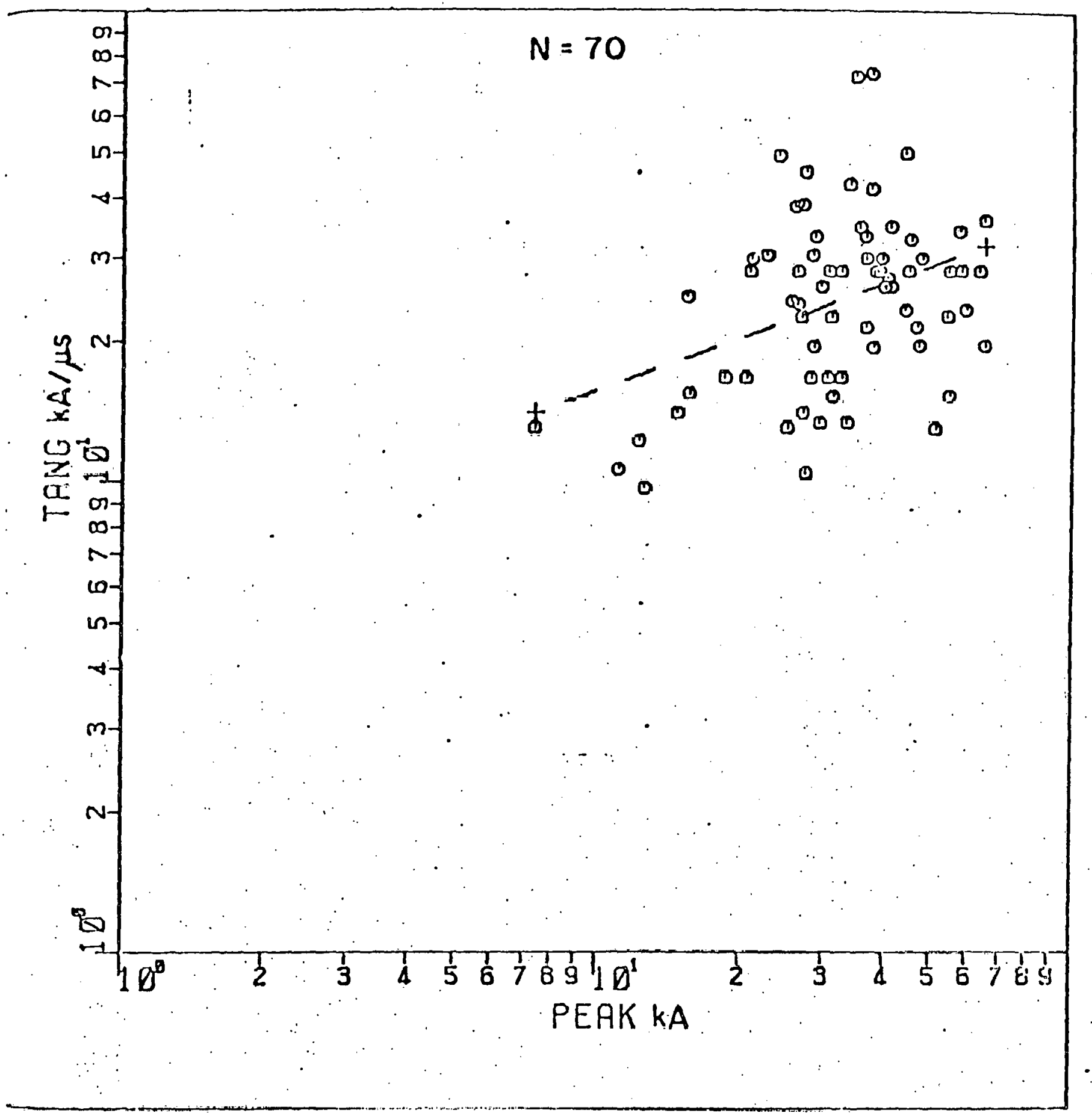

Figure $1-13 a$

Correlation Between Maximum Rate-of-Rise and Peak Current Amplitude - First Strokes 


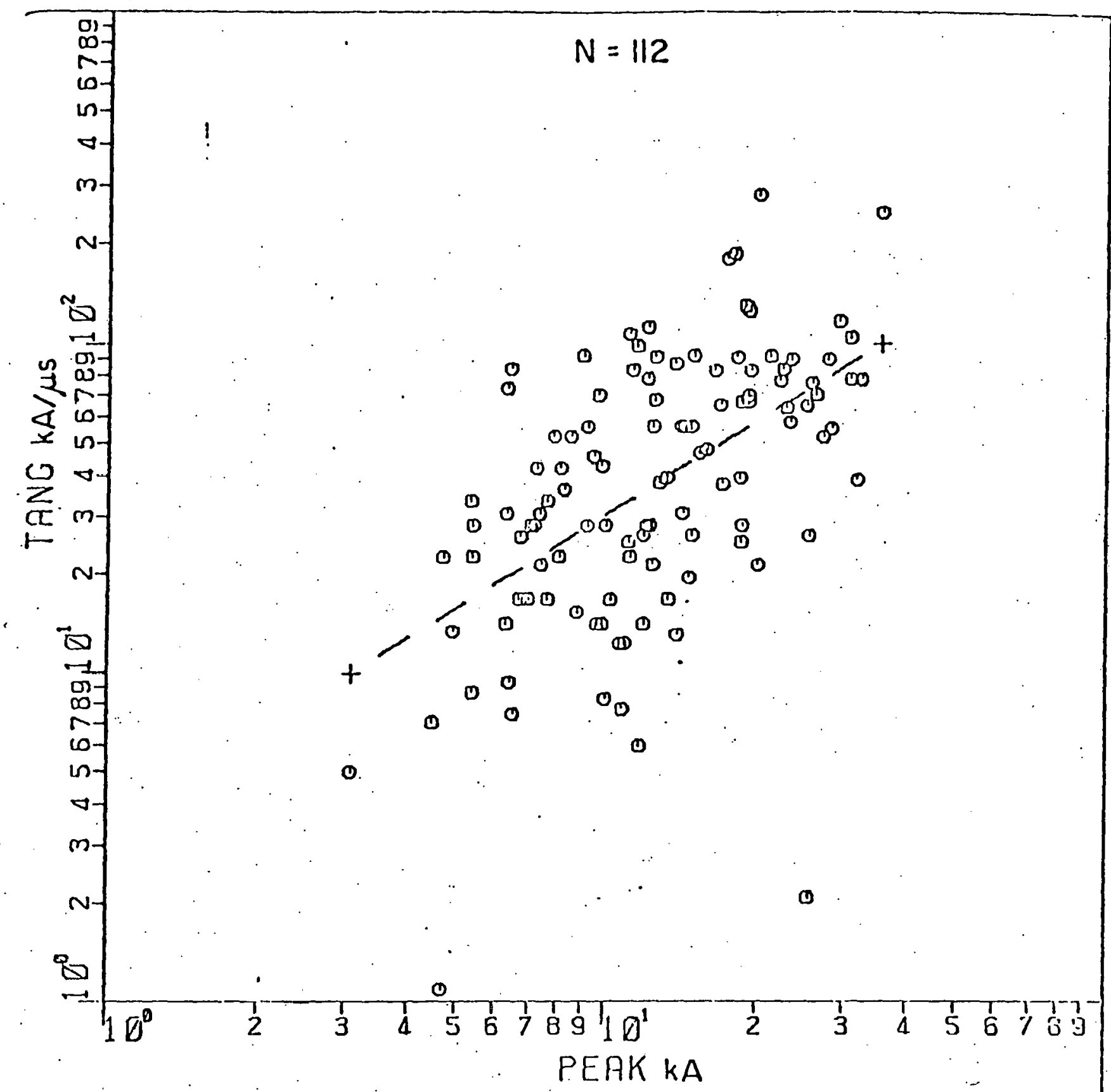

Figure 1-13b

Correlation Between Maximum Rate-of-Rise and Peak Current Amplitude - Subsequent Strokes 


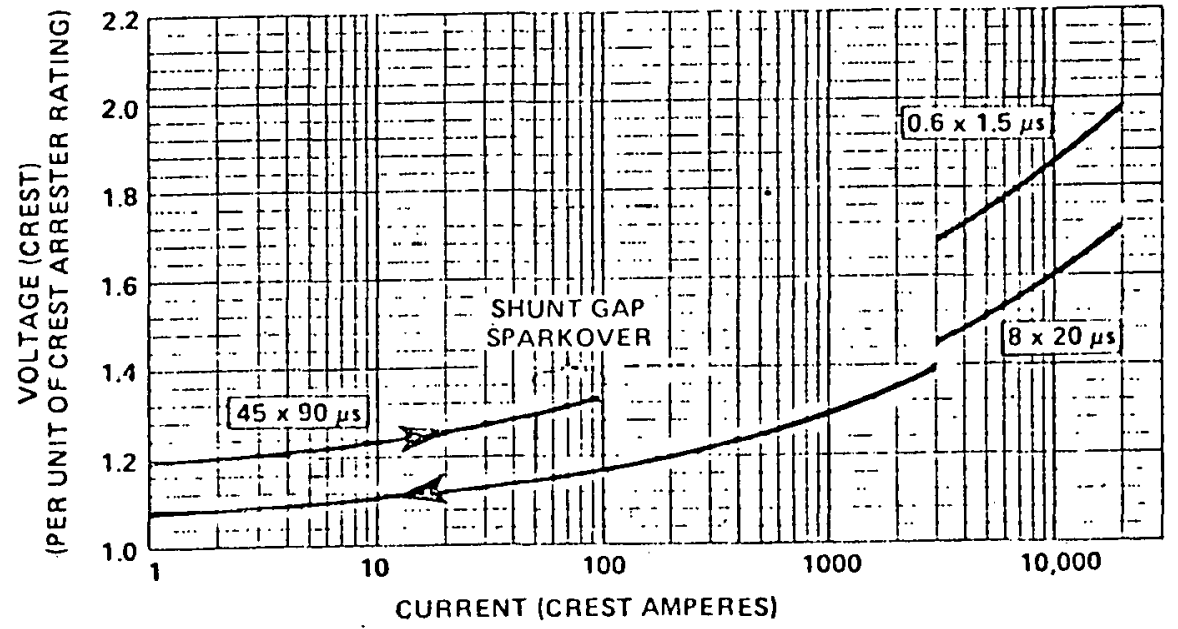

Figure $1-14$

Typical Maximum Voltage-Current Characteristics for Arrester Ratings 396-444 kV 


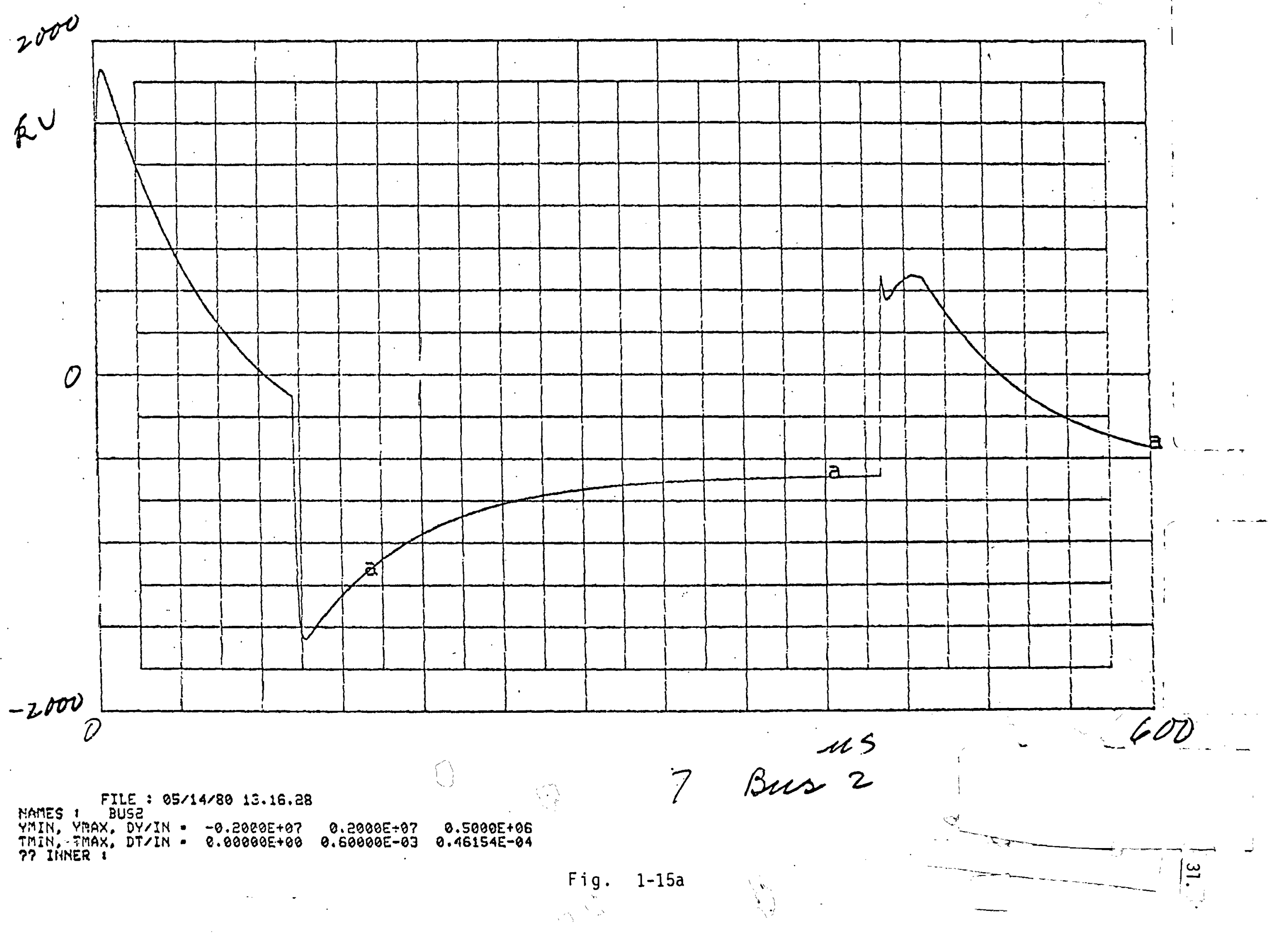




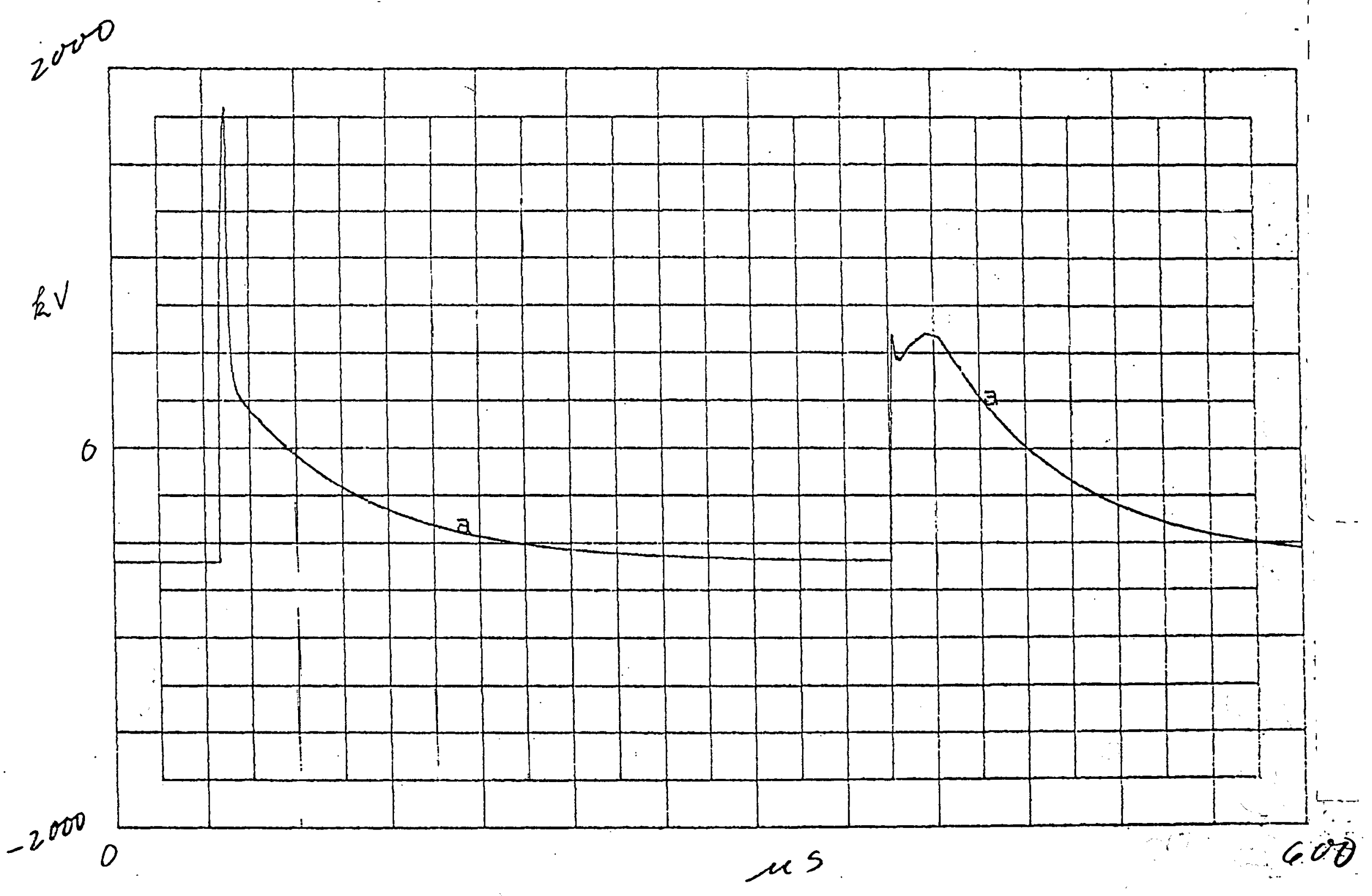

NAMES \& FILE $203 / 14 / 80$ 13.16.28

YMIN, YMAX, DYIIN - $-0.20005+0 ? \quad 0.2000 E+0 ? \cdot 0.5000 E+06$

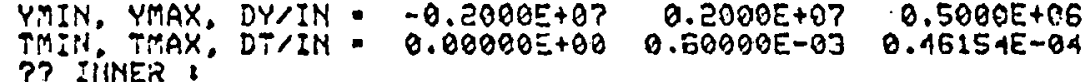

7 Bus 3

Fig. 1-15b 


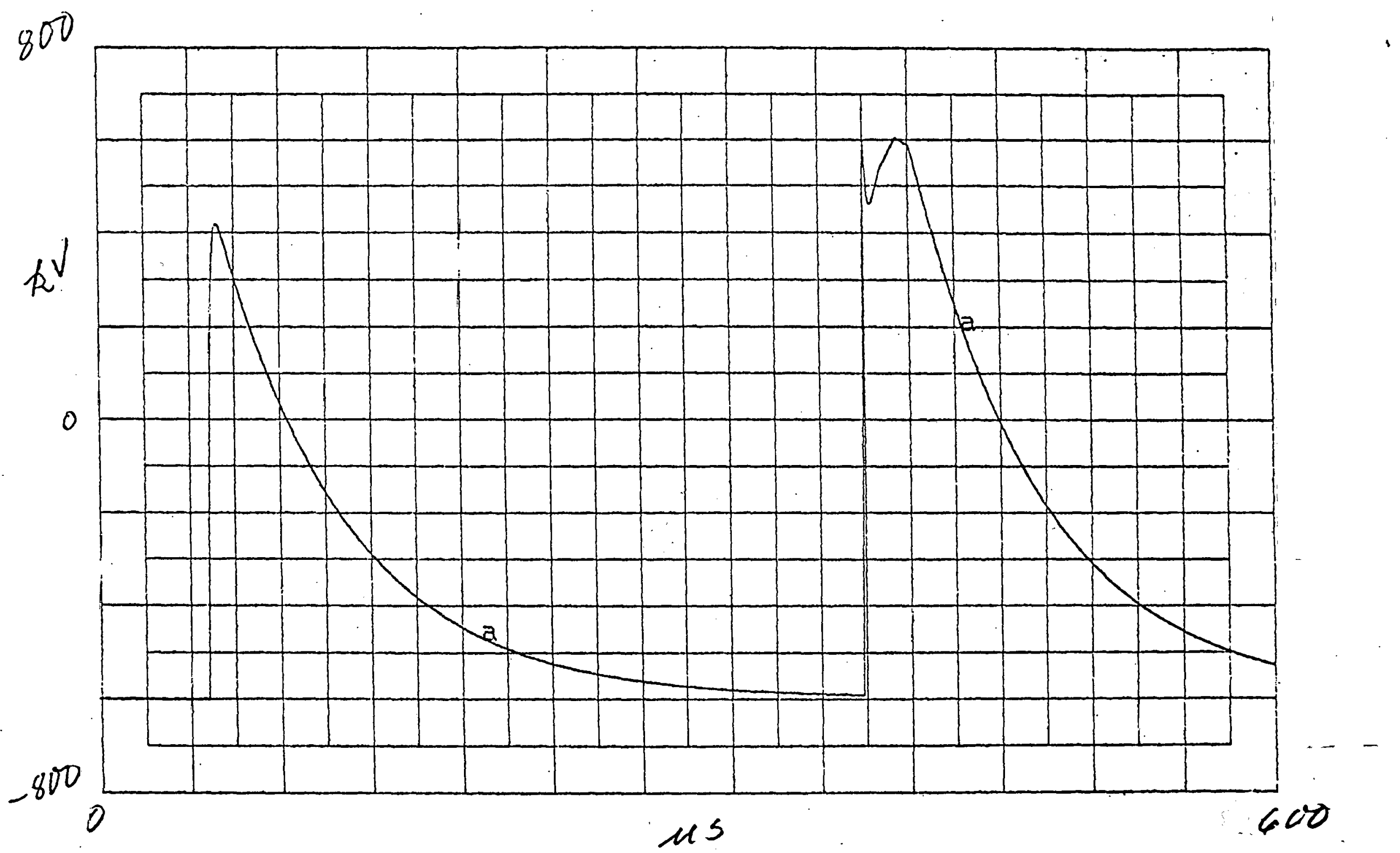

\section{NAMES : FILE: $: 05 / 14 / 8013.16 .28$}

YMIN, YMAX, DYIIN - $-0.8000 E+06 \quad 0.8000 E+06 \quad 0.2000 E+06$

TMIK, TMAX, DTIIN - $0.00000 E+\theta 0$ 0.60000E-03 $0.46154 E-04$

7 Bues 4

?? DINE? :

Fig. $1-15 c$ 


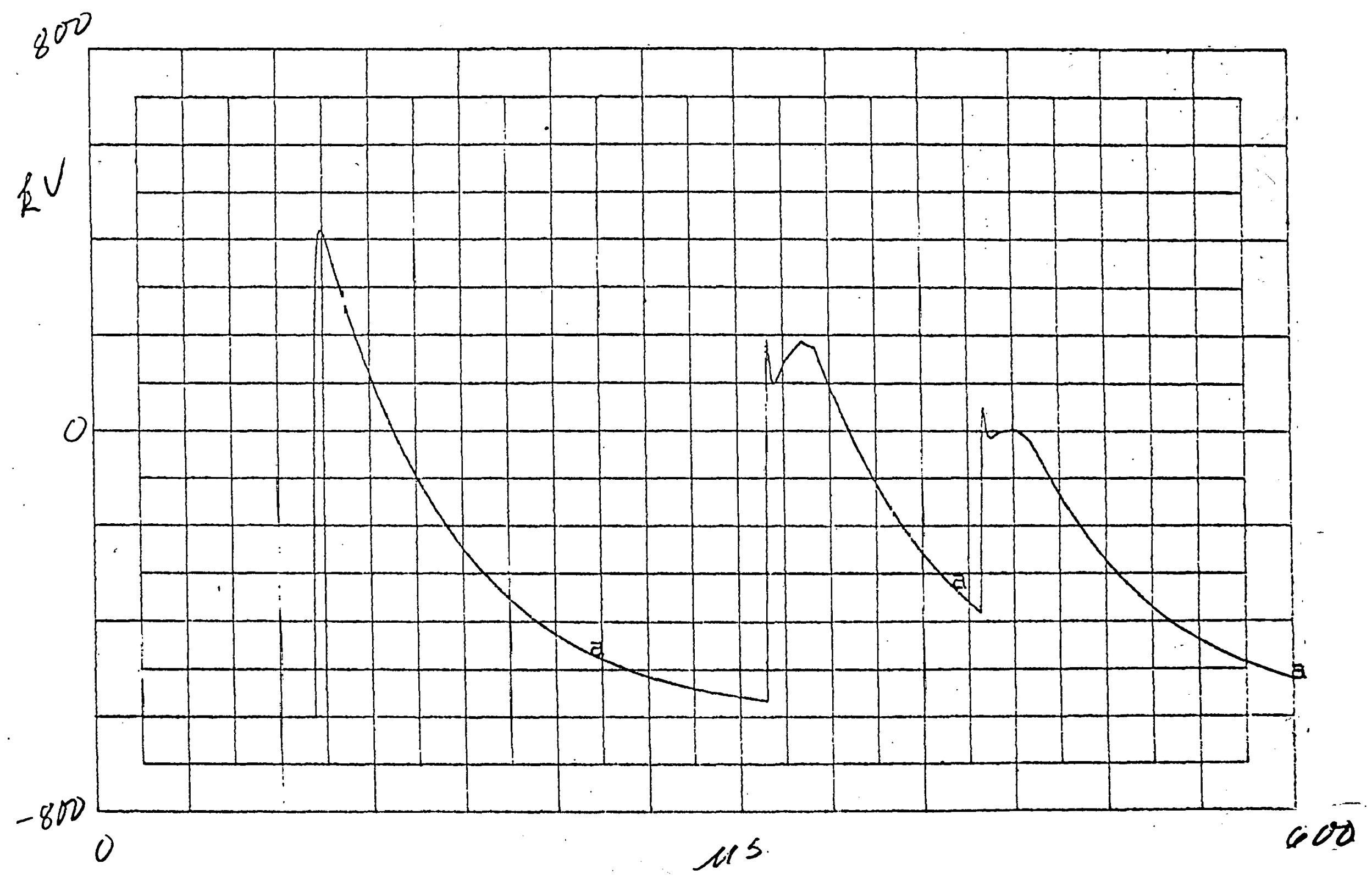

NAMES : FILE: $05 / 19 / 8013.16 .28$

YMIH, YMAX, DY,IN - $-0.8000 E+\theta 6 \quad 0.8080 E+06 \quad 0.2000 E+06$ TMIP1. TMAX', DT/IN = $0.00000 E+00$ 0.60000E-03 $0.46154 E-04$ PP INNER : 


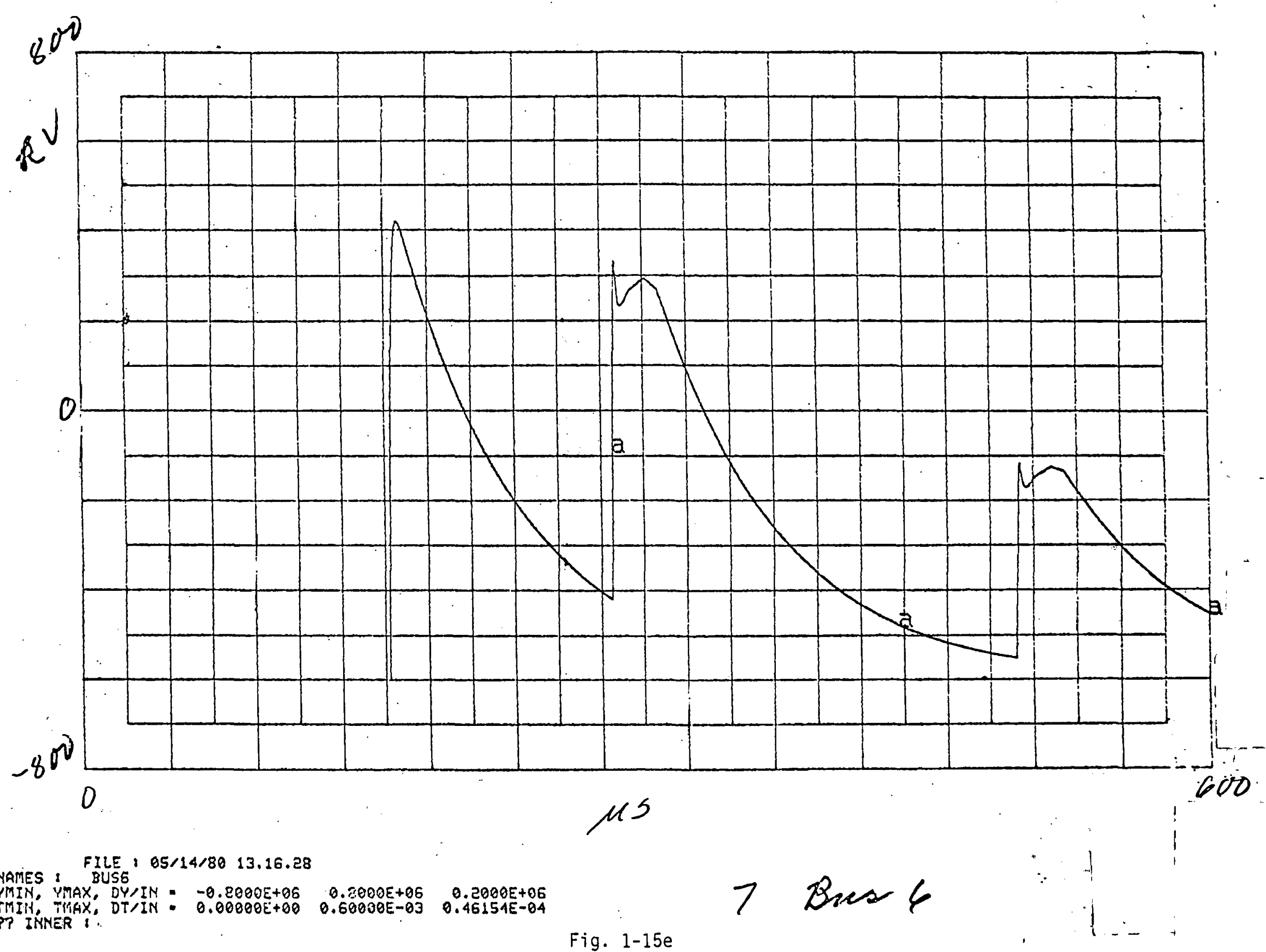




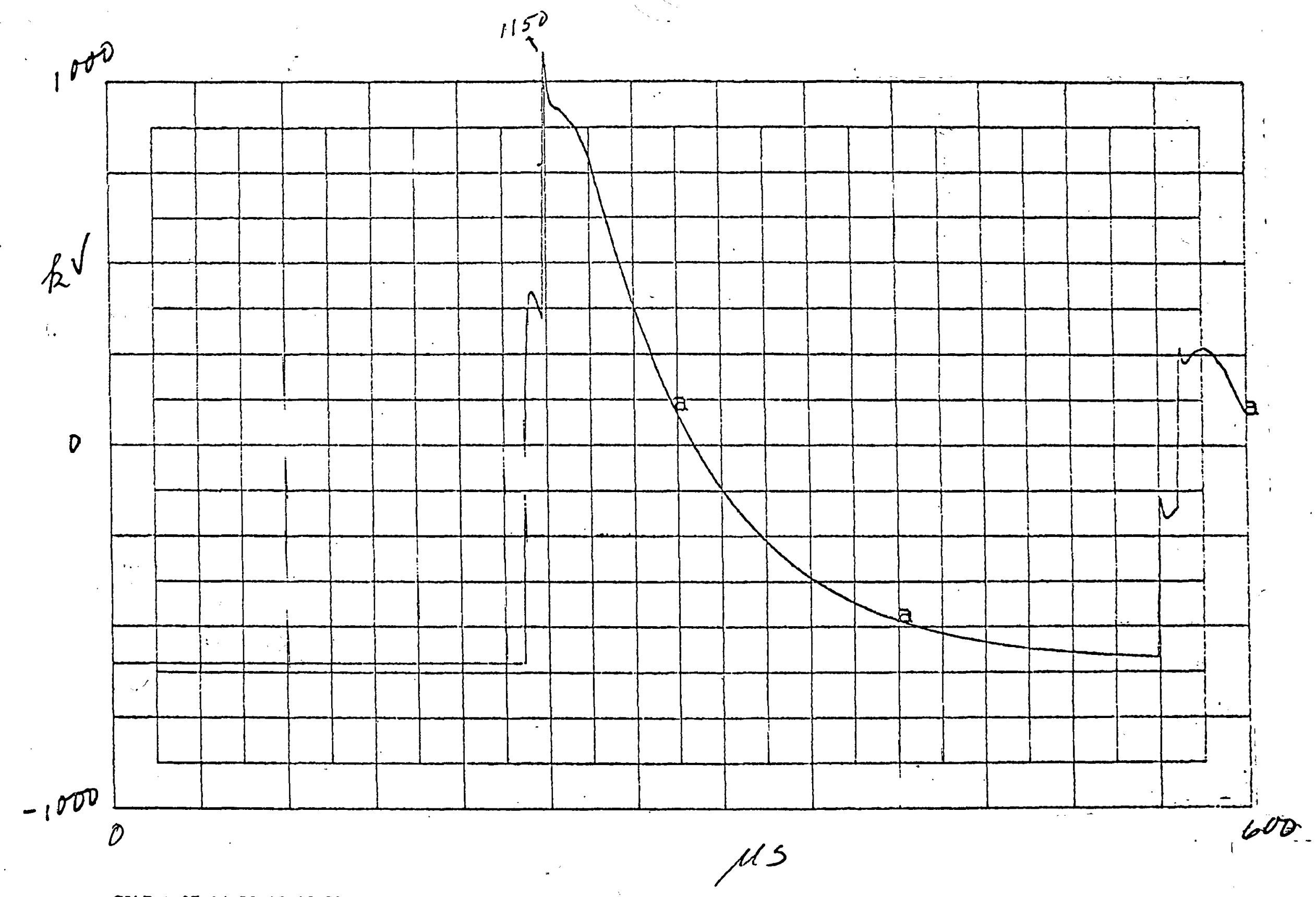

FILE : $05 / 14 / 80 \quad 13.16 .28$ 


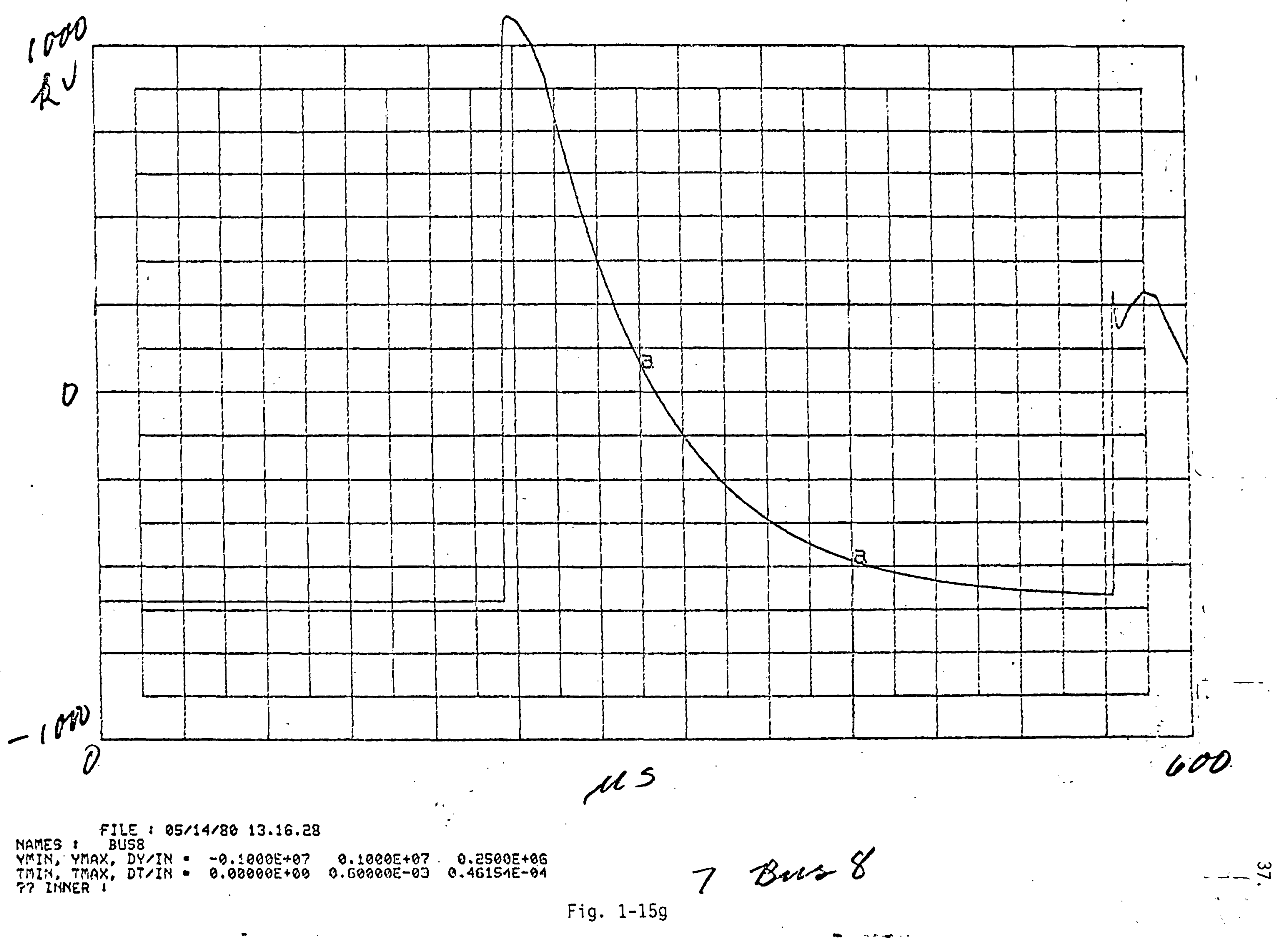




\begin{tabular}{|c|c|c|c|c|c|}
\hline $\begin{array}{l}0 \% \\
\text { Shunt } \\
\text { Gap }\end{array}$ & $\begin{array}{c}\# \\
\text { Columns }\end{array}$ & $\begin{array}{c}\text { Currert } \\
\text { Per Column } \\
\text { kA }\end{array}$ & $\begin{array}{c}\text { Total } \\
\text { Arrester } \\
\text { Current } \\
\text { kA }\end{array}$ & $\begin{array}{c}\text { Arrest } \\
\text { Volts } \\
\text { kV }\end{array}$ & $\begin{array}{l}\text { Sw Surge } \\
\text { Coordination } \\
\text { current } \\
\text { KA }\end{array}$ \\
\hline 15 & 2 & 10 & 20 & 1020 & \\
\hline 15 & 2 & 1.5 & 3 & 854 & 3 \\
\hline 15 & 2 & 1.0 & 2 & 836 & \\
\hline 15 & 2 & 0.5 & 1 & 806 & .. 1 \\
\hline
\end{tabular}

TAELE 1.1 - BIL VS. ARRESTER PROTECTIVE LEVEL 


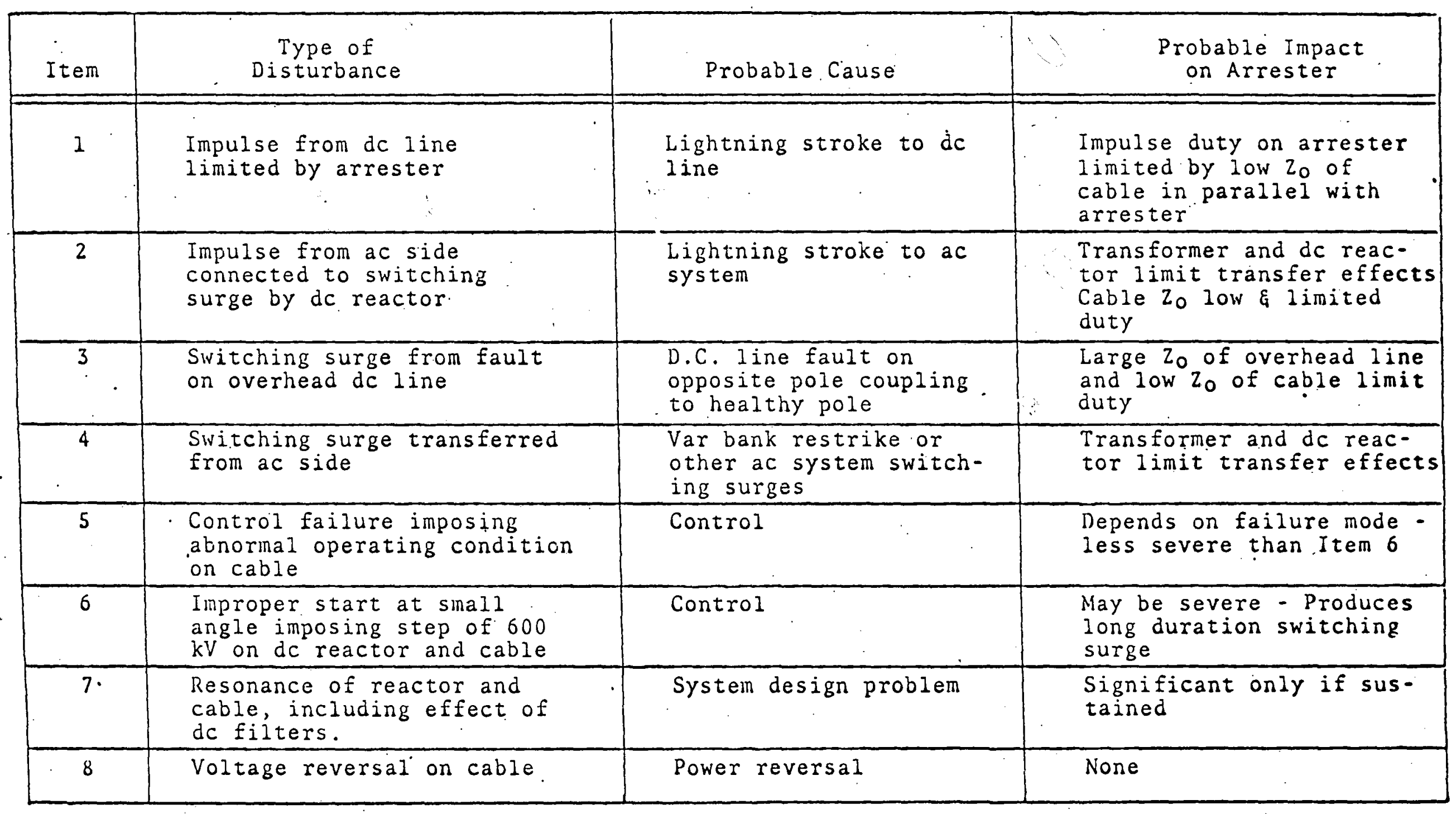

TABLE 1.2 SUMMARY OF SYSTEM DISTRUBANCES 


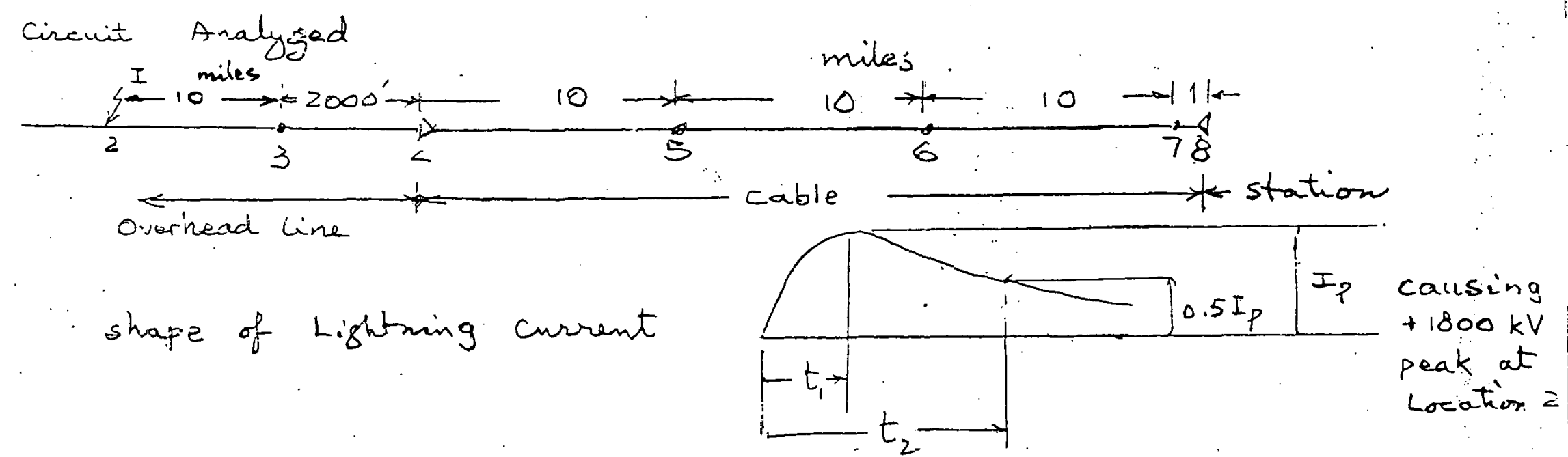

\begin{tabular}{|c|c|c|c|c|c|c|c|c|c|c|c|c|c|}
\hline $\begin{array}{c}\text { Case } \\
\#\end{array}$ & D.C. & $\begin{array}{l}I_{F} \\
K F\end{array}$ & $\begin{array}{l}t_{1} \\
\text { us }\end{array}$ & $\begin{array}{l}t_{2} \\
\text { us }\end{array}$ & 3 & $\begin{array}{c}\text { Peak } \\
4\end{array}$ & $\begin{array}{c}\text { Surge } \\
5\end{array}$ & $\begin{array}{c}\text { Vol tage } \\
6\end{array}$ & $\begin{array}{c}(k V) \text { at } \\
7\end{array}$ & 8 & Highest & Protection & $\begin{array}{c}\text { Arrester } \\
\text { Characteristics }\end{array}$ \\
\hline 3 & +500 & $8^{\frac{5}{5}}$ & 0.6 & 50 & $18 C 0$ & 1015 & 1015 & 1015 & 1070 & $=085$ & 1110 & \multirow{4}{*}{$\begin{array}{l}\text { Arresters } \\
\text { at } \\
\text { locations } \\
4 \text { and } 8\end{array}$} & \multirow{7}{*}{$\begin{array}{l}0.6 \times 1.5 \mu \mathrm{s} \\
\text { curve }\end{array}$} \\
\hline 4 & +000 & $8: \vec{x}$ & 5 & 50 & I09C & 957 & 956 & 956 & 1112 & $\therefore 371$ & 1178 & & \\
\hline 6 & 0 & 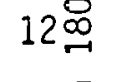 & 5 & 50 & 1799 & 761 & 761 & $761^{\circ}$ & 1153 & 1097 & 1200 & & \\
\hline 7 & -600 & $16 . \Xi$ & 5 & 50 & .1793 & 605 & 600 & 600 & $1080^{\circ}$ & 1086 & 1150 & & \\
\hline 5 & +600 & $8 \stackrel{\bar{S}}{\underline{y}}$ & 5 & 50 & 17. & 957 & 956 & 956 & 1112 & 1071 & 1112 & \multirow{5}{*}{$\begin{array}{l}\text { Additional } \\
\text { arrester } \\
\text { at } \\
\text { lacation } 3\end{array}$} & \\
\hline $8^{+}$ & +600 & 83 & 5 & 50 & 1390 & 957 & 956 & 956 & 1112 & 1071 & 1112 & & \\
\hline $9 *+$ & +600 & 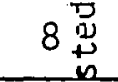 & 5 & 50 & 1.390 & 957 & 955 & 956 & 940 & 913 & 957. & & \\
\hline 10 & +600 & 8点 & 5 & 50 & 1037 & 917 & 915 & 915 & 1036 & 1503 & 1036 & & \multirow{2}{*}{$\begin{array}{c}8 \times 20 \mu s \\
\text { curve }\end{array}$} \\
\hline $11 *+$ & +600 & 8 & 5 & 50 & 1037 & 917 & 916 & 916 & 893 & $\Xi 89$ & 917 & & \\
\hline
\end{tabular}

* I $\mu \mathrm{F}$ capacitor adced at Jocation $8 \quad$ +D.C. resistances presented as limped elements.

. 


\section{TASK 2}

\subsection{New Features of Development Model}

The Development Model \#1 was described in the 2nd Quarterly Report. For the tests reported in this report, three new features were introduced.

Instead of a single insulator, two insulators (also MK I) were used, at the $20^{\prime}$ clock and the $100^{\prime}$ clock positions. The purpose was to investigate whether they could be protected against particle pollution. It will be recalled later that one hole was drilled in the bulge on each side of the insulator to the right. This was done to shine light into the space near this insulator. The light bulb against the lower hole can be seen in the upper corner of Fig. 2-1. In this picture, the bulb below it was actually much nearer to the camera. It shone light into the bulge and the light reflected outwards through the holes beside the right insulator. This explains the two bright spots on the outside wall of the bulge in Fig. 2-1.

The second new feature is Trap \#3. It can be seen at the bottom of the bulge in Fig. 2-1. Its details are shown in Fig. 2-2. It was deliberately made intu lwo scparate rompartments. in order to ascertain by what route the particles were trapped.

The third new feature is a laboratory modification of the enclosure to simulate, in part, asymmetrical corrugations. (Fig. 2-3)

\subsection{Meclianical Removal of Particles}

After the model cable was assembled, a small pinch of aluminum filing* and one foil (3/16" square) were placed at each of the following places.

* See Section 2.3.1 
(i) On each insulator, at the middle of the line of intersection between the upper surface of the insulator and the vertical plane.

(ii) On the left insulator only, at the middle of the line of intersection between the upper surface of the insulator and a plane inclined at an angle of $45^{\circ}$ towards the open end of the bulge.

(iii) On top of the expansiun joint.

(iv) Un top of the conductor.

Mechanical vibrations were set up by hammering at the test tank and then at one support of the buige and then directly at the end of the conductor. Some of the filings and foils remained on both insulators [but at location ( $i$ ) only] and also on top of the conductor. (These particles were cleaned off before electrical tests.)

As both filings and foils at location (ii) were shaken off, it was concluded that all particles could be shaken off when the cable ser.tinn was being lowered at an anqle frnm the truck into the trellch.

The insulators were not damaged and subsequently withstood the highest test voltages applied (1000 kV lightning impulse and $370 \mathrm{kV} \mathrm{DC}$ ).

\subsection{HVDC Commissioning}

\subsubsection{Particles}

After. the cable is installed, there may still be particles in the cable. The object of HVDC commissioning is to drive such residual particles into traps without causing particle-induced breakdowns and without contaminating the insulators. For the test purpose, particles were placed in various places in the model cable before testing. 
The various particles used are listed in Table 2-1

The aluminum filings are as the term indicates. They have uncontrolled shapes and sizes; although those having smaller sizes tend to be smoother. Examples of sizes and shapes are shown in Fig. 2-4.

Table 2-2 shows the sieve-analysis of more than $100 \mathrm{gm}$ of the filings. If one assumes that the particles had spherical shapes and a diameter equal to the mean of the openings of two successive sieves, the number of these particles in 0.1 gram of filings would be as shown in the penultimate column. The last column shows the number of particles found in a cleaned $20-\mathrm{ft}$ cable section. Whenever filings were used in our tests, the weight far exceeded $0.1 \mathrm{gm}$; therefore, the number of particles used was 2 to 6 orders more than that found in a realistic cable. The tests thus represented extremely severe conditions.

\subsubsection{Driving Particles Into Trap}

Control of particle motion was discussed in the Second Quarterly Report.

Given a perfectly horizontal conductor within a perfectly coaxial enclosure, axial motion can be affected by shaping the enclosure profile. Three types of profile were tested:
(a) Plain
(b) Symmetrical Corrugation
(c) Asymmetrical Corrugation

The asymmetrical corrugation was found by tests to be effective, even for driving fine particles. Computer simulation discussed in Appendix 2-A agrees with this finding. 
It is well-known that elongated particles are prompt to hover on the negative electrode. Its bouncing motions are promoted by reducing the voltage to stop its hovering.

The test procedure is illustrated in Fig. 2-5. The top graph depicts that the voltage was raised slowiy until particle motion was observed through the view port. The voltage was then held for a certain period before it was lowered to zero. The current through the cable-model was monitored simultaneously to study the possibilily of munftoring the actual cable during HVDC commissioning. The lower graph depicts the reading of an indicating meter. Fig. 2-6 illustrates a simultaneous recording of the voltage and the current during one raising-holding-lowering voltage cycle. Such recordings will be made and analyzed throughout this project.

The raising-holding-lowering voltage cycle was repeated a few times before the holding voltage was increased, as depicted in Fig. 2-5.

The test results showed that all particles used could be driven out of the straight section of the model cable without inducing breakdowns. The ease of the driving process depends on the particle properties and on the enclosure profile. The lighter the particle density and the larger the length/cross-section ratio, the more easily the particle can be driven. The symmetrical profile is definitely the least conducive while the plain electrode is probably the most conducive. With the plain enclosure, particles repel each other axially even when the voltage is too low to cause any bouncing. 
The most difficult task is to drive the small filings in symmetrical corrugation. The very small particles could remain bouncing within one corrugation throughout the longest period of observation (about 1 hour). At relatively low voltage $(-40 \mathrm{kV})$, they started bouncing within a small sector between 5 and $70^{\prime}$ clock positions. At higher and higher voltages, the sector became wider and wider until at about $-90 \mathrm{kV}$. At $-90 \mathrm{kV}$, the sector extended clockwise from 2 to $100^{\prime}$ clock positions. It was only then they moved quickly out of the straight section of the model cable.

With the simulated asymmetrical corrugation, fine powders started to move axially as soon as they start to bounce. They came out of the straight section in both directions with preference away from the steeper face of the corrugation. However, the specifically shaped particles showed no definite directional preference.

The straight section of the model cable is 20 "long. Further test will be made with longer models. Interpretation of the test results in term of full-length cable sections is given in Section 2.5 .

\subsubsection{Retention of Particles}

The HVDC commissioning tests were made with negative voltage applied to the conductor. The test was terminated after particle activity had stopped. Positive voltage was then applied scveral times. It was reported in an earlier report that enameled copper particles could be pulled out of Trap \#1 on the first polarity reversal. However, with Traps \#2 and \#3 no particles were pulled out. Also, no particles trapped in the expansion-joint shield were ever pulled' out on polarity reversal. 


\subsubsection{Protection of Insulators}

The interception and capturing of particles by the high field around the expansion-joint shield was observed.

Particles placed on the base of the insulator remained unmoved throughout the commissioning tests and the polarity reversal.

Insulators were contaminated by only a few particles smaller than $100 \mathrm{\mu m}^{*}$ but only when they were placed nearly horizontally (at 2 and $100^{\prime c l o c k}$ positions) and only when the enclosure had symmetrical corrugations. It should be reralled that fine particles were driven out after the "bouncing seclur" had extended to the whole lower half of the enclosure with symmetrical corrugations. With asymmetrical corrugations, fine particles were driven out when the voltage during the "holding" period.was low enough to result in a small "bouncing sector."

In short, the insulators placed above the expansion joint between $2 o^{\prime c l o c k}$ and 10 o'r.lnrk. positions werc protected froiii all types of particles during HVDC commissioning, with plain cnclosure and wilh enclosure having asymmetrical currugations. These insulators were also proterted from all particles cxccpt fine filings with enclosure having symmetrical corrugations.

* While protection of insulator against these fine particips was achieved by using asymmetrical corrugations, it may be not.en that such particles had 10 cffect on the insuldtur strength under lightning impulse (see Fig. 2-7). 


\subsection{Highest Voltage Applied - "As-Cast" Conductor}

The model cable having symmetrical corrugations and with 2 MK-1 insulators was tested with lightning impulses to the highest voltage the external bushing could withstand, which was $\pm 1000 \mathrm{kV}$. The withstand voltage of the model cable should be higher.

The diameter of the "as-cast" conductor is $3-1 / 2$ " and that of the "peak" of the corrugation 10". Assuming conservatively the withstand voltage of this $3.5 / 10$ cable to be $1000 \mathrm{kV}$, the withstand voltage is comparable to the recently published data (Ref. 2-1) obtained with a 7/21 cable. To compare the data of different cable systems, the voltage is converted to gradient, which in turn is expressed as a fraction of the theoretical maximum withstand gradient (Fig. 2-8). The "as-cast" conductor is seen as good as, if not better than, the extruded conductor dielectrically. It may be recalled that the "as-cast" conductors are much cheaper and require less energy to produce than extruded conductors.

The $-1000 \mathrm{kV}$ withstand voltage for the $3.5 / 10$ cable can be translated as $-2000 \mathrm{kV}$ for a $7 / 20$ cable. The positive withstand voltage should be even higher: The withstand voltage is thus well above the projected $1300 \mathrm{kV}$ BIL .

\subsection{Discussion}

The $D C$ commissioning, using raising-holding-lowering voltage cycle, has been successfully demonstratcd with the model cable. Particles of all types can be driven out of the straight section into the bulge and trapped either in the expansion-joint shield or in the trap at the bottom of the bulge. Trapped particles remain trapped during voltage reversals. Particles of all lypes can be prevented from contaminating the insulators even when 
the insulators are placed as low as at the $20^{\prime}$ clock or $100^{\prime}$ clock position. However, questions should now be considered as to the validity of applying the results obtained with 20 " model cables to the 40 " practical $600 \mathrm{kV}$ cable even though the final answers must await the test of a fullscale model cable.

Driving particles into traps in the bulge by bouncing motion

All but the fine filings were driven out of the model cable in both dircctions with practically the same ease. This was so even with the asymmetrical currugations. One pnssible explanation is the randun directions of their initial rotations, discussed in Appendix 2-A, which bias the directions of their axial motions independent of the angles of the surface at subsequent impacts. If this explanation is true, then they will be eventually driven out of a straight section of any length.

As for the fine particles, their rotation momentums are probably rather small owing to their close resemblance of spheres. Their motions are probably well presented by the simulation Model \#2 (Appendix 2-A), which depicts their observed motions fairly well. Both the simulation results and the test results show that (1) they bounce within a symmetrical corrugation almost indefinitely, (2) they have a net axial motion in an enclosure having asymmetrical corrugations, and (3) the net axial motion is away from tlie sleeper side of the asymmetrical corrugation. Therefore, one would expect that with an enclosure having asymmetrical corrugations, they can be driven into the bulge no matter the length of the straight sections of the cable.

Protection of insulators

From the tests with the enclosure having asymmetrical corrugations, it can be deduced that activities of fine particles were essentially confined to near the entrance of the bulge and consequentiy at a distance from the 
insulators. Only about half a dozen of fine particles were trapped in the inner compartment of Trap \#3 while "hundreds" and "thousands" were trapped respectively in the expansion-joint and in the outer compartment. of Trap \#3. In the latter two places, their number was the largest near. the entrances from the straight section and tapered off away from the entrance.

With the size of the model increased to that of a practical $600 \mathrm{kV}$ cable, the insulators will be further away from the activity of fine particles, consequently better protection can be expected.

Particles of larger sizes, both during hovering and during bouncing, were seen to invade into the upper half of the model cable. They were also seen hovering at the ends of, and also under, the expansion-joint shield, substantiating the design concept of capturing particles. They were trapped in comparable numbers in the inner compartment of Trap \#3 and in the expansion-joint shield. Most were trapped in the outer compartment of Trap \#3 but were distributed much more uniformiy compared with the trapped fine particles. However, none of these particles ever contaminated the insulators throughout the tests. The distribution of these trapped particles is consistent with visual observations that particle activities extended well into the bulge but the particles were captured before reaching the insulators. It is possible that visual observations may have missed those particles which did reach the insulator but were bounced off. The effectiveness of these modes of protection do not seem to have correlation with the size of the model cable (the capturing concept can be realized by empirical design for cable of any size). Hence effective protection of insulators in a practical cable is promising. Trapping and Retention

Trapping and retention of particles in traps are related to gradient. They can be made as effective in a practical cable as in the model cables tested. 
50.

\subsection{References}

2-1. C. Vincent, J. Giao Trinh, F.A.M. Rizk "Dielectric Performance of CGI Cables for EHV Transmission at 550 and $800 \mathrm{kV}, "$ International Symposium on Electrical Insulation, Boston, USA, June 1980. 


\section{PAGES 51 to 54 WERE INTENTIONALLY LEFT BLANK}


NEGATIVE VOLTAGE

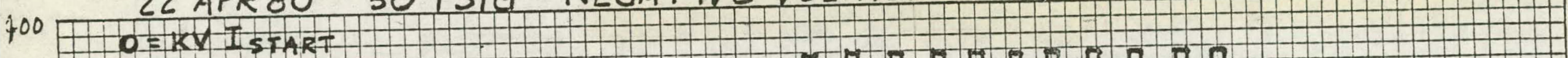

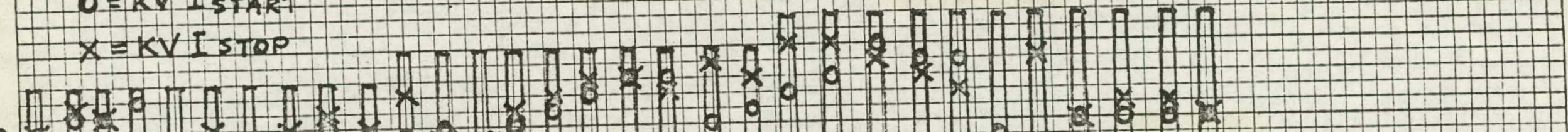

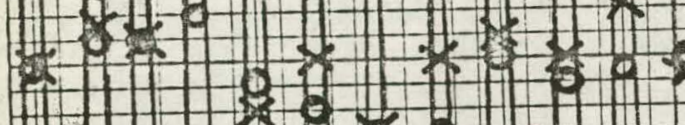

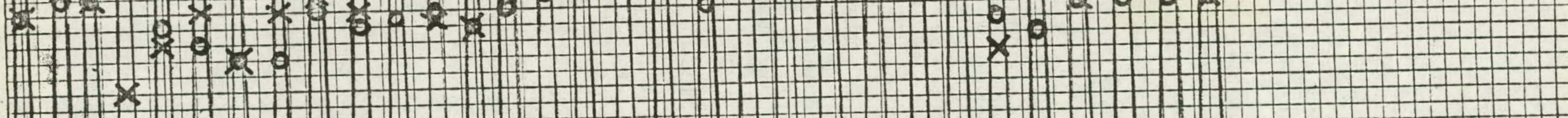

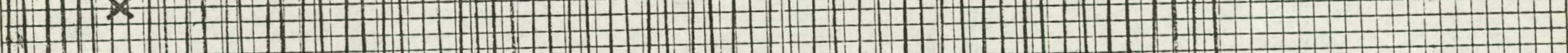

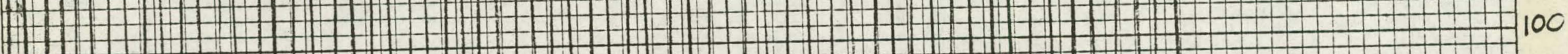

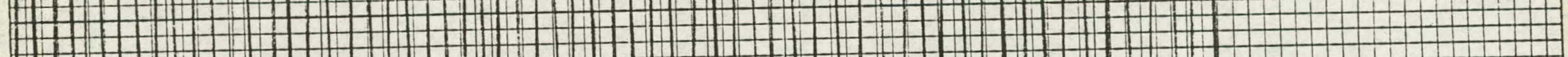

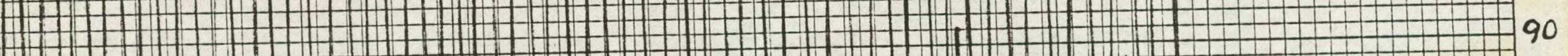

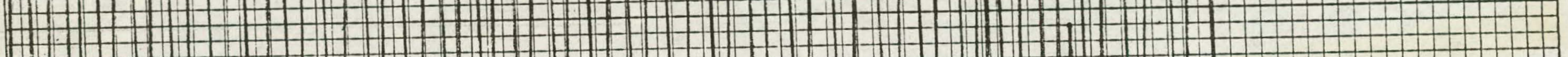

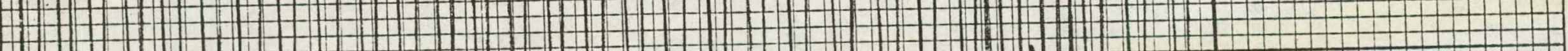

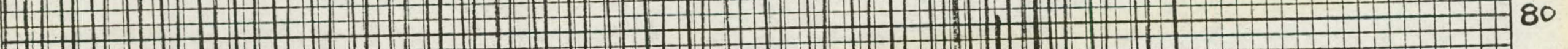

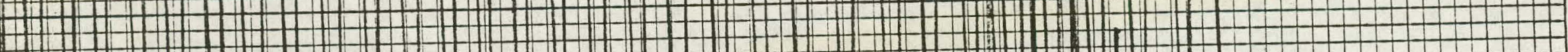
\begin{tabular}{l}
\hline \\
\hline
\end{tabular}

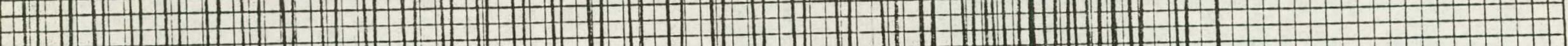

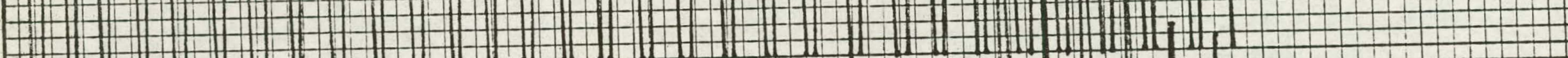

0 -

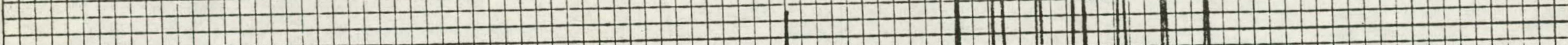

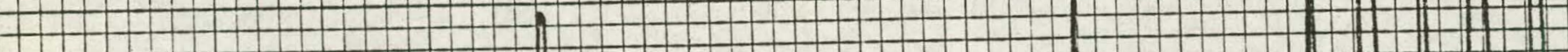

40.

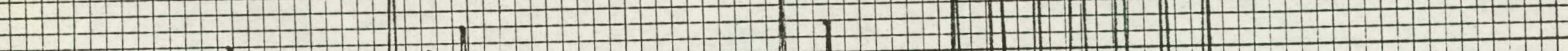

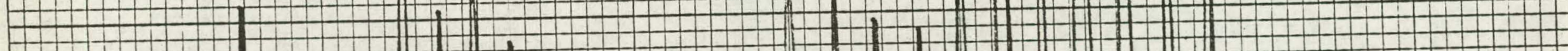

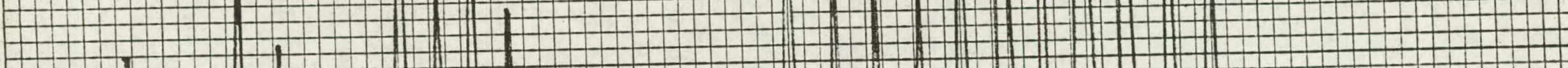

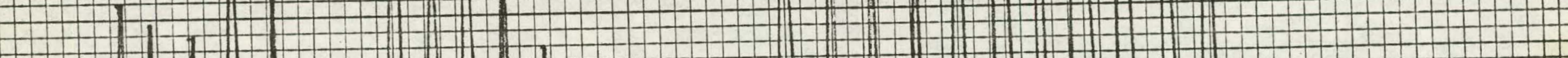
a (1)

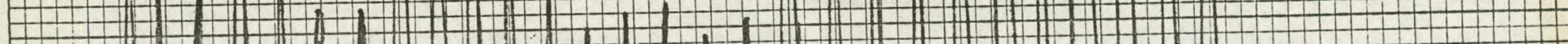

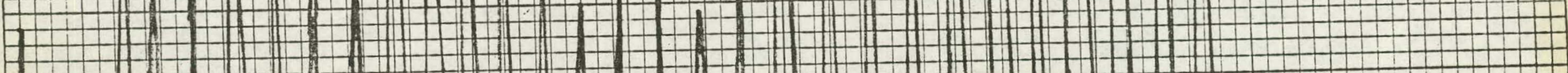

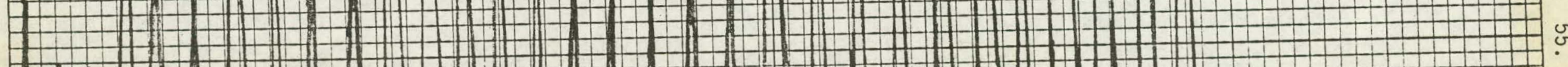

10

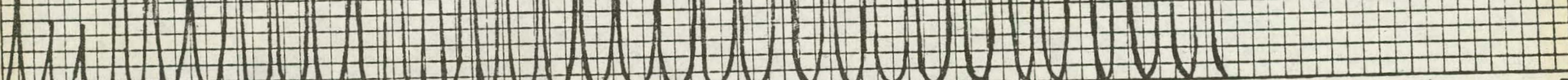


Fig. 2-6. Example of Voltage and Current Records of a Raising-Holding-Lowering Voltage Cycle
( $a$ and $b$ ) Beginning
(c)
Ending

Note: The current starts at $115 \mathrm{kV}$, indicating the beginning of particle activities. It then increases with voltage, indicating incrcasing particle activities. During the holding period the current follows a decreasing trend, indicating trapping of some particles. 


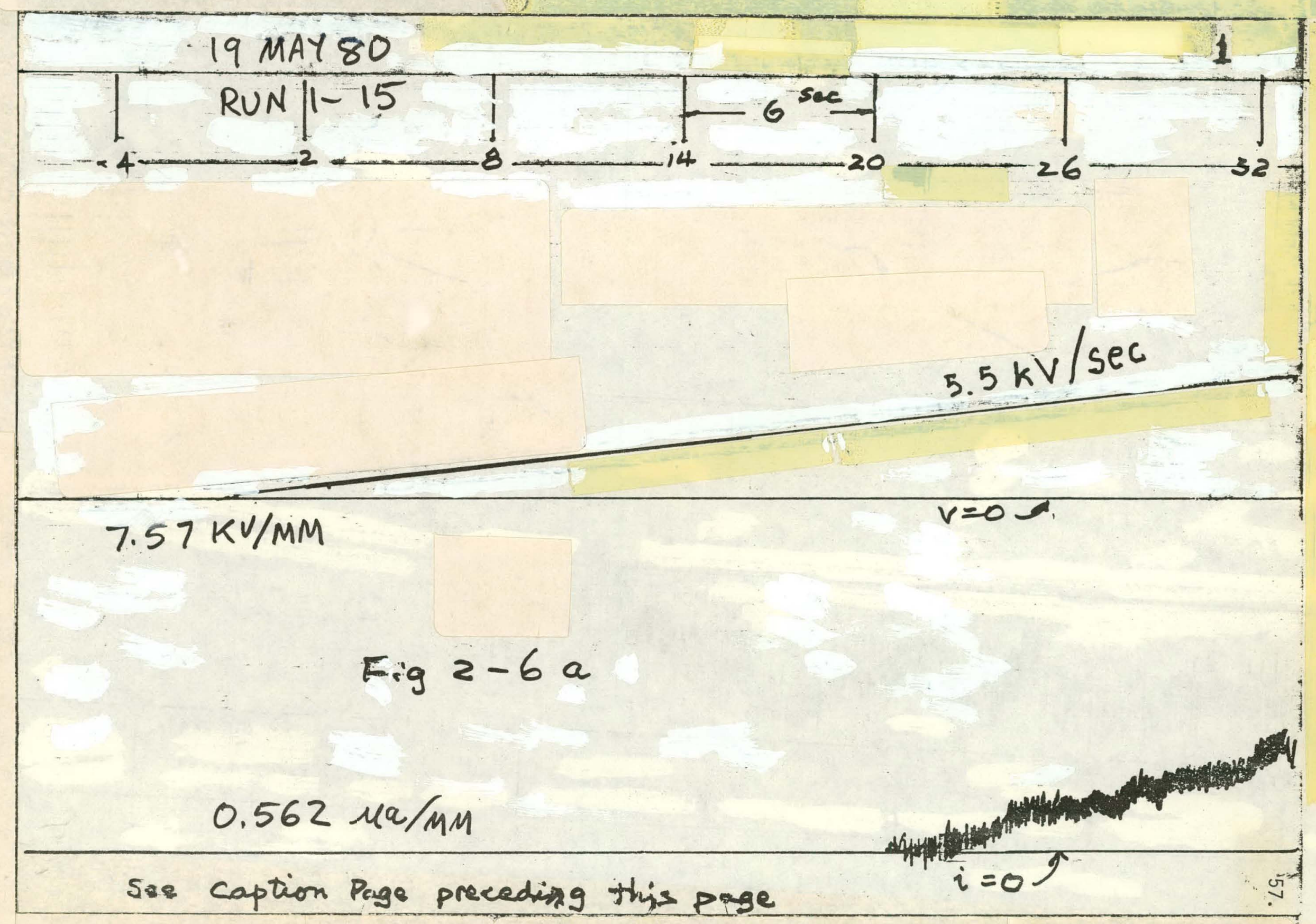




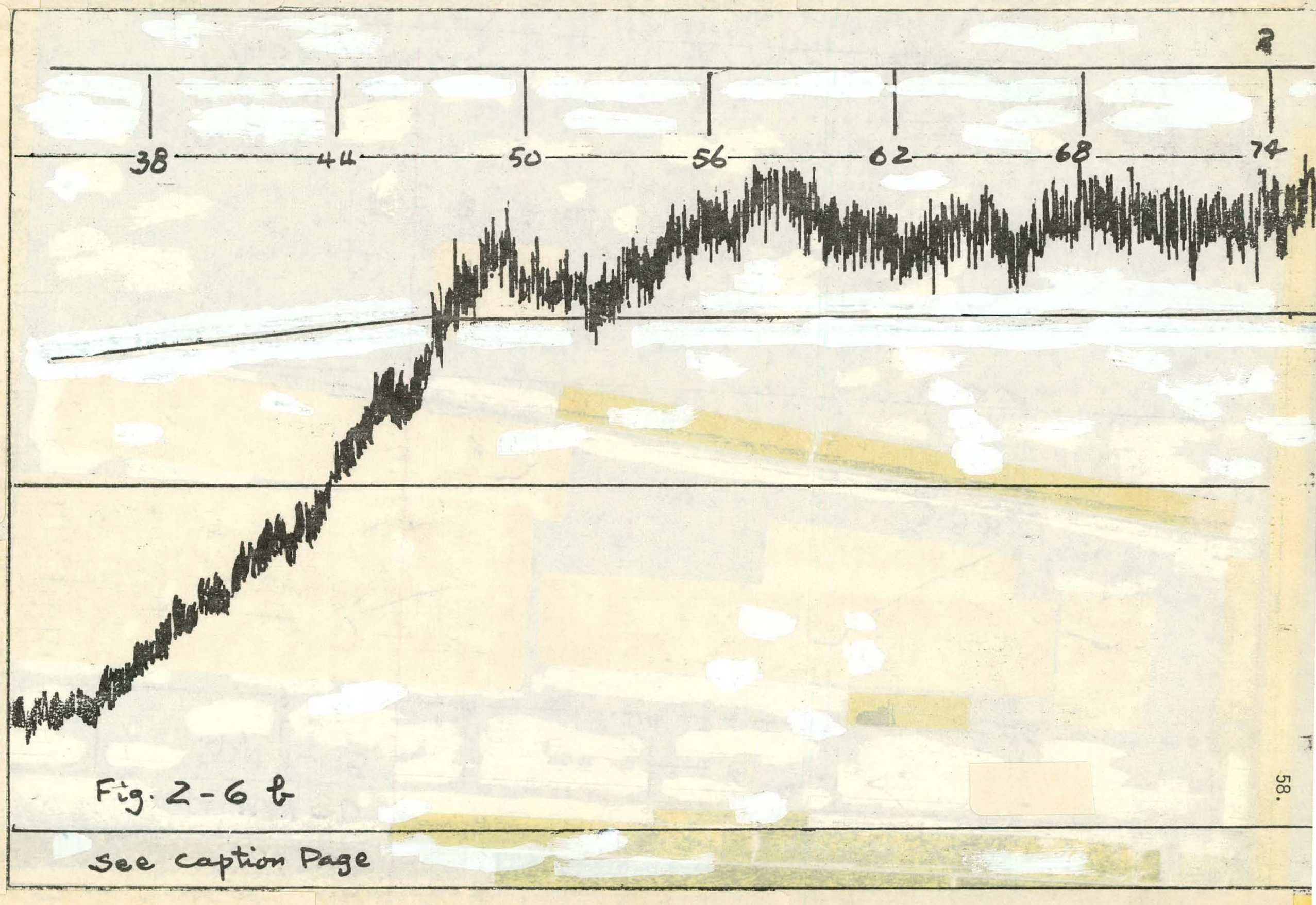




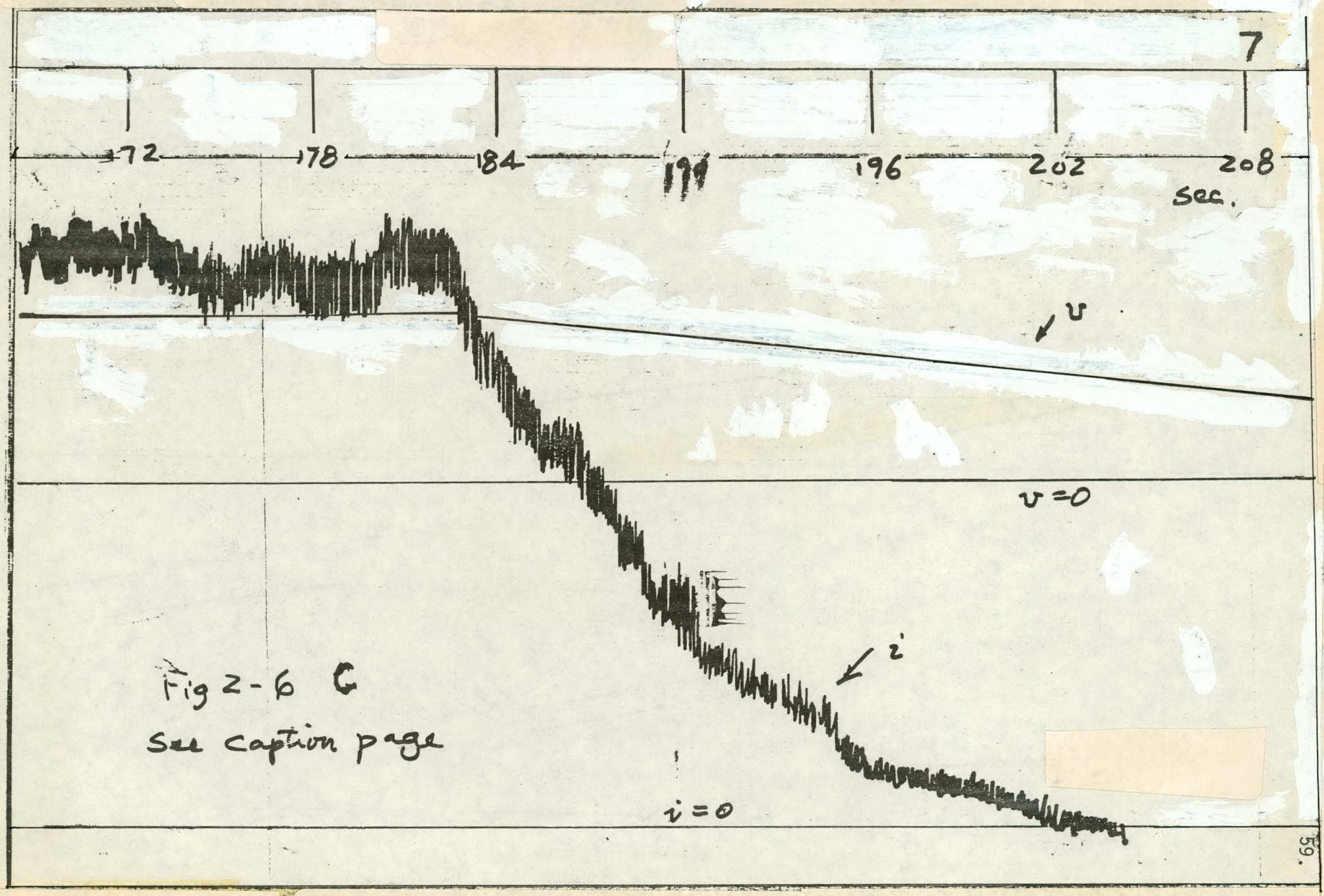



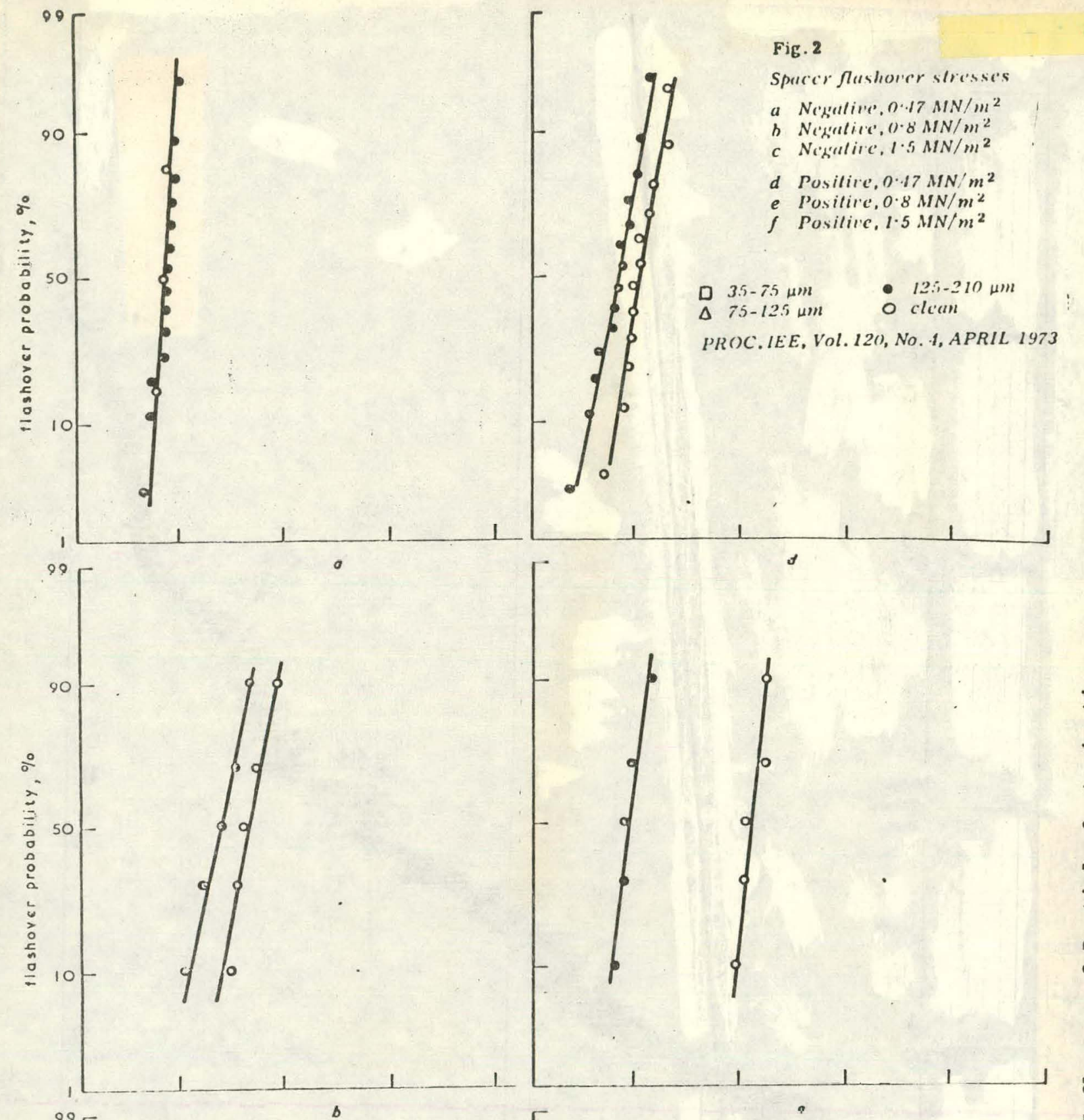

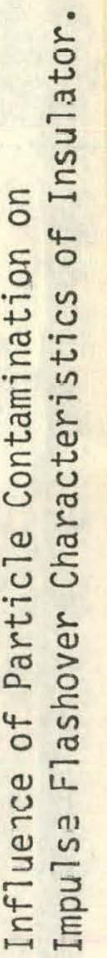
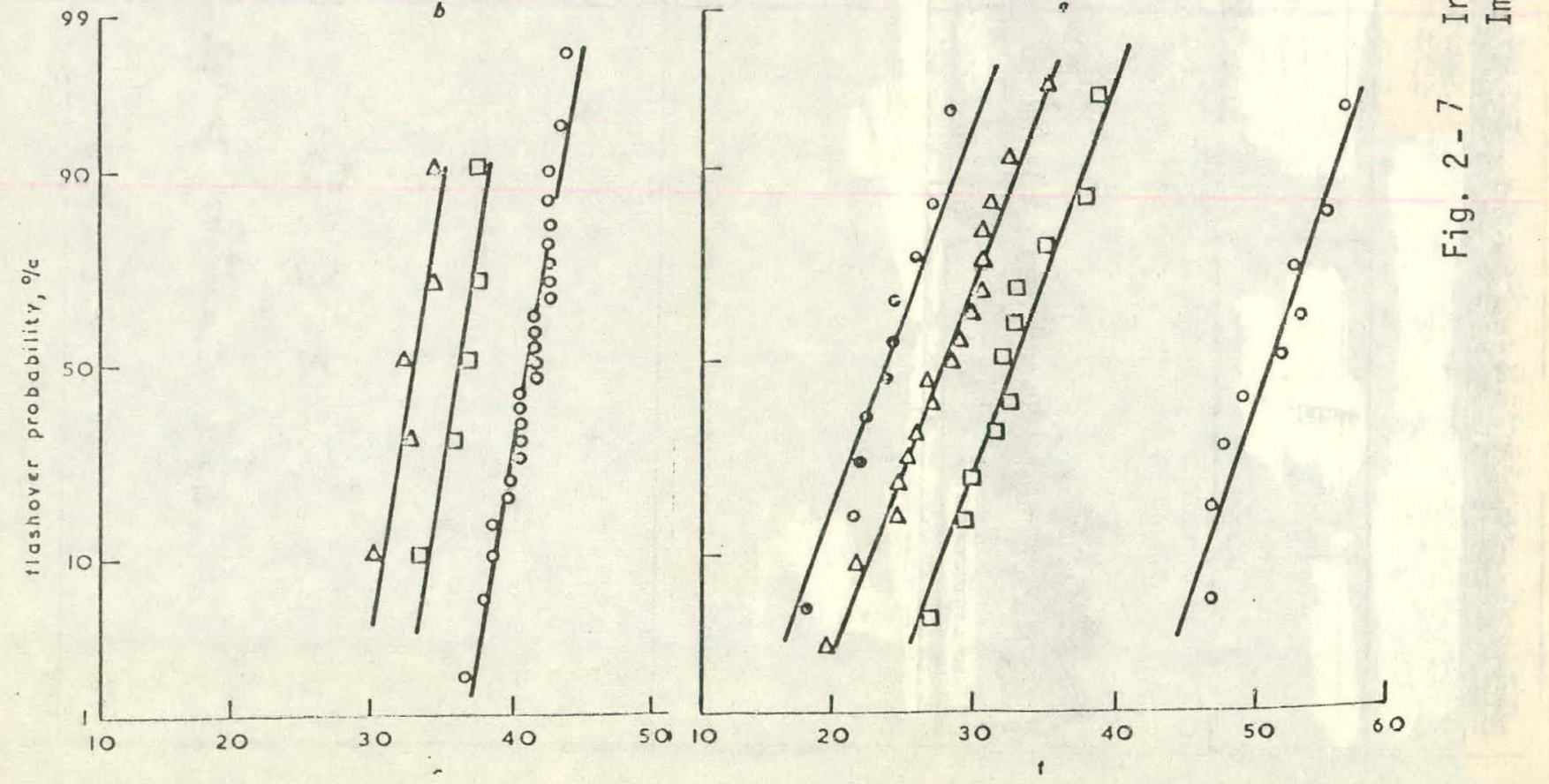


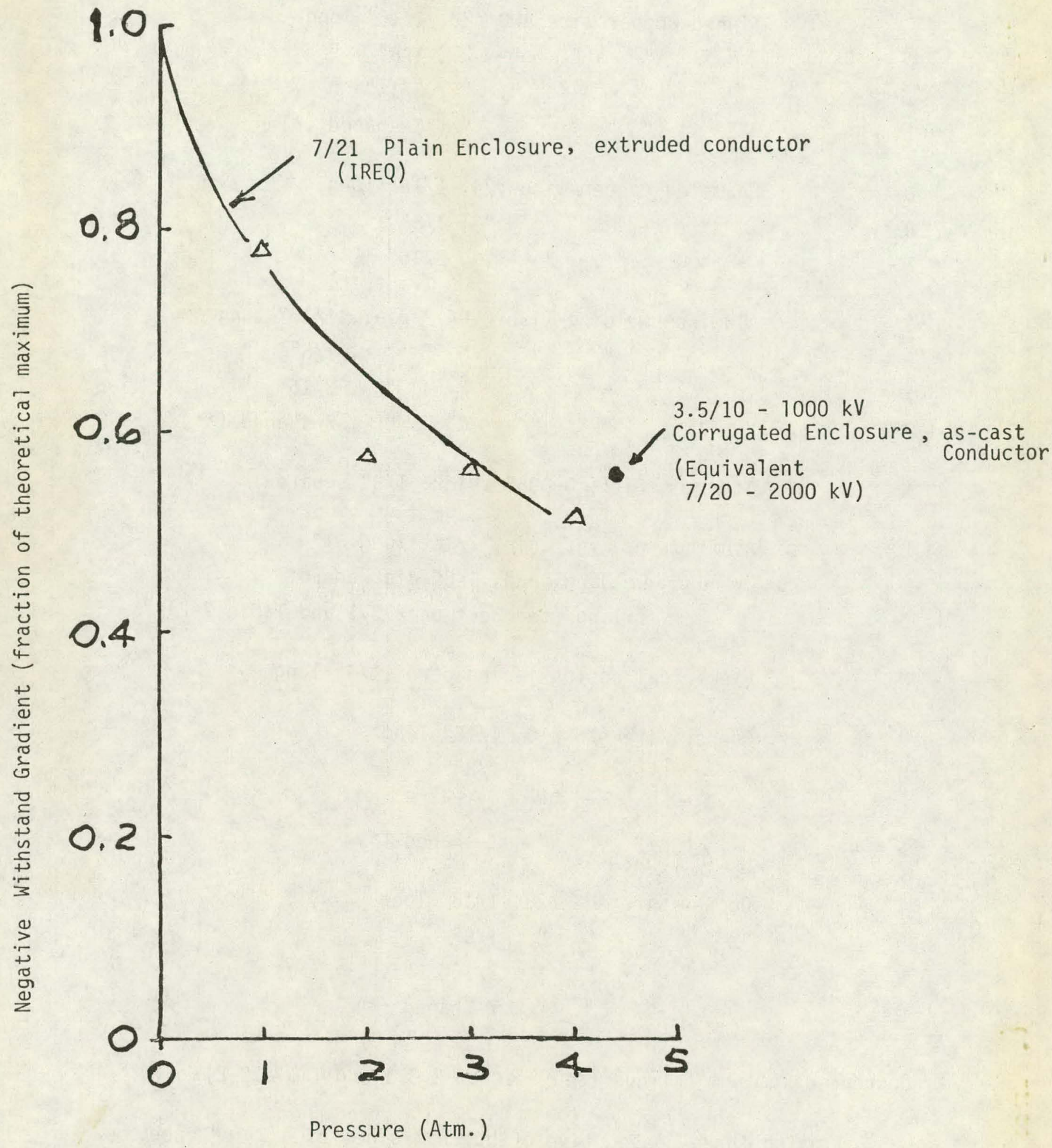

Fig. 2-8 Lightning Impulse Withstand Gradient

- Comparison between "As-Cast" and Extrudent Conductors 
Type

Designation

A

C

E

I

B

D

F

G

II

$x$

$\mathrm{J}$

K

$\mathrm{L}$

M

0

N

P

Q

$\mathrm{R}$

S

T

U

v

W

\section{Description}

Tinned copper wire AWG \#22, 1/16" long

"

"

"

" " ", $3 / 16 "$ "

"

$"$

H

Enameled copper wire \#24, 1/16" long

$"$

"1

Aluminum welding wire $0.047^{\prime \prime}$ dia., $1 / 16^{\prime \prime}$ long

"1

"

II
" 1

" 1

" 11
", $1 / 8$ " "

", $3 / 16 "$ "

Aluminum foil, $0.006^{\prime \prime}$ thick, $1 / 8^{\prime \prime}$ square

A7uminum machine chip, $3 / 16$ " long

" welding bead, $1 / 8$ " dia. appro.

" filing (see Section 2.3.1 and Table 2-2)

Electrical cotton lacing card, 1/4" long

C.иpнer wire AWG $\# 18,1 / 16 "$ long

$$
\begin{aligned}
& \text { " " ", } 1 / 8 \text { " " } \\
& \text { " " ", 3/16" " } \\
& \text { " ", Z-shaped (*) }
\end{aligned}
$$

Copper wire AWG \#23, 1/16" long

$$
\begin{aligned}
& \text { " " } 1 / 8 " \text { " } \\
& \text { " ", 3/16" " } \\
& \text { " " ", L-shaped (*) }
\end{aligned}
$$

Degreasedaluminum filings (see Section 2.3.1 and Table 2-2).

* Following three consecutive orthogonal sides of a $3 / 16$ " cube. ** " " " " " $3 / 8 "$ ". 
63.

Table 2-2

Analysis of Aluminum Filings
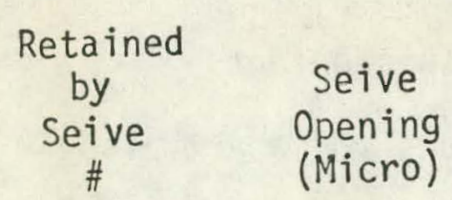

12

850

30

600

300

246

125

120

170

270

Thru Seive \#270
88

53
Assumed Mean diameter Weight Retained
Particle Number

Number in $0.1 \mathrm{gm}$ of Filing in

$20 \mathrm{ft}$ of Cable

(*)

2.5

900

3

4

$2 \times 10^{2}$

0

$5 \times 10^{2}$

0

12.2

273

52.1

$7 \times 10^{3}$

0

$8 \times 10^{3}$

6

10.1

106

3.0

71

$2 \times 10^{7}$

19

$2 \times 10^{7}$

124

* G. W. Brown, et al IEEE Trans. PAS-97, No. 1 Jan/Feb. 1978, p. 59 


\subsection{Thermal Cycling of Insulator MK I}

One MK.I insulator was subjected to sixteen 12-hour cycles between $+105^{\circ} \mathrm{C}$ and $-40^{\circ} \mathrm{C}$. There were no visible cracks or other defects afterwards. X-ray photographs taken at two orientations $90^{\circ}$ apart also showed no cracks of any kind. Corona tests also showed that no change had been caused by the thermal cycling test (Table 3-1).

\subsection{Rritiral Review}

A critical review has been started by C. E. Welsh. The objective is to issue a report on the effect of material selection as well as processing into specific spacer shape on the long-term dielectric performance of the spacer. 


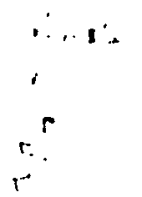

TABLE $3-1$

Corona Measurements: 1 Atmosphere, $\mathrm{SF}_{6}$

Sensitivity: $1 \mathrm{pC} / \mathrm{cm}$

Before Temp. Dy

$\begin{array}{lcl}\text { CS } & \text { CEN } & \text { pC \& 50 kV } \\ k V \text { rms } & k V \text { rms } & \\ 40 & 38 & 3\end{array}$

After Temp. By

(16 cycles

$-40^{\circ} \mathrm{C}$ to $\left.+105^{\circ} \mathrm{C}\right) \quad 40$

37

3 
TASK 4.1 ENCLOSURE

Cost estimates are being obtained for asymmetric corrugated pipe in the size range of interest. A preliminary evaluation by a manacturer, Pacific Roller Die, led to the conclusion that only new tooling would be required. Costs, other than tooling, should be the same as symmetric corrugated pipe. Tooling costs should be approximately $\$ 80,000$. 
TASK 4.2 CONDUCTOR

The mechanical parameters of the conductor contained in Task 4.2.5 (its deflection, loads imparted to the insulators, and stresses) affect the other parts of the program, such as the insulator and enclosure design, gas dielectric study, and expansion joint design. This conductor design study was completed to provide useful information for these tasks taken over a broad range of possible conductor designs. For the purposes of this study, the following were defined as fixed:

1. Conductor Material - 1350 alloy aluminum

2. Support - Two spans, conductor supported at center and ends

3. Fixity - Pinned at ends, moment connection at center

4. Mechanical Loading - Bending moment and shear due to conductor weight

The following were defined as variable:

1. Conductor outer diameter

2. Conductor inner diameter

3. Conductor length

The thermal analysis and gas dielectric study will

determine what constraints exist on these variables; this

mechanical treatment determines their effects. Both solid and hollow conductors were analyzed by setting appropriate values for the inner and outer diameters.

\subsubsection{Computation}

Two computer programswere written to generate the needed data. The first one (COND) operates interactively, and generates area, weight, support reactions, deflections, stresses, and thermal expansion rates. A description and listing of COND are given in App. 4.1. Results of several selected COND runs 
are given in App. 4.2.

The second program (COND1) is adapted from COND, 'but writes data to an output file for subsequent plotting. The program assigns incremental values of conductor length from 30 to 70. feet, and requires the interactive input of the output file extension and wall thickness. A program description and listing is found in App. 4.3. Its output graphs are described in the following sections and exist in Figures 4.1-4.4.

\subsubsection{Deflection}

Deflection curves are shown in Fig. 4.1. The most deflection occurs with a solid conductor, since with increasing wall thickness, its weight increases faster than its stiffness. The maximum deflection occurs slightly closer to the ends than midspan because of the center moment connection, and averages about .07 inches for $40 \mathrm{ft}$. conductor lengths. The effect of conductor deflection is to decrease slightly the gas gap towards the center, compared with the ends. It may have a beneficial effect in moving particles. Deflection is not considered to be a problem except possibly with very long lengths.

\section{2 .3 Stresses}

The strcsses resulting from, the conductor's weight are shown in Fig. 4.2. The maximum stress cunsists of a Mohr's circle combination of bending and shear stresses, and exists at the center support. In every case the bending stress is much larger than the shear stress, and so contributes almost completely to the maximum stress. Levels of about 1000 psi are experienced by 40 ft. lengths, which is about $5 \%$ of the rated ultimate strength.

\section{$\underline{4.2 .4 \text { Support Loads }}$}

Support loads due to conductor weight are higher at the center support than at the ends, again because of the center moment 
connection for the given 2 span condition, 5/8 of each span weight is imposed at the center support. (See Fig. 4.3 for center loads and Fig. 4:4 for end loads). "As might be expected, a solid conductor represents proportionately more load than hollow, and the load rises linearly with conductor lergth. Center loads for a $40 \mathrm{ft}$. conductor range from a high of 827 lbs. (solid) to a low of 459 lbs. (1" wal1). These vertical loads represent a small part of the expected insulator strength, so that the center and end support arrangement can be considered acceptable.

\subsubsection{Conductor Length}

A11 of the above have been examined as a function of conductor length. Other considerations aside, no mechanical problems exist in utilizing the longer (50-60 ft.) lengths. At this point it is judged that $40 \mathrm{ft}$. lengths will nevertheless be the most economical when shipping constraints and costs are considered, even though fewer bulges and insulators would be used in longer lengths. More work needs to be done in assessing these costs. The significance of the trends shown in Figs. 4.14.4 is that these data can be applied to the cost data to determine the most economical length for various scenarios of shipping constraints. At present it appears practical to use one design (having a $60 \mathrm{ft}$. rating) for all conductor lengths up to $60 \mathrm{ft}$. 
FIGURE 4.2

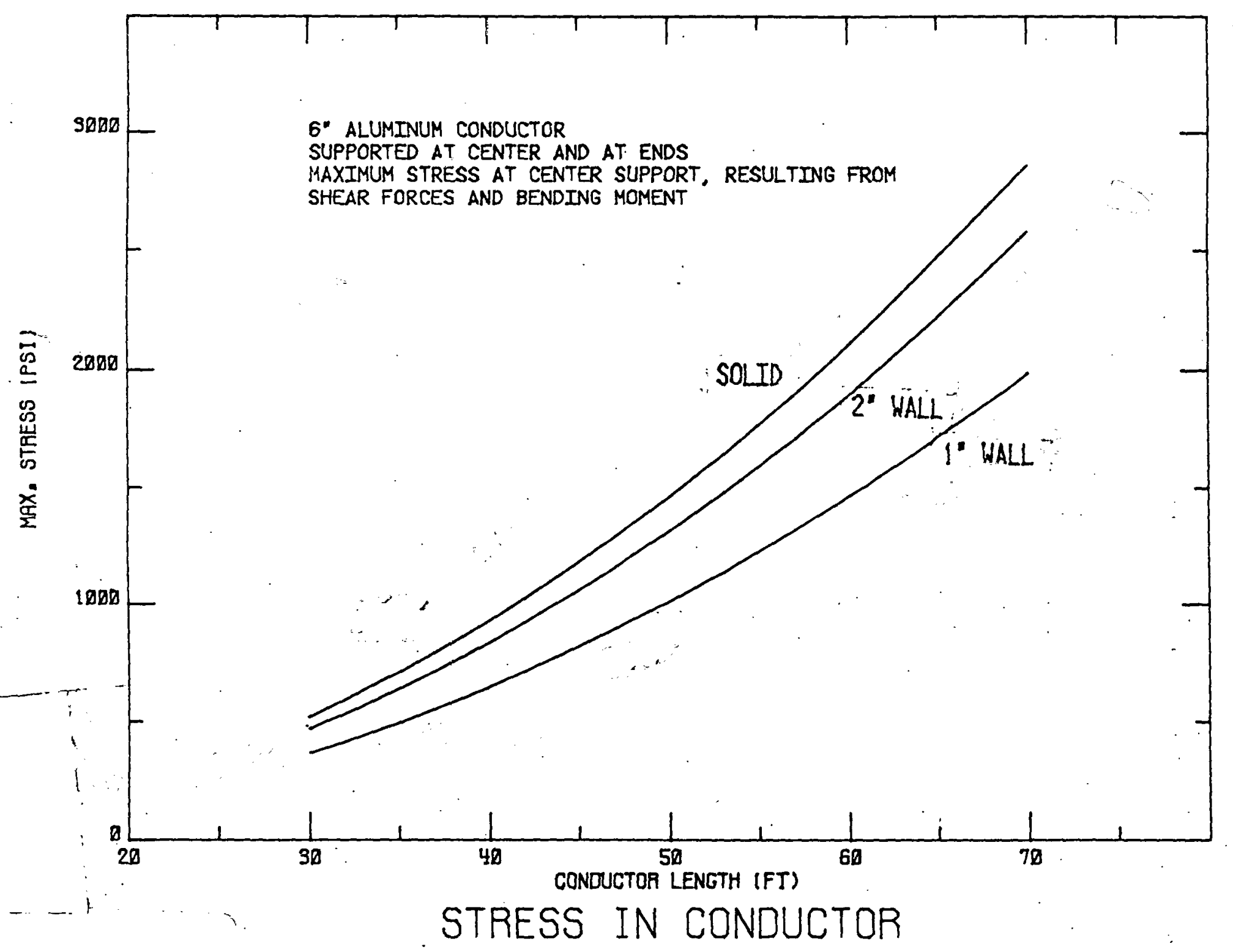


FIGURE 4.3

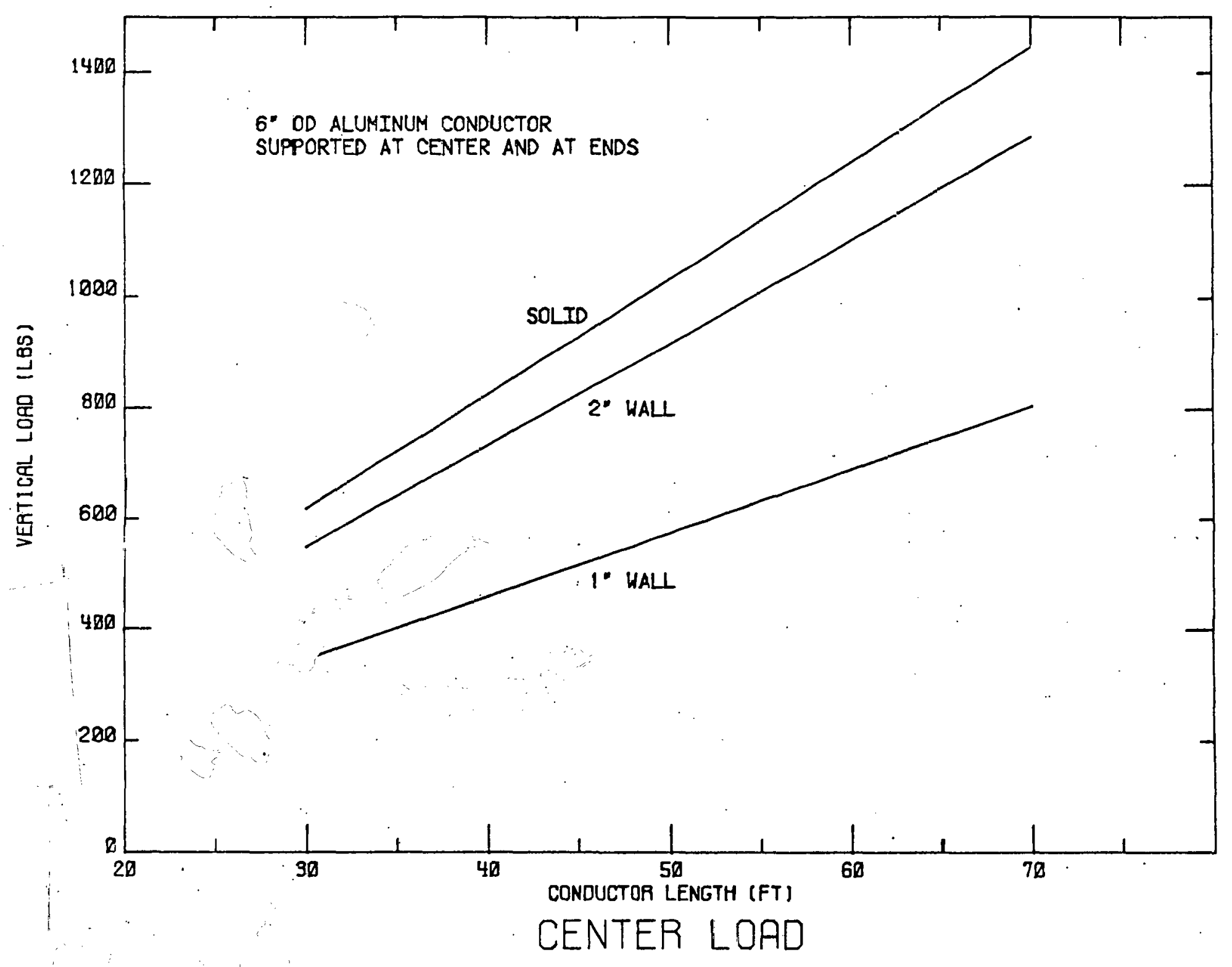


- FIGURE 4.4

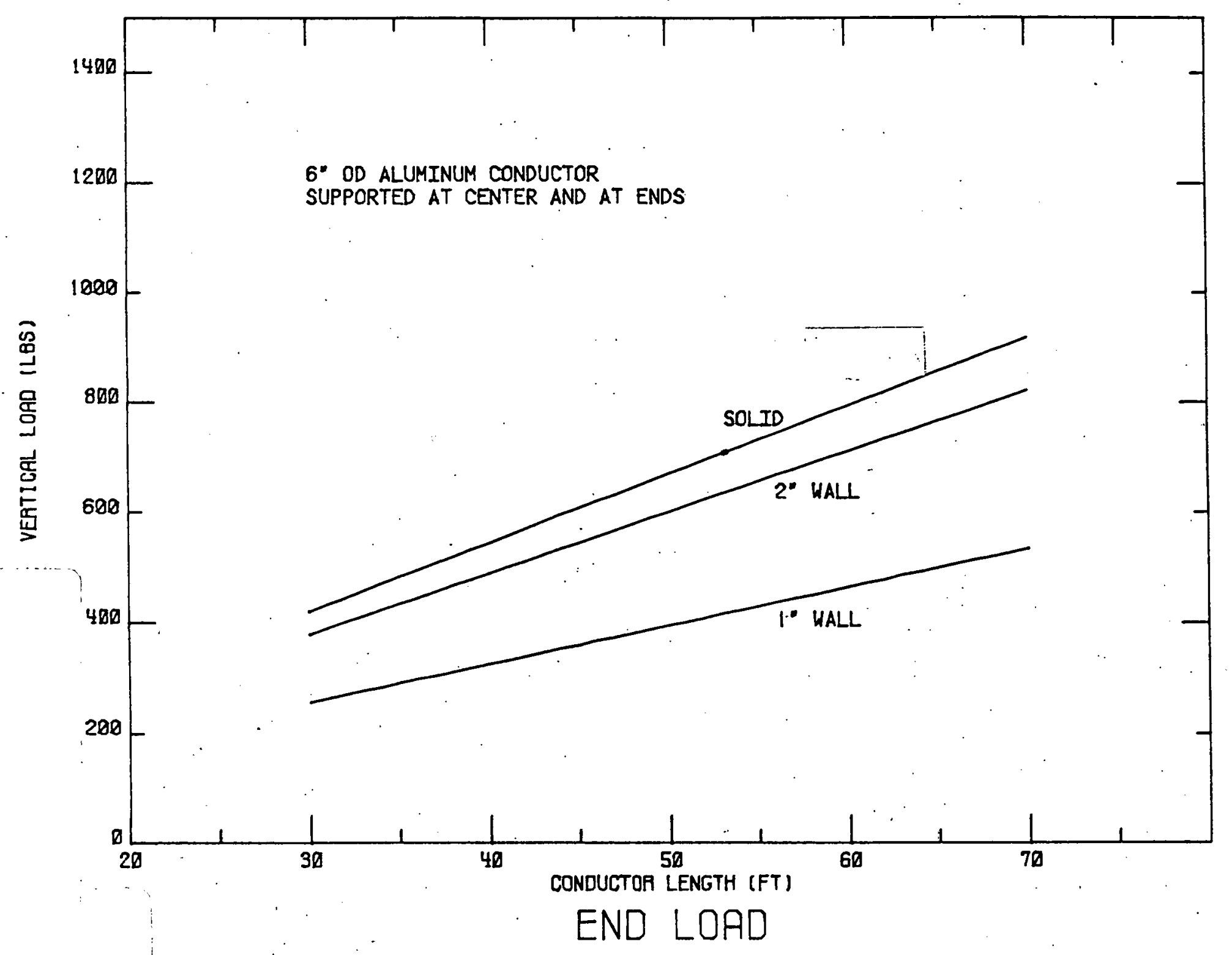


TASK 4.3 CONDUCTOR AND ENCLOSURE JOINTS

Machining and Assembly Procedures of the Vertical Leaf Expansion Joint - Refer to Figures 4.5 and 4.6

In connection with Task 4.3, a prototype of the vertical leaf joint is being made at the present time for subsequent testing. The following is a listing of the steps that have been taken to construct the prototype model, and a listing of possible methods for future mass production. An up-dated version of the status of the prototype construction is presented in Table 4.1. A bill of material is presented in Table 4.2.

\subsubsection{End Plates}

Two 1-1/4 inch wide plates were cut from a 14 inch diameter 1100 aluminum ingot. The plates were then saw cut to the 12 inch outer diameter.

\subsubsection{Joint Body}

In preparation for the joint body, the remainder of the ingot was then machined by an outside machine shop to a 12 inch diameter. Chords were cut and subsequent milling operations produced lengths of the cross section in DWg. HD=027901-DM. (Figure 4.7)

Mass production methods for these pieces could be accomplished by a single aluminum casting with a poesible machining operation to improve the tolerances of the slots for the leaves and spacers.

\subsubsection{Side and Bottom Transition Pieces}

Material (called Alcuplate) has been ordered from Texas Instruments, Inc. The Alcuplate will be saw cut to length for the prototype. When Alcuplate is purchased in mill quantities, width and thickness dimensions can be specified, and 
the price decreases to $\$ 2.95$ per $1 \mathrm{~b}$, (a mill quantity is 10,000 1bs.). Pieces from the coil can be sheared to: proper length. 4.3 .4 Leaf Spacers.

A $3 / 16$ inch plate of OFHC copper, $1 / 8$ to $1 / 4$ hard, was purchased and saw cut to oversize dimensions. The holes were drilled and then the spacers were bolted together in bundles so that the spacers could be milled to final dimensions. The edges that the leaves will flex against were broken with a file.

A mass production method for this piece would be to purchase extruded lengths of OFHC copper with a cross section (similar to the end view in Dwg. D-027903DM. (Figure 4.9) The. extrusion would be sheared to length, holes punched, and straightened. The pieces may also be made by stamping from sheet. An ultrasonic solder dip would provide the necessary tinning.

\subsubsection{Vertical Leaf}

Extra hard or spring tempered OFHC copper was purchased to the specified width and thickness dimension in Dwg. 非D-027902DM. (Figure 4.8) The material was received in a coil and then cut to an oversize length. The leaves were milled to the proper dimension and the holes were located and drilled.

In mass production, the leaves could be produced by shearing to length, punching holes, and straightening, or stamping from sheet to combine these steps.

The leaves will be tinned approximately one inch on each end for the subsequent soldering operation. 4.3.6 Soldering

The assembly drawing and part drawings were reviewed by a soldering expert from the Joining Division of the Alcoa Technical 
Center. Confidence was expressed in soldering the joint by first tinning the individual pieces (joint body, Alcuplate, leaves, and leaf spacer); then assembly these parts in a jig and heating so that the solder reflows.

In choosing the flux and solder for this application, it is necessary to avoid prolonged temperatures above $575^{\circ} \mathrm{F}$ to prevent formation of a brittle intermetalic compound at the Cu-A1 surface in the Alcuplate. Alcoa flux 非69 has an effective fluxing range from $350^{\circ} \mathrm{F}$ to $550^{\circ} \mathrm{F}$, and the melting point of $50 / 50$ tin-lead solder is $495^{\circ} \mathrm{F}$. The maximum projected operating temperature of the gas insulated conductor is $212^{\circ} \mathrm{F}$. The prototype expansion joint will be soldered at the Alcoa Technical Center and, at that time, a more detailed procedure will be formulated. 
FICURE 4.5

77.

VERTICAL LEAF EXPANSION JOINT

\section{SIDE SECTIONAL VIEW \\ PROTO MODEL}

\section{End P1ate}

Dwg 非D-027804DM

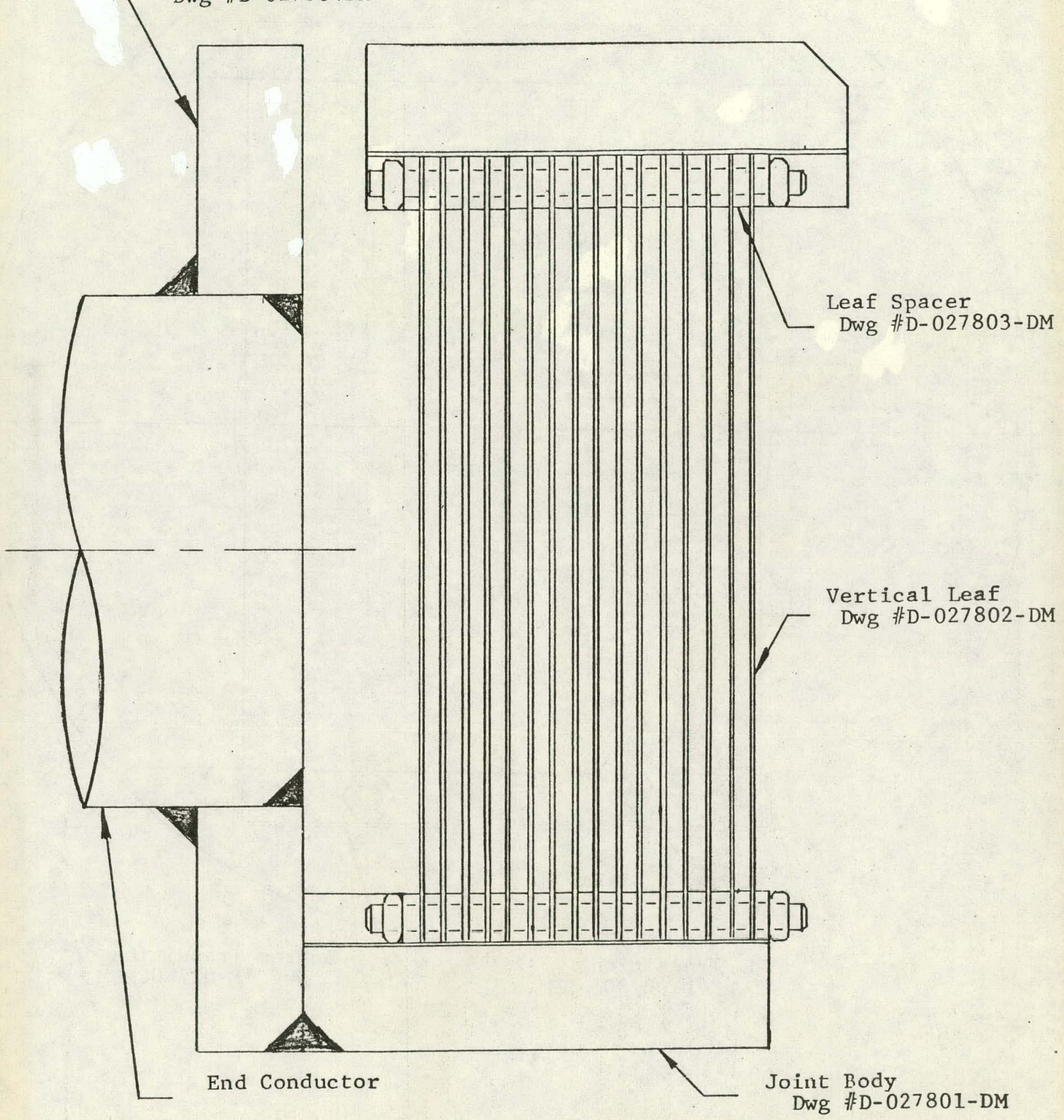


FIGURE 4.6

78.

VERTICAL LEAF EXPANSION JOINT

END VIEW

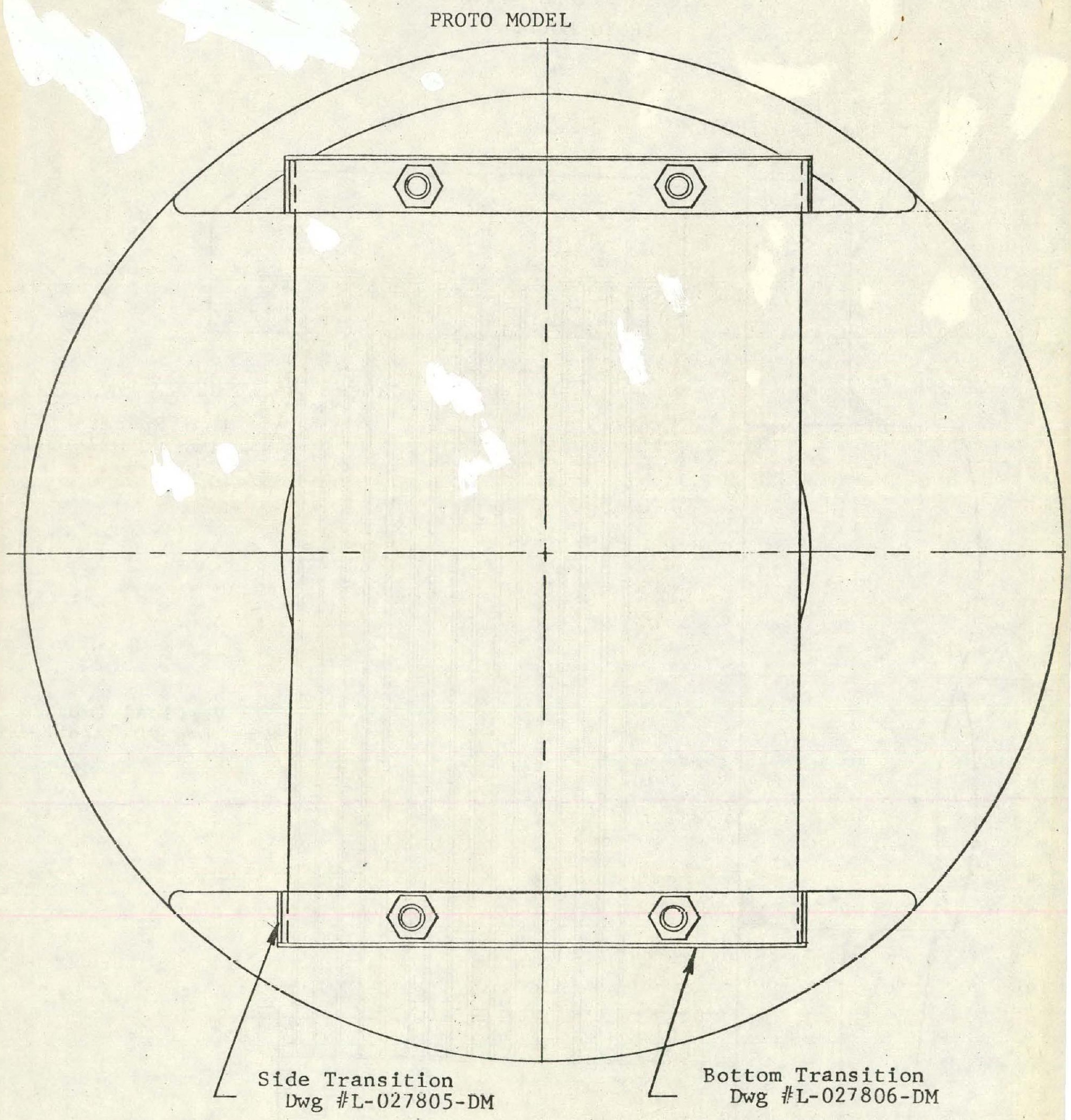




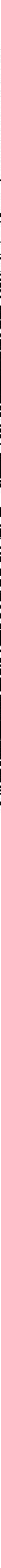




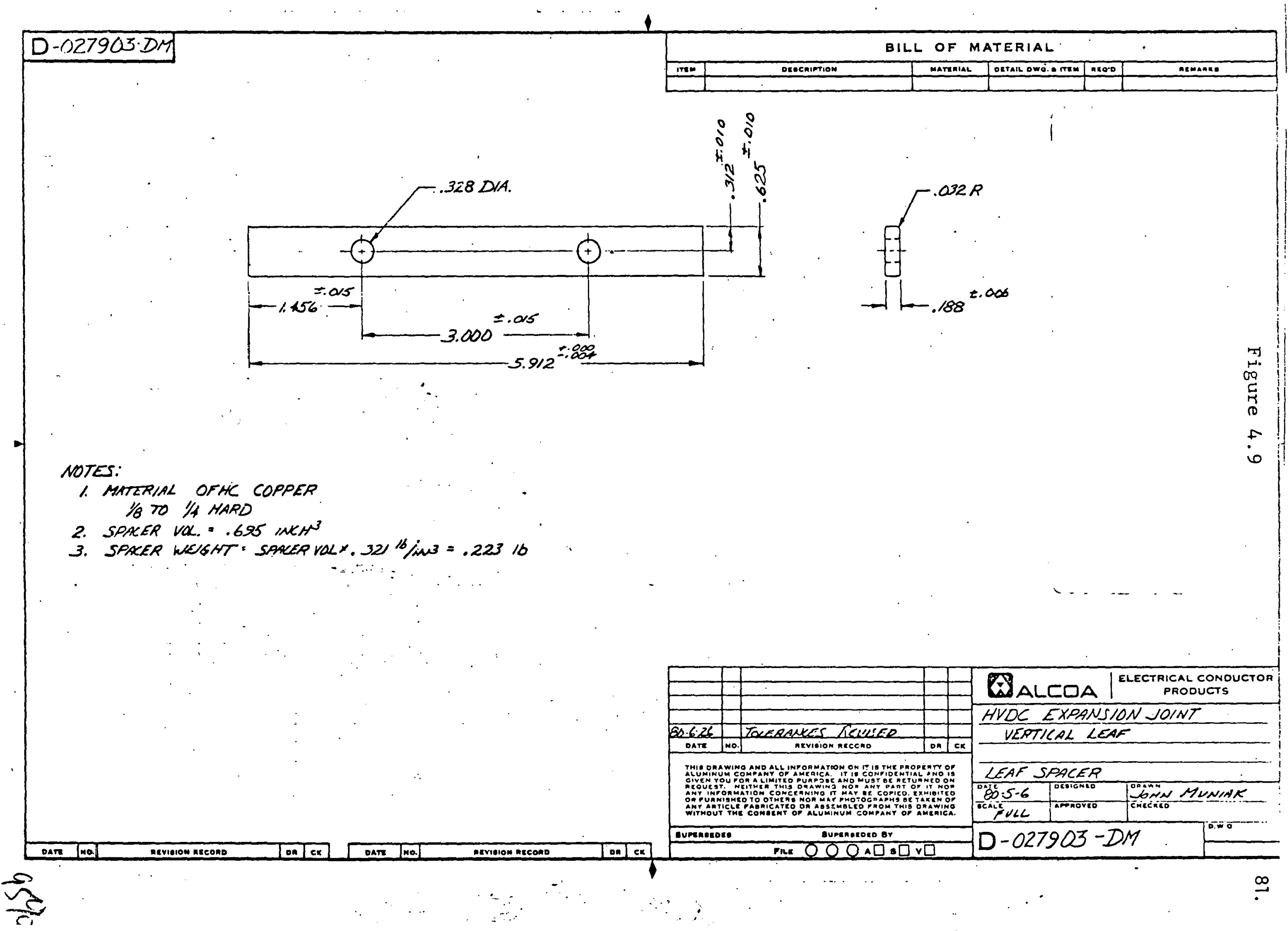




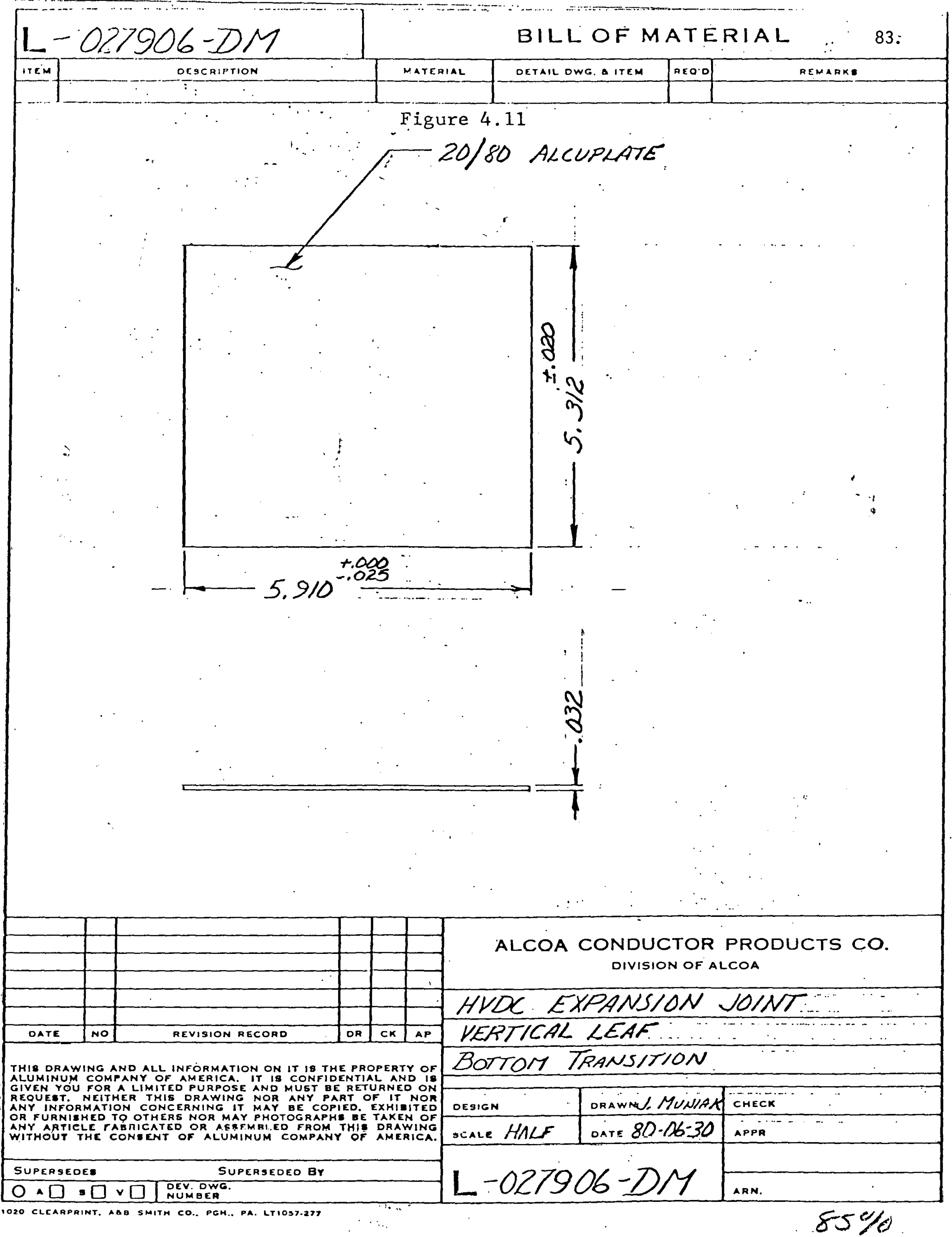


$\therefore$ TABLE 非 4.1

PROTOTYPE STATUS

VERTICAL LEAF EXPANSION JOINT

$$
\text { 80-07-14 }
$$

Piece Name

End Conductors

Find Plates

Joint Body

Side Transition

Bottom Transition

Leaf Spacers

Vertica1 Leaves
Materia1

Ordered

$\mathrm{X}$

$\mathrm{X}$

$\mathrm{x}$

$\mathrm{X}$

$x$

$\mathrm{x}$

$\mathrm{X}$
Matèrial

Received

$x$

$\mathrm{X}$

$\mathrm{X}$

$\mathrm{X}$

$\dot{x}$

$x$

$\mathrm{X}$
Part Status

Finished

In Process

Finished

In Process

In Process

Finished

Finished 
TABLE 非 4.2

MATERIAL COSTS

VERTICAL LEAF EXPANSION JOINT

$30 \%$ CONDUCTANCE - $40^{\prime} \& 60^{\prime}$ SECTIONS

Piece Name
End plates
Joint body
Side transition
Bottom transition
Leaf spacers
Vertical leaves
$5 / 16$ threaded rod
$5 / 16$ washers
$5 / 16$ nuts
Hanging stud for
insulator
Outer shield

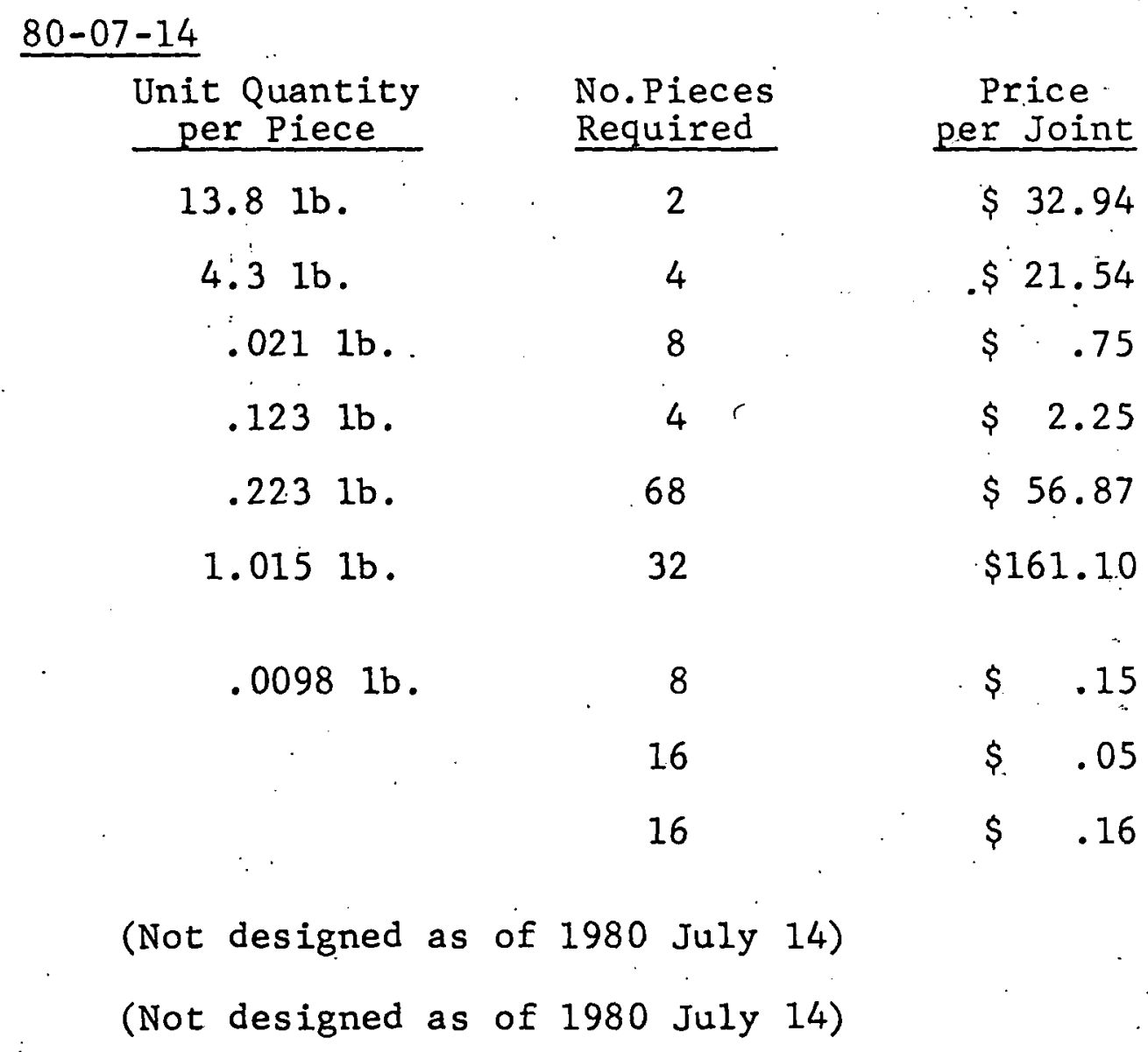




\section{TASK 4.4 FIELD ASSEMBLY AND JOINING}

The enclosure joint will be a clam-shell type construction which will incorporate a particle trap in the lower half and a method of attaching the insulator in the upper half as shown in Fig. 4.12. The joint will be welded to the enclosure. The weld will form the gas tight seal but a gasket-type seal will act as a dam to prevent weld contamination from entering the system. A similar seal has been used successfully in gas bus installations. The longitudinal joint between the clam-shell halves will also use a gasket seal system.

The enclosure joint will be designed to accommodate gradual changes in line direction and elevation by misaligning the enclosure and joint a few degrees prior to welding.

The field assembly will be an important factor in determining the reliability and cost of the installed system. A number of important operations must be performed in the field. We feel this is unavoidable and have, therefore, proposed a system which will minimize the chance of error. The actual joining will be accomplished using a special joining machine located above or beside the trench in which the conductors will be buried (Fig. 4.13). It will carry a portable clean room to surround the joining area, jigs and fixtures to hold and align conductor sections, welding equipment, and a 11 other support equipment.

Individual conductor sections will be assembled, cleaned and sealed in the factory with a 3-part end cap as shown in Fig. 4.14 and $4.15 \mathrm{a}$. A split disc will seal the gas space and support the central conductor. A separate end cap will protect the central conductor.

In the field, the center end caps will be removed to expose the central conductor and the expansion joint welded in place (Fig. 4.15b). The gas space remains sealed by the split disc end cap. The joint weld can 
be made with automated equipment due to the ample access space available. The insulator can then be attached to the expansion joint and the joint shield put in place.

The upper half of the enclosure-joint can be positioned and the insulator attached as shown in Fig. $4.15 \mathrm{c}$. The gas space is still sealed during these operations.

After a thorough cleaning, the split disc end caps, can be removed and the bottom portion of the enclosure joint put in place as shown in Fig. 4.15d. The welding of the enclosure joint can then be completed and inspected. Using this procedure, field assembly can take place with a minimum chance of contaminating the system.

As the system is lowered into the trench behind the joining machine, the sections will be subjected to mechanical vibration to move any particles into the traps at the enclosure joints.

Field repair will be accomplished by reversing the installation procedures. We propose replacing complete conductor sections rather than attempting to replace individual. components. 


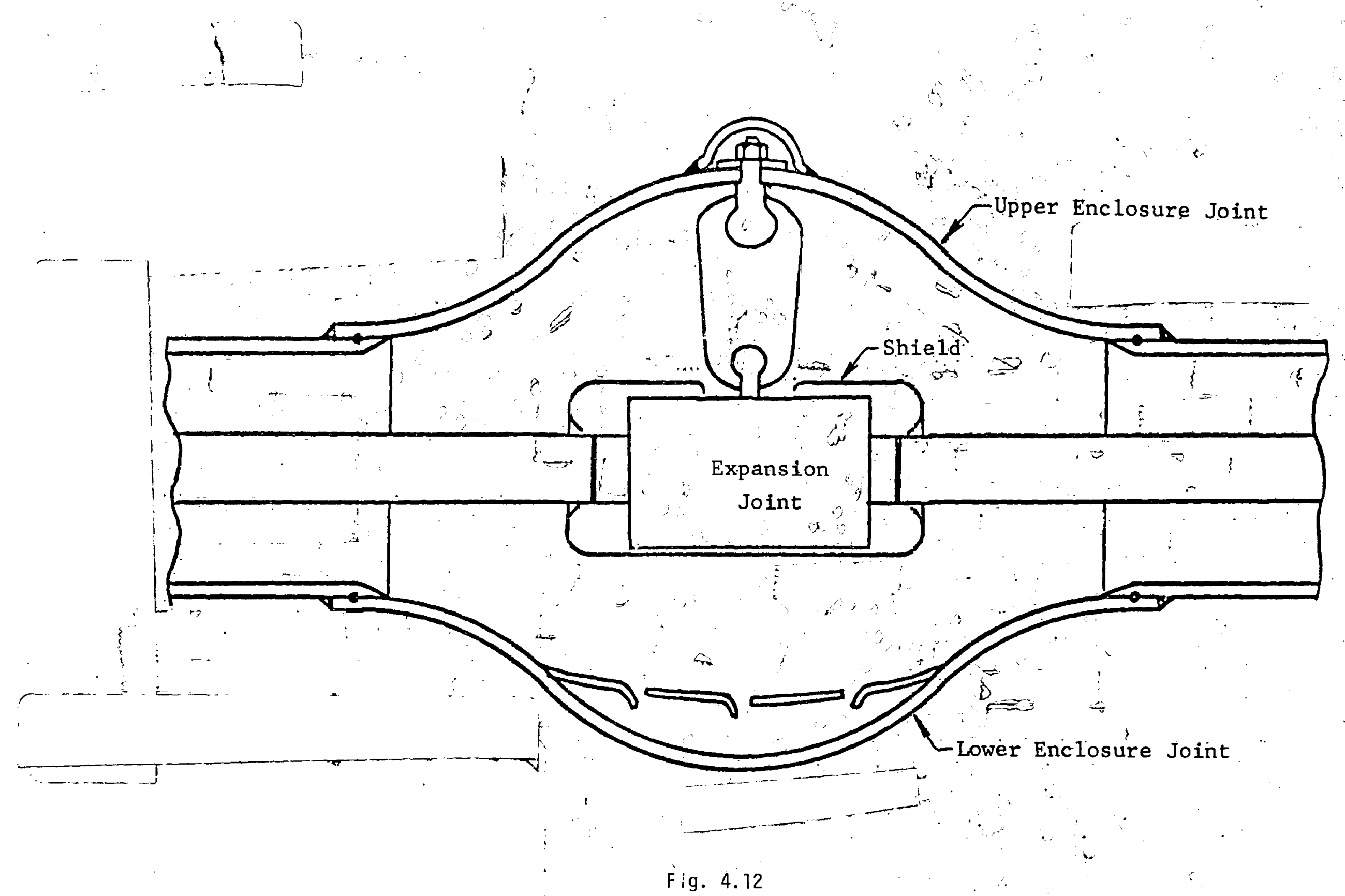




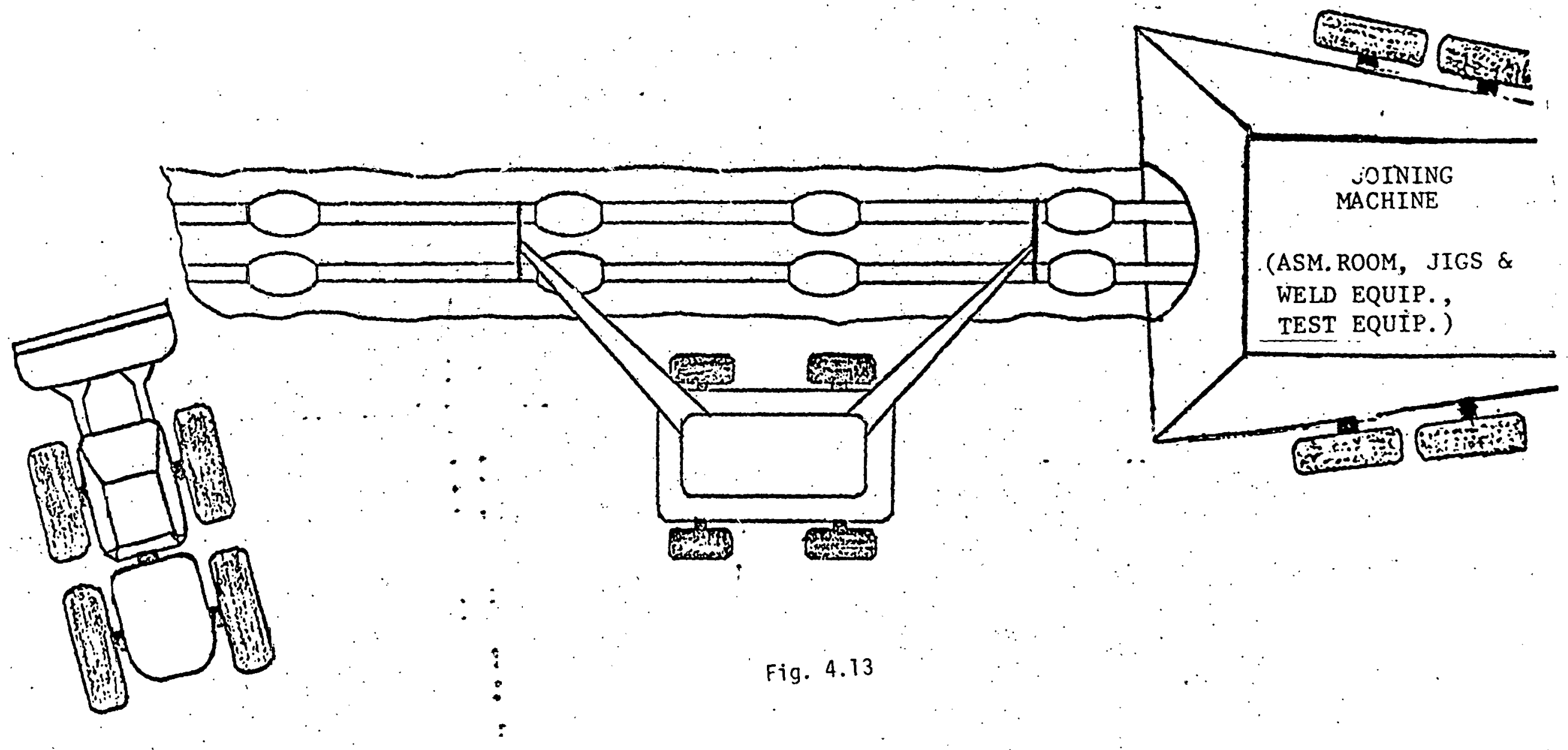

$\frac{a}{2}$

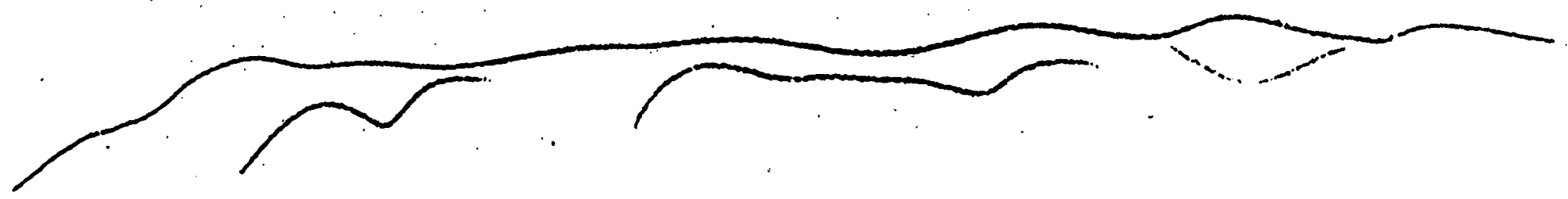


90.

Fig. 4.14 Three Part end CaP

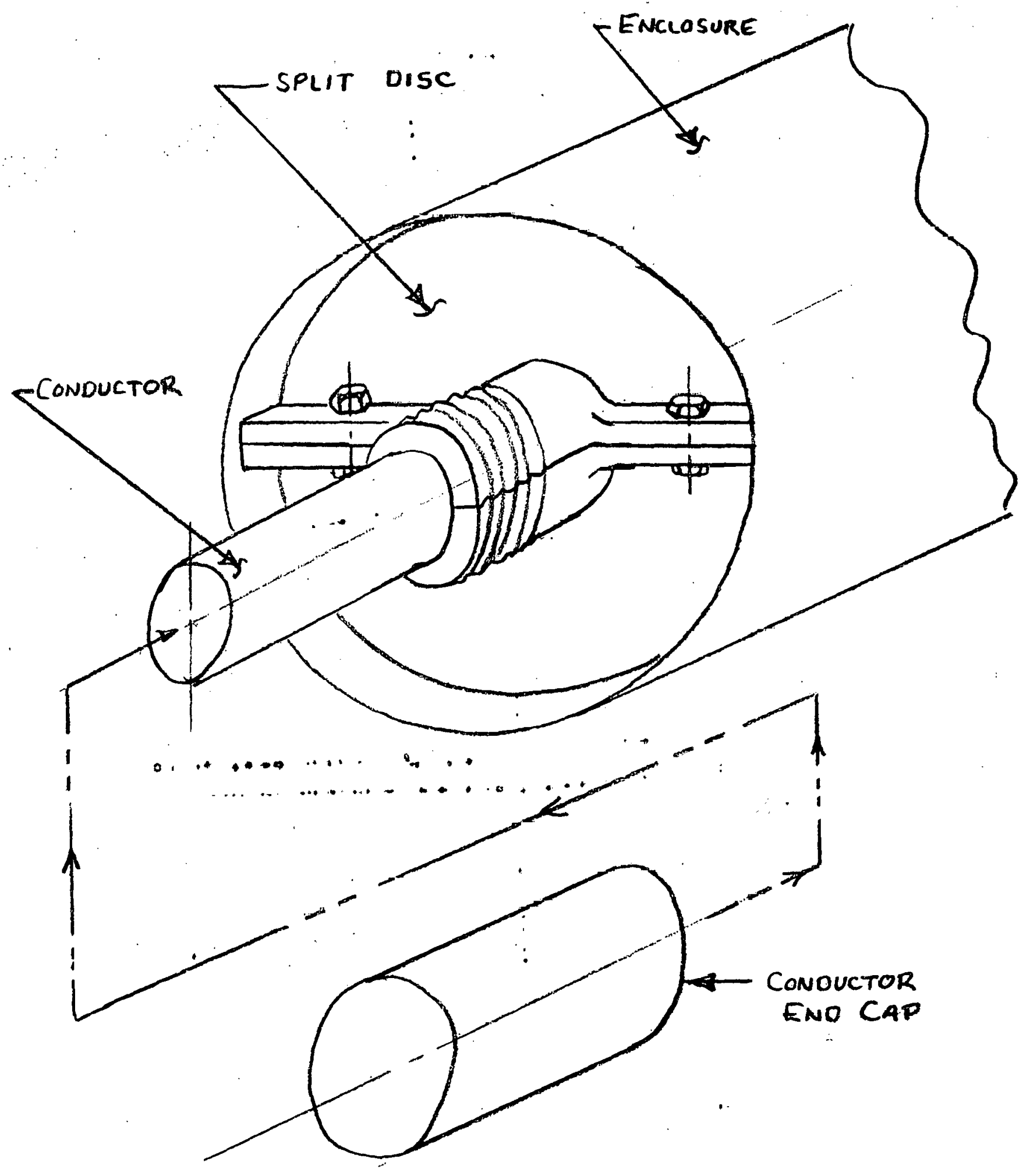



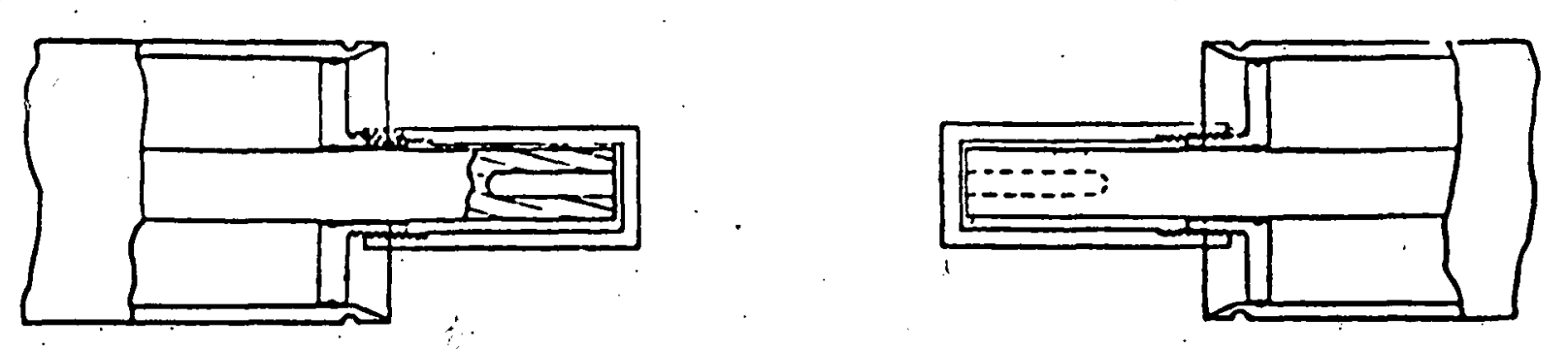

91.

Fig. $4.75 a$
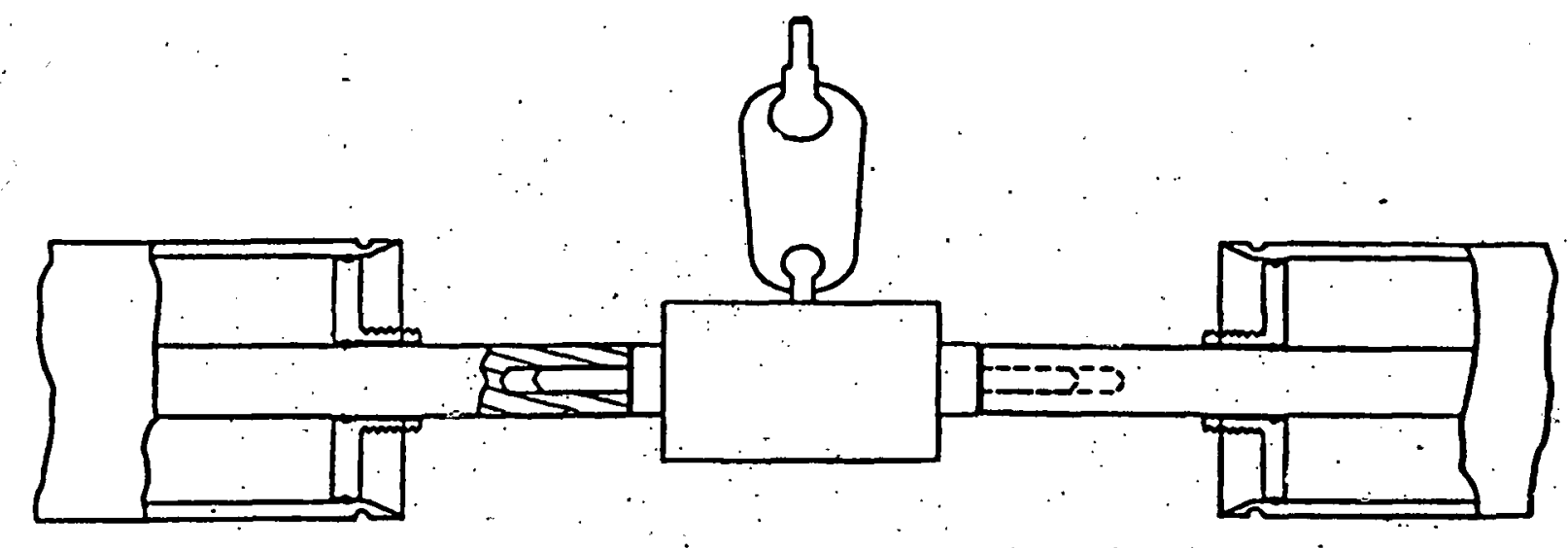

Fig. $4.15 \mathrm{~b}$

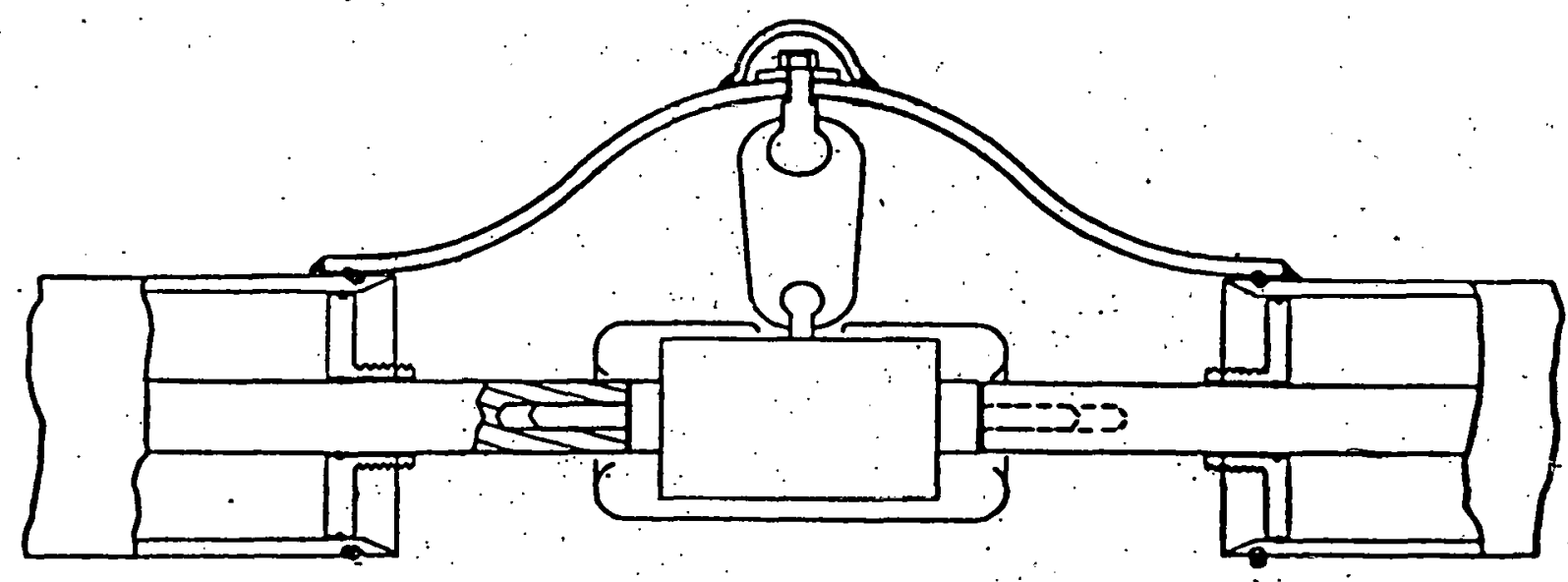

Fig. $4.15 \mathrm{c}$

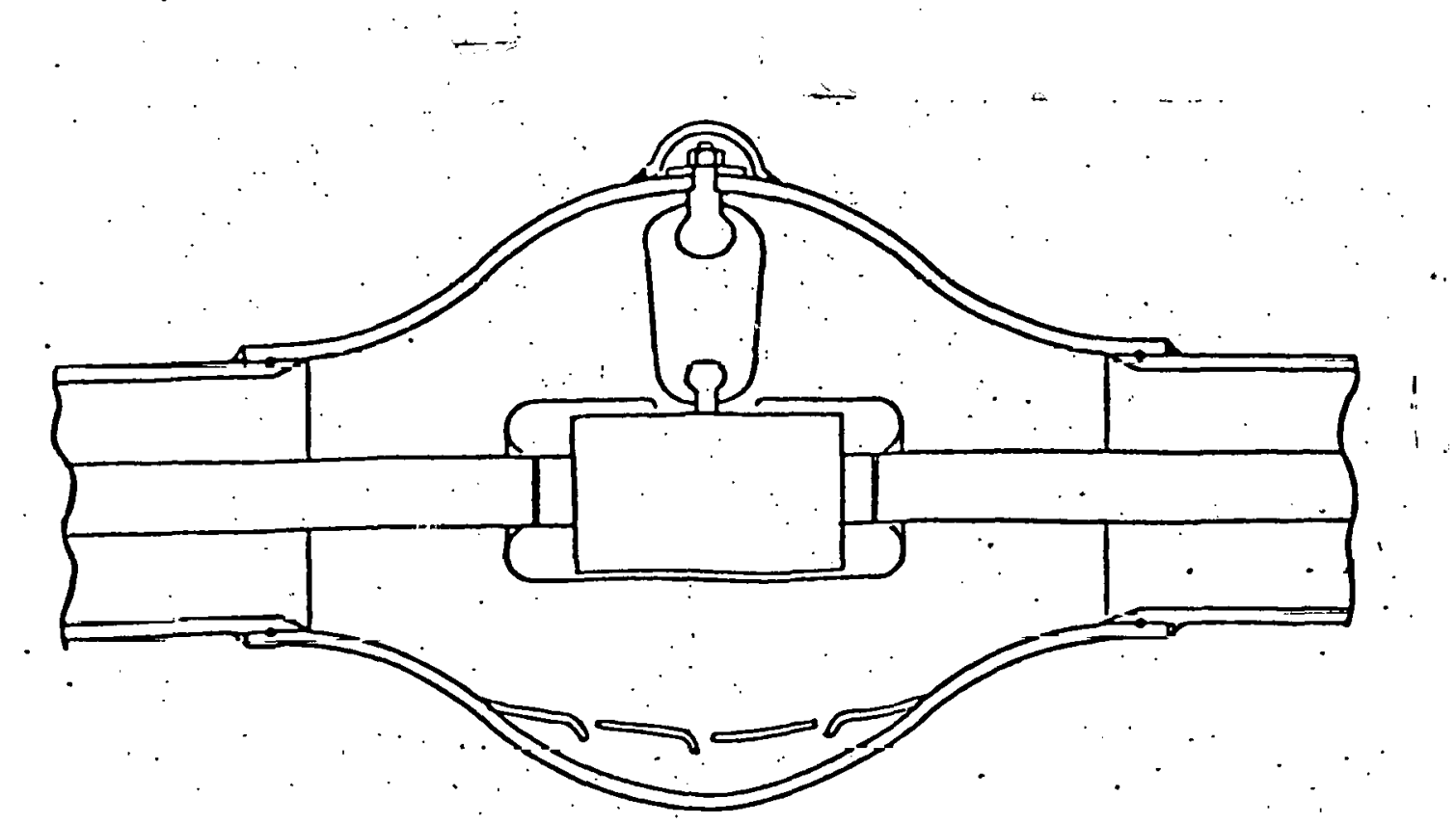

Fig. $4.15 \mathrm{~d}$ 


\section{Simplified Models of Particle Bouncing Motion}

The bouncing motion of a particle within a corrugated enclosure is extremely complex. However, some qualitative considerations lead to two models useful to assess qualitatively the effect of asymmetry of the corrugation. The complexity can be seen by following the particle depicted conceptually in Fig. 2-A-1. A conducting particle resting on the enclosure will acquire positive surface charges as negative voltage is applied to the conductor. The surface charge will be distributed to maintain the particle surface at equipotential. As the voltage is raised high enough, the particle will stand up below the flux line due to gravity pull. As it stands up, the surface charge will be redistributed. The charge density will be higher at its upper part. Generally the center of the resultant upward force will not coincide with the center of gravity. Also, as it stands up the net upward force increases. It will then be elevated towards the conductor, with a horizontal velocity, a rotation, and a dominating vertical velocity. During its flight towards the conductor, it is acted on by the constant gravity, by an increasing electrical force and by the drag of the gas. The horizontal velocity is due to the horizontal component of the electrical field. This component diminishes quickly above the corrugation. The radial (vertical) component of the electrical force is much larger. and increases rapidly towards the conductor. Hence the particle will experience a decreasing horizontal acceleration and an increasing vertical acceleration. The surface charges will redistribute themselves continuously during the flight, shifting the center of the net force continuously. The complexity is further increased when the particle is influenced by other particles and by space charges and, 
when corona occurs at its tip or tips, by the reaction of the corona wind. In general, the above considerations lead to a curved upward path, which approaches the vertical asymptotically.

The rebounce path from the conductor downward would be more to the vertical than the upward path for the following reasons. As it hits the conductor, the particle acquires positive charges which are an order larger. than the charges it carries up. It is in a field an order higher than that at the enclosure. The initial electrical force is thus two orders higher than the initial upward force. The electrical forre is aided hy the transferred momentum after impact. Even when the verticle electrical force is decreasing as the particle moves toward the enclosure, its vertical velocity increases rapidly. The horizontal electrical force, which becomes noticeable only near the enclosure, will have little time to deflect the path. Hence the downward path will be essentially straight.

The rebounce at the enclosure occurs after the particle acquires a large momentum. Owing to the relatively low field at the enclosure and the smaller positive charges the particle acquires, the rebounce angle is likely to be governed by mechanical transfer of momentum on impact.

The above very qualitative considerations lead to the two simplified models used (Fig. 2-A-2).

For both models, the enclosure is assumed to have a saw-tooth profile. Particles are assumed to move only in the vertical plane containing the axis of the cable, thus only below the conductor where $1 \mathrm{t}$ is assumed to be initialiy. The surface at the point of impact is assumed to have a random variation within 0.5 degree from the ideal geometry. The rebounce from the enclosure is assumed to follow the laws of impact. Gas drag is ignored. 
For Model \#1, the entire path is assumed to follow the laws of impact. This is an approximation of bouncing due to impulse voltage.

For Model \#2, the upward motion is assumed to turn vertical as the particle reaches a certain height $\mathrm{D1}$. The rebounce from the conductor is also assumed to be vertical. This is an approximation of bouncing under DC voltage. As D1 is an approximation of the height at which the vertical component of the electrical force becomes dominating, it decreases with increasing $D C$ voltage.

Tables 2-A show some results of the simulation runs. In these runs, impact of rigid bodies was assumed; thus, the axial motion is exaggerated in Model \#1. The axial motion on impact at the enclosure in Model \#2 is also exaggerated but the exaggeration is masked by the arbitrary value of D1. Nevertheless, these results should show the effect of corrugation qualitatively.

Only one particle is simulated in isolation. It is assumed to start downward just right of the "valley" in the middle of a 40-ft cable section. The pitch of the corrugation is assumed to be $2^{\prime \prime}$ (as used in the model cable). Hence a particle will be out of the $40-\mathrm{ft}$.cable section after having been displaced by more than 120 corrugations.

Table 2-A-1 shows the results of Model \#1. Examples of individual runs are shown in Figs. 2-A-3 and 2-A-4. Table 2-A-2 shows the results of Model \#2. Examples of individual runs are shown in Figs. 2-A-5 and 2-A-6.

While the models are very simplified, the results seem to indicate the following.

Even with asymmetrical corrugation, the particles tend to "oscillate" along the axial direction of the cable. The range of oscillation was referred to in an earlier report as "cycling range." The random nature of the surface at the 
point of impact tends to break the oscillation pattern. Even without the randomness of the surface, the cycling range is larger for asymmetrical than for symmetrical corrugation.

Axial motion is more directed away from the part of corrugation with the steeper slope. This is in agreement with test observations of motion of fine particles. Model \#2 also agrees with the test observation that fine particles remained in the same symmetrical corrugation almost indefinitely but can be driven out of the cable section having asymmetrical corrugations.

Model \#2 indicates that with HVDC cuminissioning, asymmetrical corrugations are more effective with smaller D1, i.e., at relatively lower OC voltaye. This is a useful conclusion. The fact that fine particles in asymetrical corrugation are driven out at low voltages does support this conclusion. 


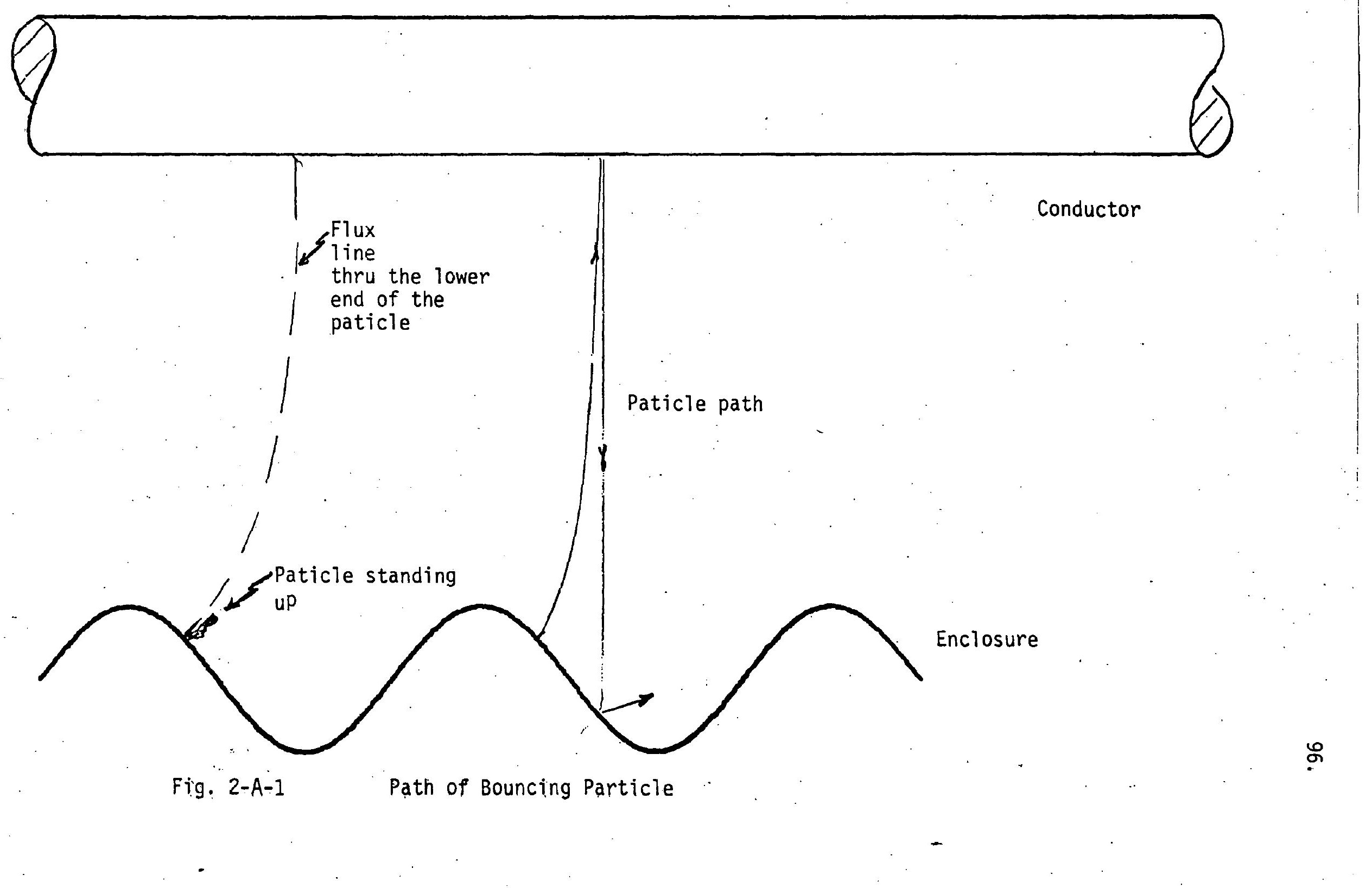


97.

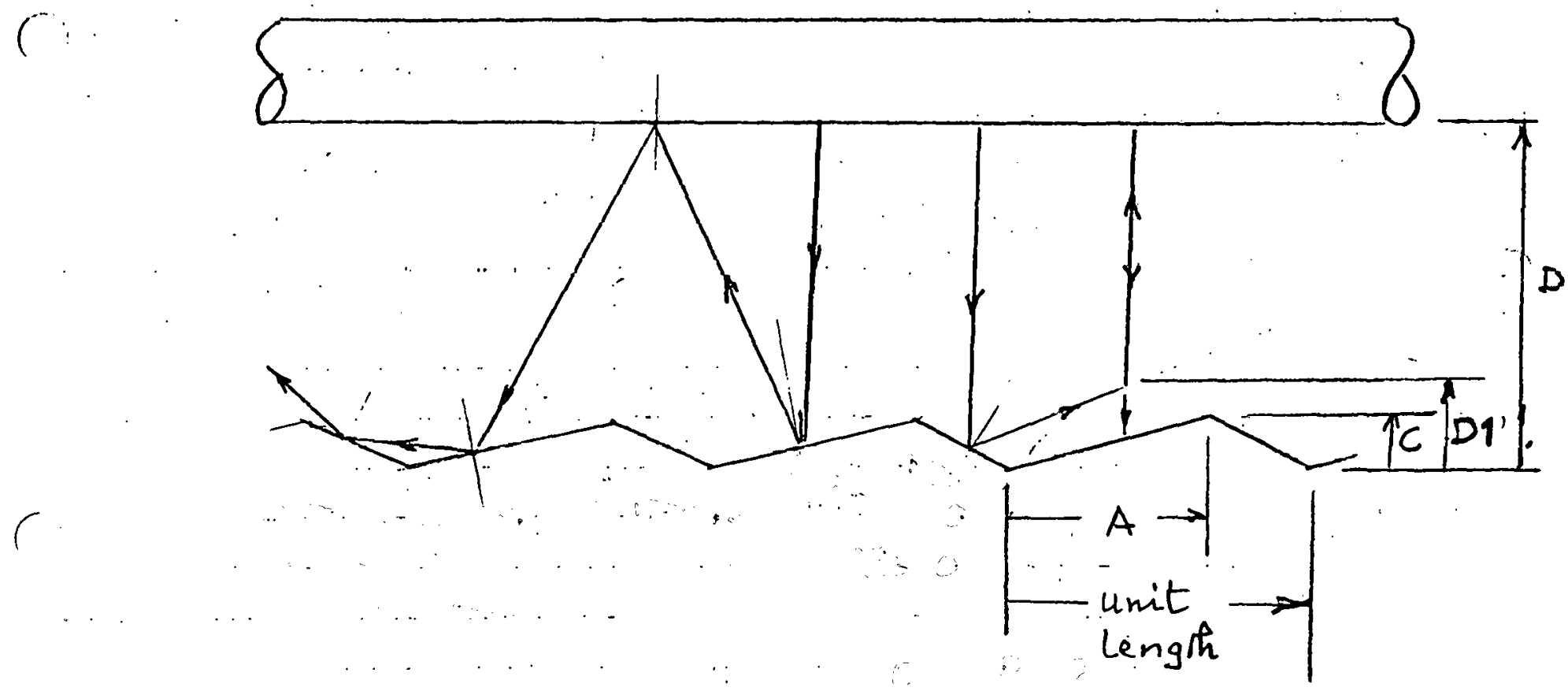

model \#i

model \#

negative $\longrightarrow$ positive

C.

D

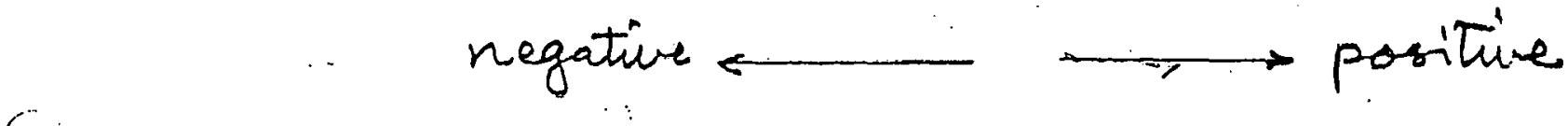

Fig. 2-A-2 Simluation Models for Bouncing Motion 
FATH OF THE 1-TH PARTICLE SIMULATION MODEL \#1 RUN \#? ON JULY 21,1989 CONDUCTOR TO UALLEY OF CORRUGATION $=1.625$ CORRUGATION FACTOR=0.5 CORRUGATION HEIGHT $=0.25$

CABLE LENGTH $=2 * 120$ CORRUGATIONS

X-RANGE: FRON - 183 TO 121 CORRUGATIONS

PARTICLE STARTS AT $X=\theta$ FINISHES AT $X=120.656176715$ FROM B TO 9 P BOUNCES

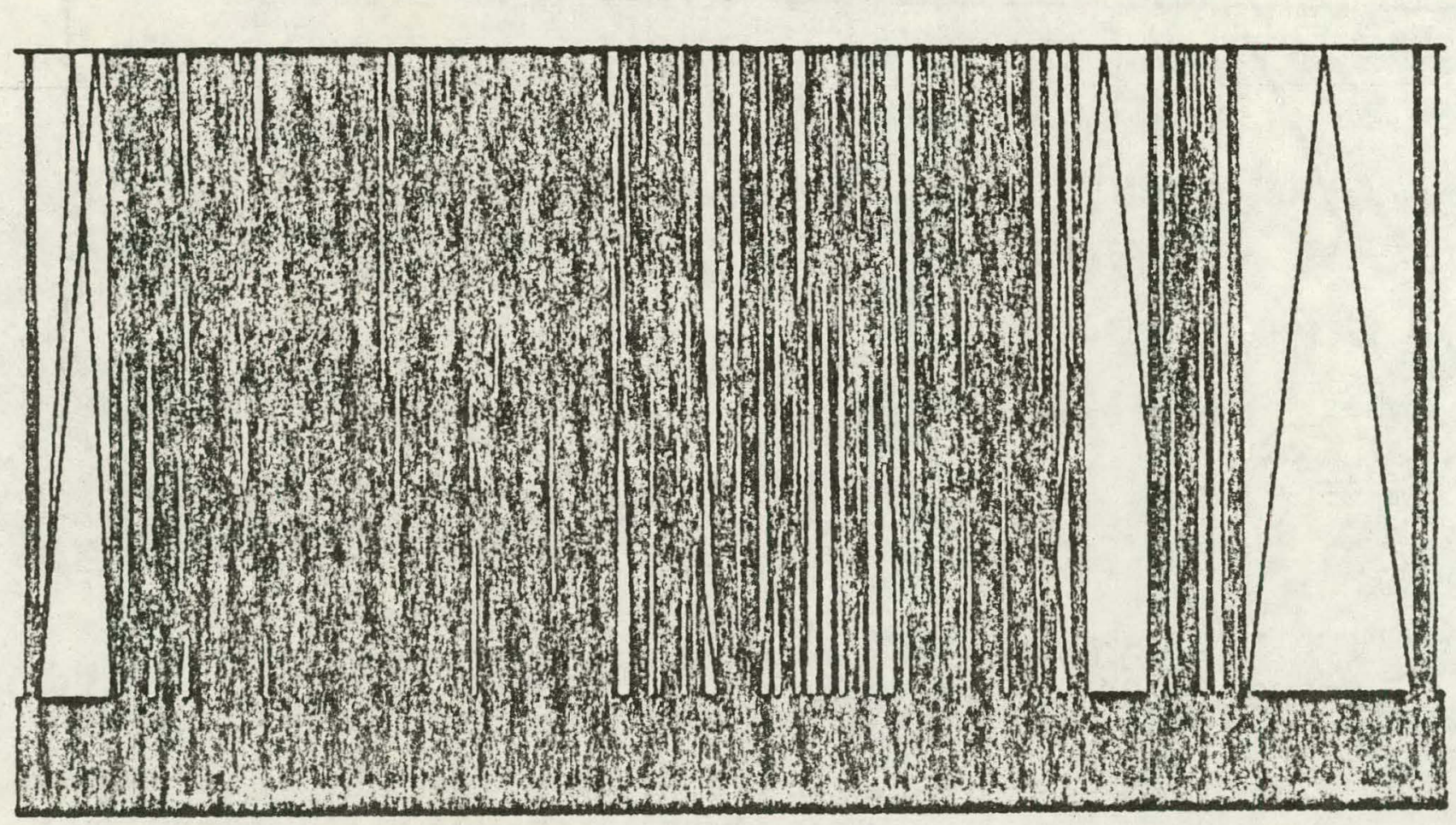

\section{COHDUCTOR}

ENCLUSURE

Fig. 2-A-3a 
PATH OF THE 1-TH PARTICLE SIMULATION MODEL \#1

RUN AT ON JULY 21,1980 CONDUCTOR TO UALLEY OF CORRUGATION=1.625

CORRUGATION FACTOR=0.5 CORRUGATION HEIGHT $=0.25$

CABLE LENGTH $=2 * 120$ CORRUGATIOHS

N-AXIS: BOUNCES FROM 1 TO 9 ? 9

Y-AXIS: AXIAL MOTION FROM - 102.476963288 TO 120.656176715

PARTICLE STARTS AT $Y=B$ FINISHES AT $Y=120.656176715$

AFTER 979 BOUNCES

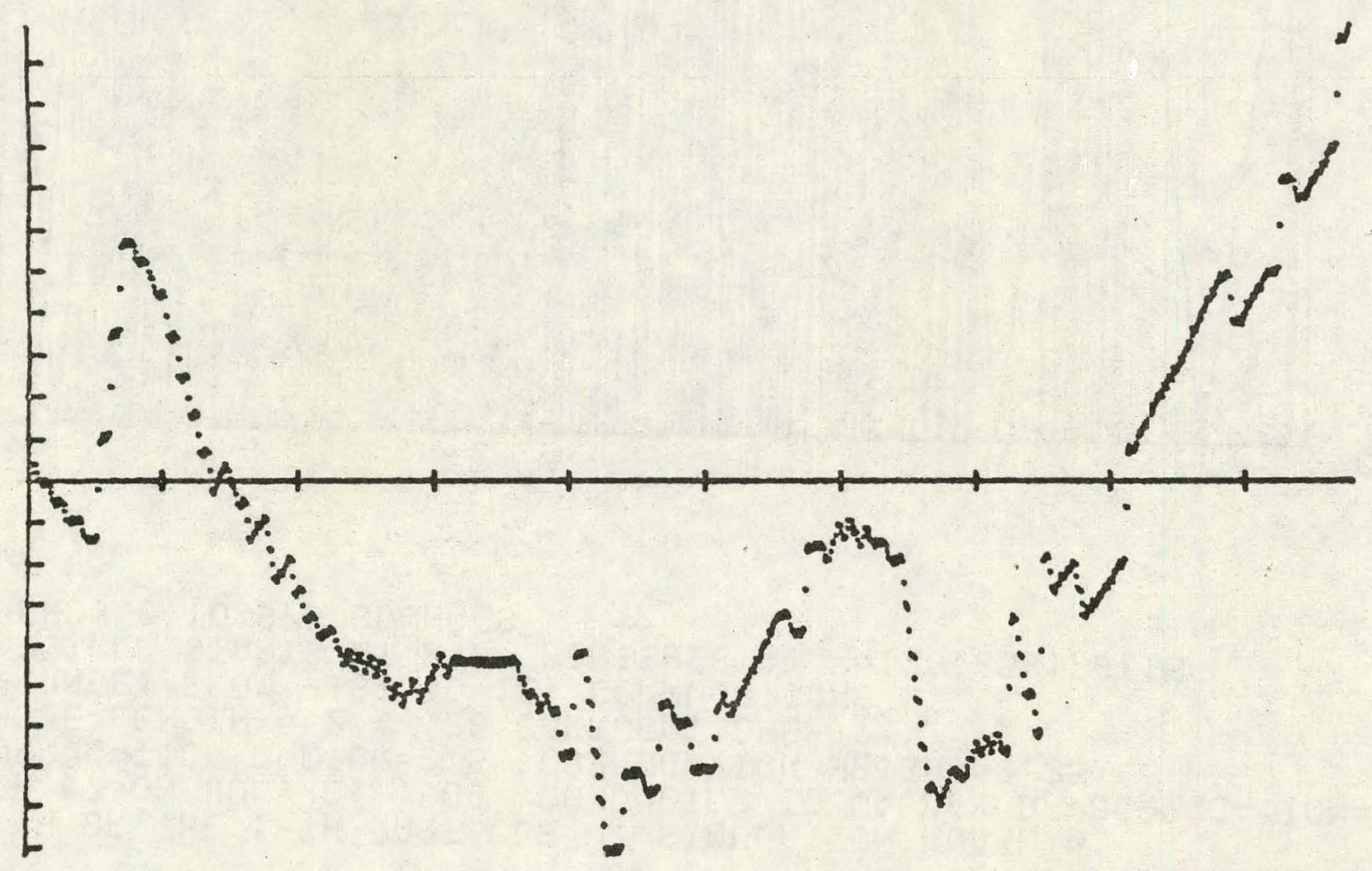

Fig. 2-A-3b

Axial Displacement vs. Number of Deflections 
PATH OF THE 1-TH PARTICLE SIMULATION MODEL \#1 RUN \#S ON JULY 20,198B CONDUCTOR TO UALLEY OF CORRUGATION=1.625 CORRUGATION FACTOR $=0.3$ CORRUGATIOH HEIGHT $=0.25$

C.ABLE LENGTH $=2 * 12$ * CORRUGATIOHS

$X$-RANGE: FROM -123 TO 27 CORRUGATIONS

PARTICLE STARTS AT $x=B$ FINISHES AT $x=-122.445446231$

FRUM B TO 981 BOUHCES

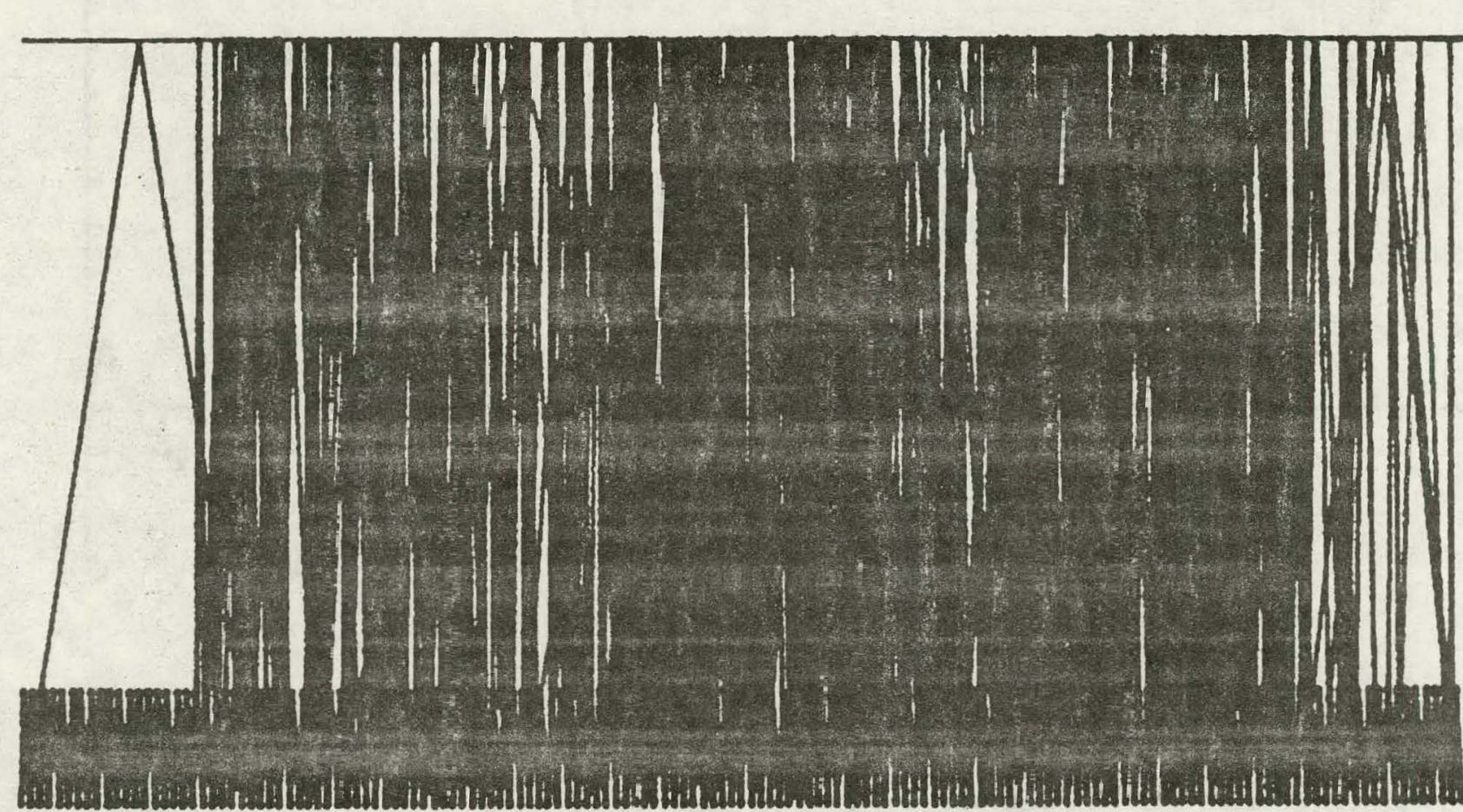

COHDUCTOR

ENCLOSURE

Fig. $2-A-4 a$ 
PATH OF THE 1-TH PARTICLE SIMULATION MODEL \#1

RUN \#8 ON JULY 20, 1980 CONDUCTOR TO UALLEY OF CORRUGATION=1.625 CORRUGATION FACT JR $=0.3$ CORRUGATION HEIGHT $=0.25$

CABLE LENGTH $=2 * 120$ CORRUGATIONS

X-AXIS: BOUNCES FRUM 1 TO 981

Y-AXIS: AXIAL MOTION FROM -122.445446231 TO 26.1856725581

PARTICLE STARTS AT $Y=0$ FIHISHES AT $Y=-122.445446231$

AFTER 981 BOUNCES

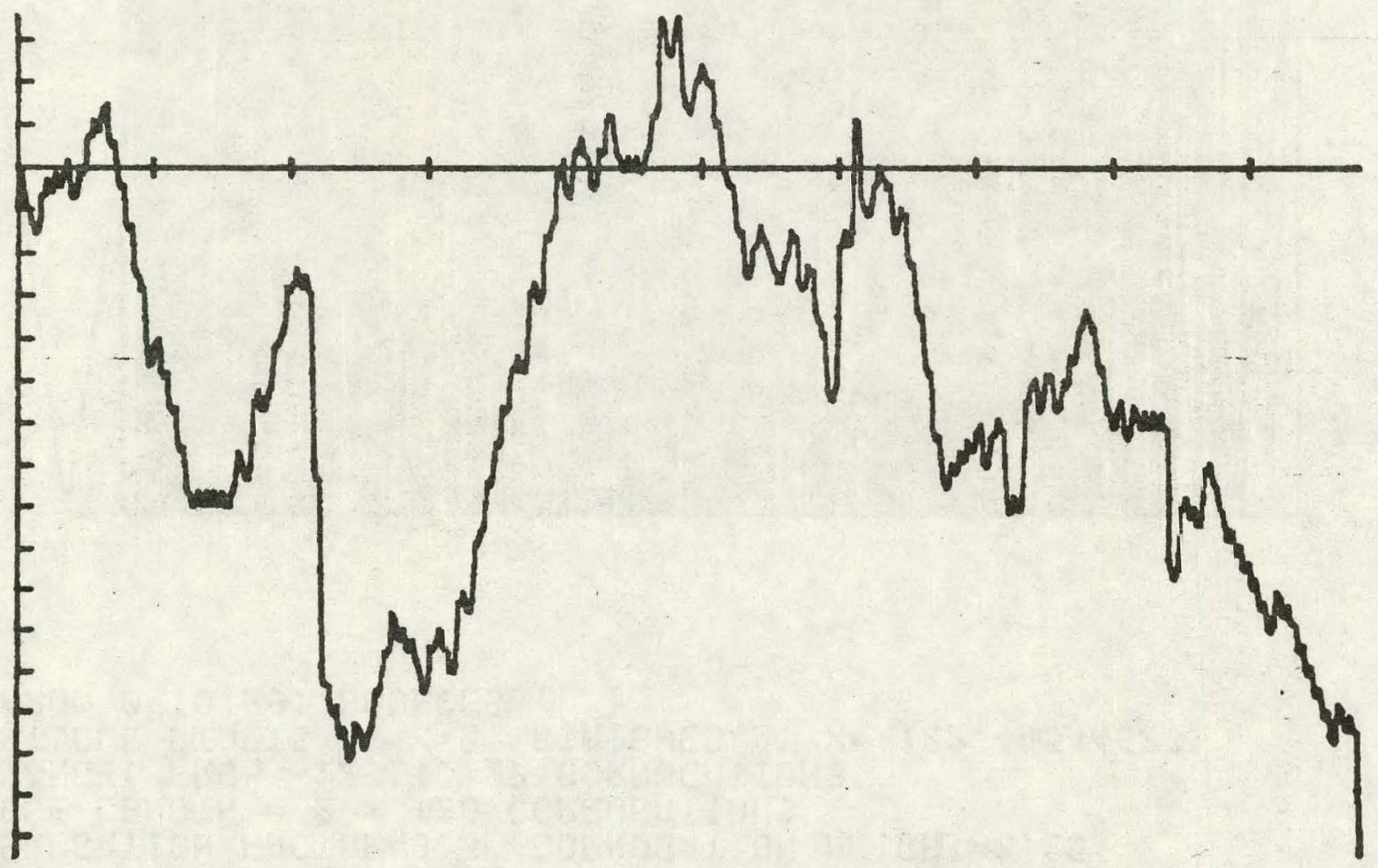

Fig. 2-A-4b

Axial Displacement vs. Number of Deflections 
PATH OF THE 1-TH PARTICLE

RLIN \#10 ON JU_-Y 21,1980 CONDUCTOR TO UALLEY OF CORRUGATION $=1.625$

CORRUGATION FACTOR $=0.5$ CORRUGATION HEIGHT $=0.25$

CABLE LENGTH $=2 \times 120$ CORRUGATIONS

$X$-RANGE: FRON -49 TO 7 CORRUGATIOHS

PARTICLE STARTS AT $x=B$ FINISHES AT $x=-37.3761880053$

FROM B TO 100 G BÜUHCES

Electric force becomes dominating at $Y=1.25$

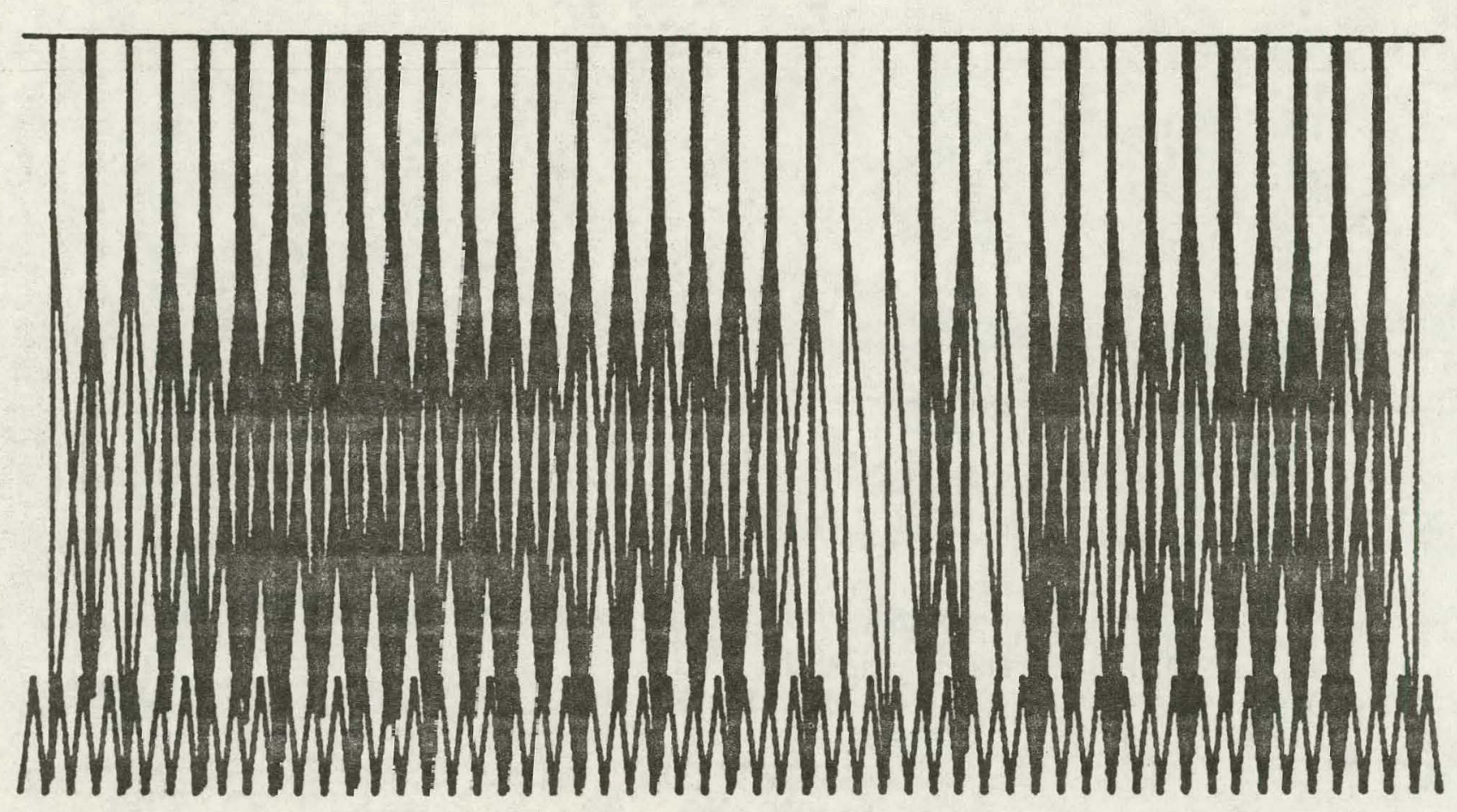

CONOUCTOR

ENCLOSURE

Fig. $2-A-5 a$ 
PATH OF THE 1-TH PARTICLE SIMULATION MODEL "2

RUN *10 ON JULY 21,1980 CONDUCTOR TO UALLEY OF CORRUGATION $=1.625$

CURRUGATION FACTOR $=0.5$ CORRUGATIOH HEIGHT $=0.25$

CABLE LENETH $=2 * 120$ CORRUGATIONS

$X$-AXIS: BOUNCES FROM 1 TO 1000

Y-AXIS: AXIAL MOTION FROM -48.0476955023 TO $6.1022389210 ?$

PARTICLE STARTS AT $Y=0$ FINISHES AT $Y=-37.3761080053$

AFTER $1 B B B$ BOUHCES

Electric force becomes dominating at $Y=1.25$

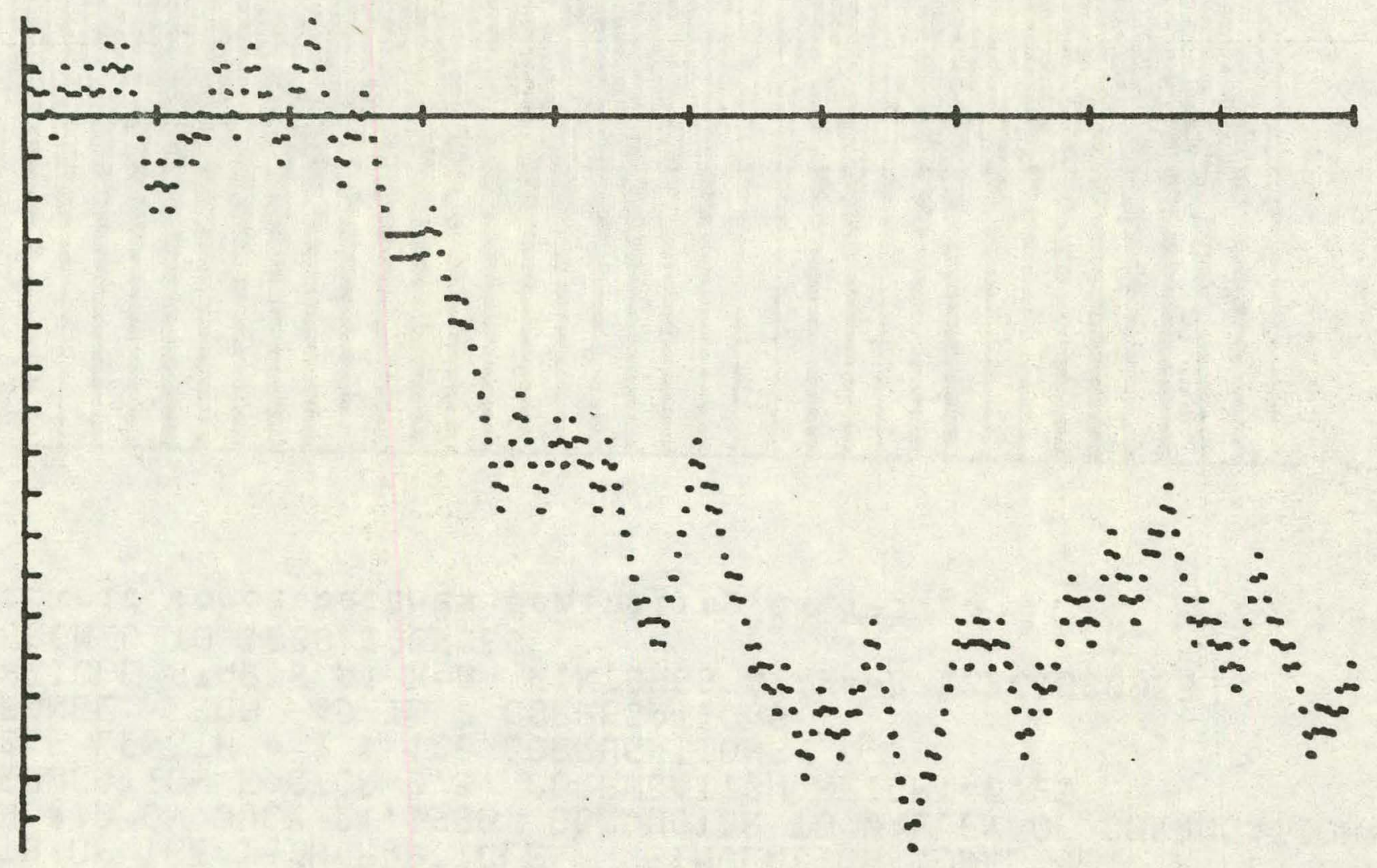

Fig. 2-A-5b

Axial Displacement vs. Number of Deflections 
PATH OF THE 1-TH PARTICLE SIMULATION MODEL \#2

(MO-805)

RUN *10 ON JULY 21,1980 CONDUCTOR TO UALLEY OF CORRUGATION=1.625

CORRUGATION FACTOR $=0.5$ CORRUGATION HEIGHT $=0.25$

CABLE LENGTH $=2 * 120$ CORRUGATIONS

$X$-RANGE: FROM -62 TO $?$ CORRUGATIONS

PARTICLE STARTS AT $X=B$ FINISHES AT $x=-32.372642686$

FROM $10 B 0$ TO 2000 BOUNCES

Electric force becomes dominating at $Y=1.25$

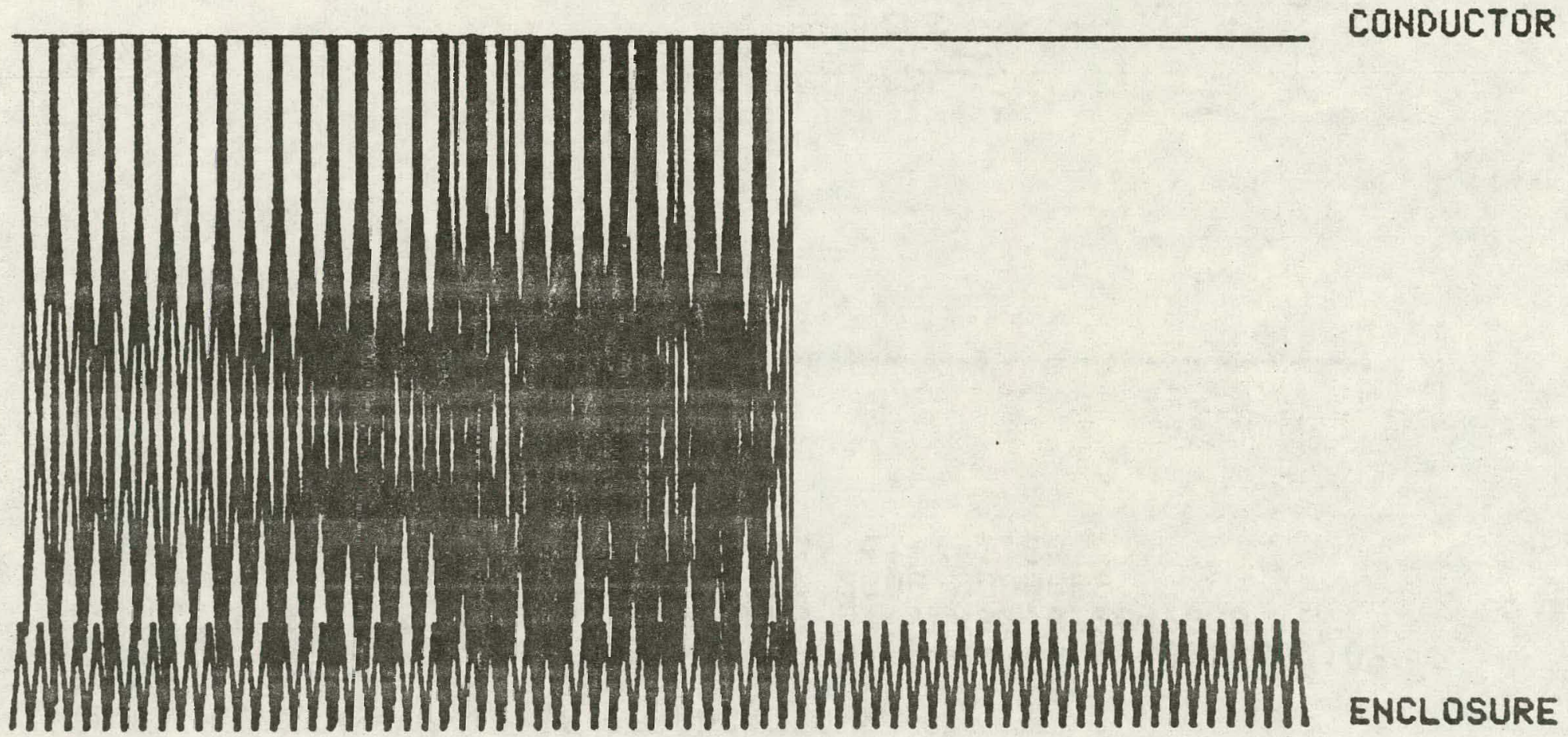

Fig. $2-A-5 c$ 
PATH OF THE 1-TH PARTICLE SIMULATION MODEL \#2

RUN $\# 10$ OH JULY 21,1980 CONDUCTOR TO UALLEY OF CORRUGATIOH $=1.625$

CORRUGATION FACTOR $=0.5$ CORRUGATION HEIGHT $=0.25$

CABLE LENGTH $=2 * 120$ CORRUGATIONS

$X$-A.XIS: BOUNCES FROM 10B1 TO 2000

Y-AXIS: AXIAL MOTION FROM -61.4705119764 TO 6.10223892107

PARTICLE STARTS AT $Y=B$ FINISHES AT $Y=-32.372642686$

AFTER $2 B 00$ BOUNCES

Electric force becomes dominating at $Y=1.25$

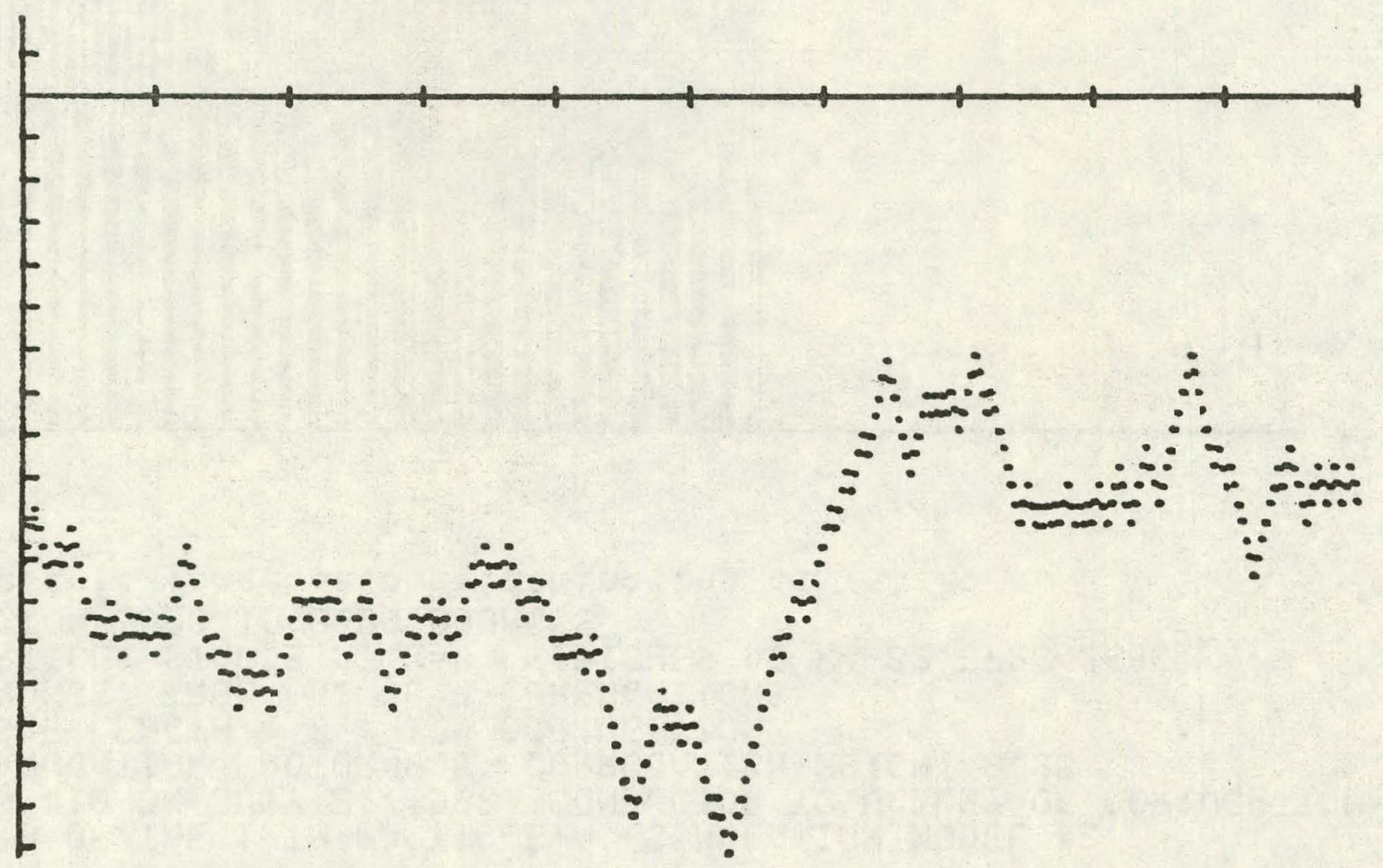

Fig. 2-A-5d 
PATH OF THE 1-TH PARTICLE SIMULATION MODEL \#2

RUN \#1 3 ON JULY 21,1989 CONDUCTOR TO UALLEY OF CORRUGATION $=1.625$
CORRUGATION FACTOR=0.5 CORRLGATIOH HEIGHT $=8.375$

CABLE LENGTH $=2 * 128$ CORRUGATIONS

$X$-RAMGE: FROM -22 TO 54 CCRRUGATIOHS

PARTICLE STARTS AT $X=0$ FINISHES AT $X=-2.2434057833$

FROM $10 B 0$ TO 2080 BOUNCES

Electric force becomes dominating at $Y=1.175$

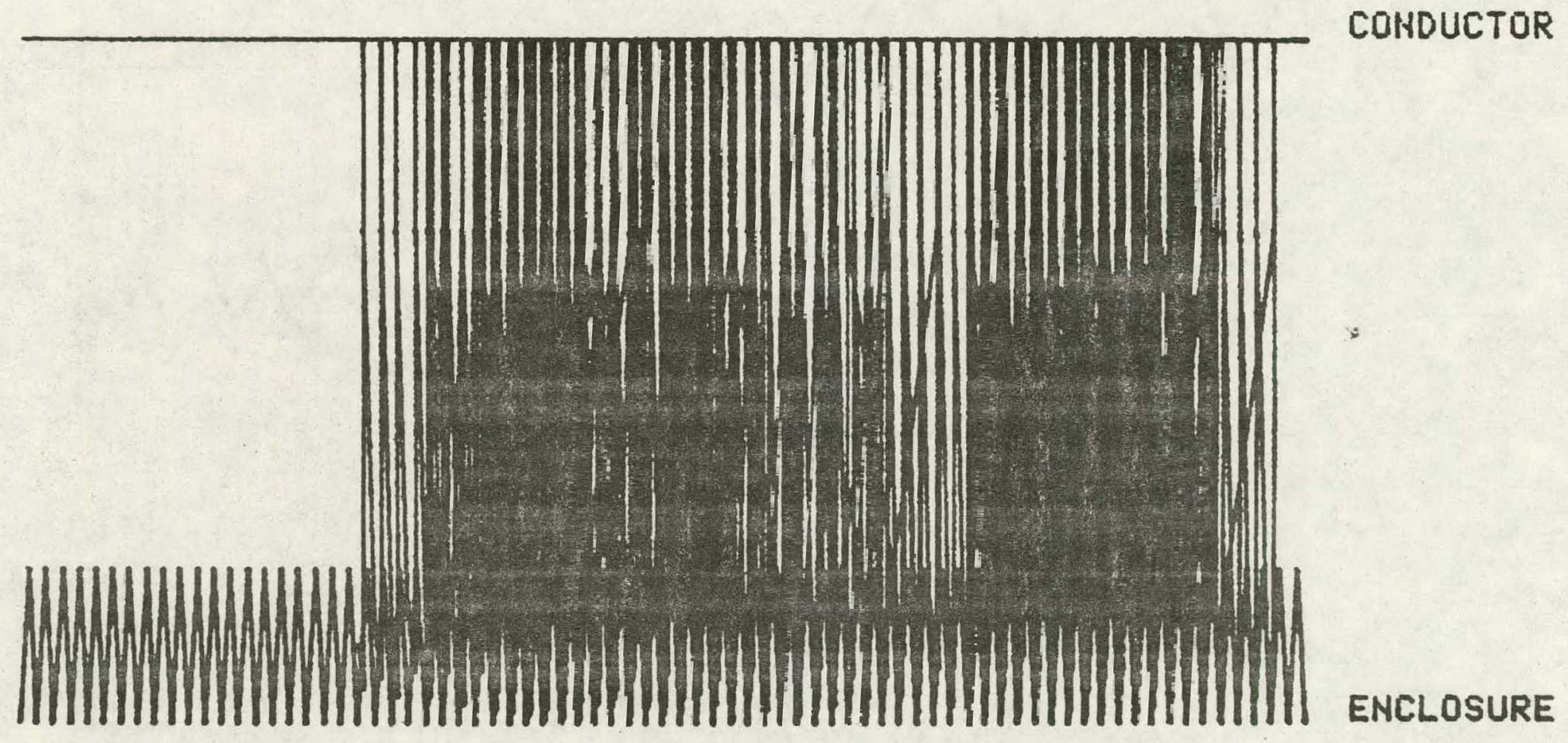

Fig. $2-7-5 c$

Bouncing Path 
PATH OF THE 1-TH PARTICLE SIMULATION MODEL \#2 RUN 13 ON JULY 21,1980 CONDUCTOR TO UALLEY OF CORRUGATION=1.625 CORRUGATION FACTOR $=0.5$ CORRUGATION HEIGHT $=0.375$ CABLE LENGTH $=2 * 120$ CORRUGATIONS

$X$-AXIS: BOUNCES FROM 1001 TO 2000

Y-AXIS: AXIAL MOTION FROM -21.1416429504 TO 53.1985175356

PARTICLE STARTS AT $Y=0$ FINISHES AT $Y=-2.2434057833$

AFTER 2000 BOUNCES

Electric force becomes dominating at $Y=1.175$

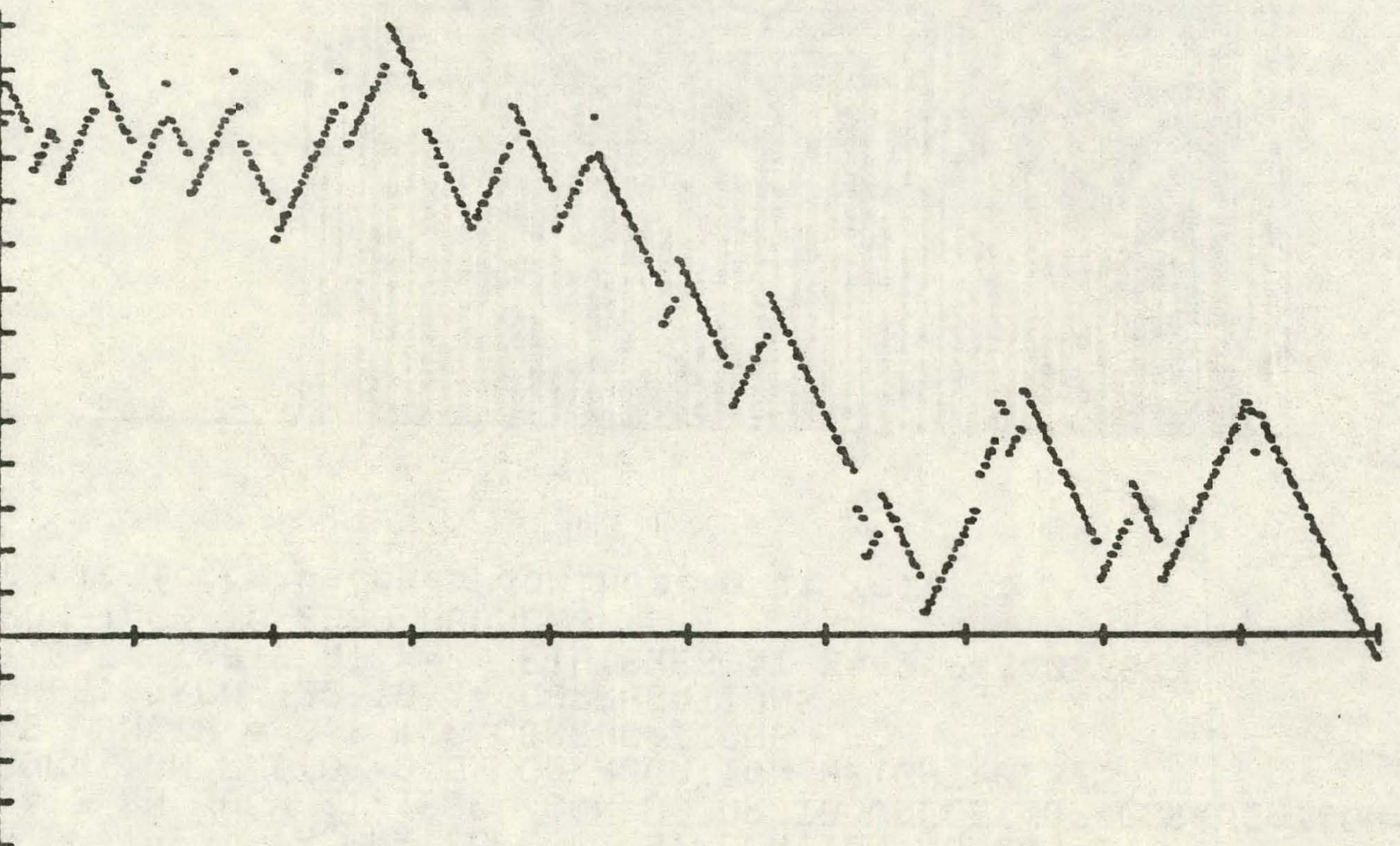

Fig. $2-A-5 d$ 
PATH OF THE 1-TH PARTICLE SIMULATION MOCEL \#2 RUN \#13 ON JULY 20, 1980 CONDUCTOR TO UALLEY CF CORRUGATION=1.625 CORRLGATION FACT JR $=E .3$ CORRUGATION HEJGHT $=0.25$

CABLE LENGTH $=2 * 12 B$ CORRUGATIONS

$X$-RANGE: FROM - 124 TO 4 CORRUGATIONS

PARTICLE STARTS AT $X=0$ FINISHES AT $X=-123.707178099$ FROM $B$ TO 672 BOUNCES

Electric force becomes dominating at $Y=1.25$

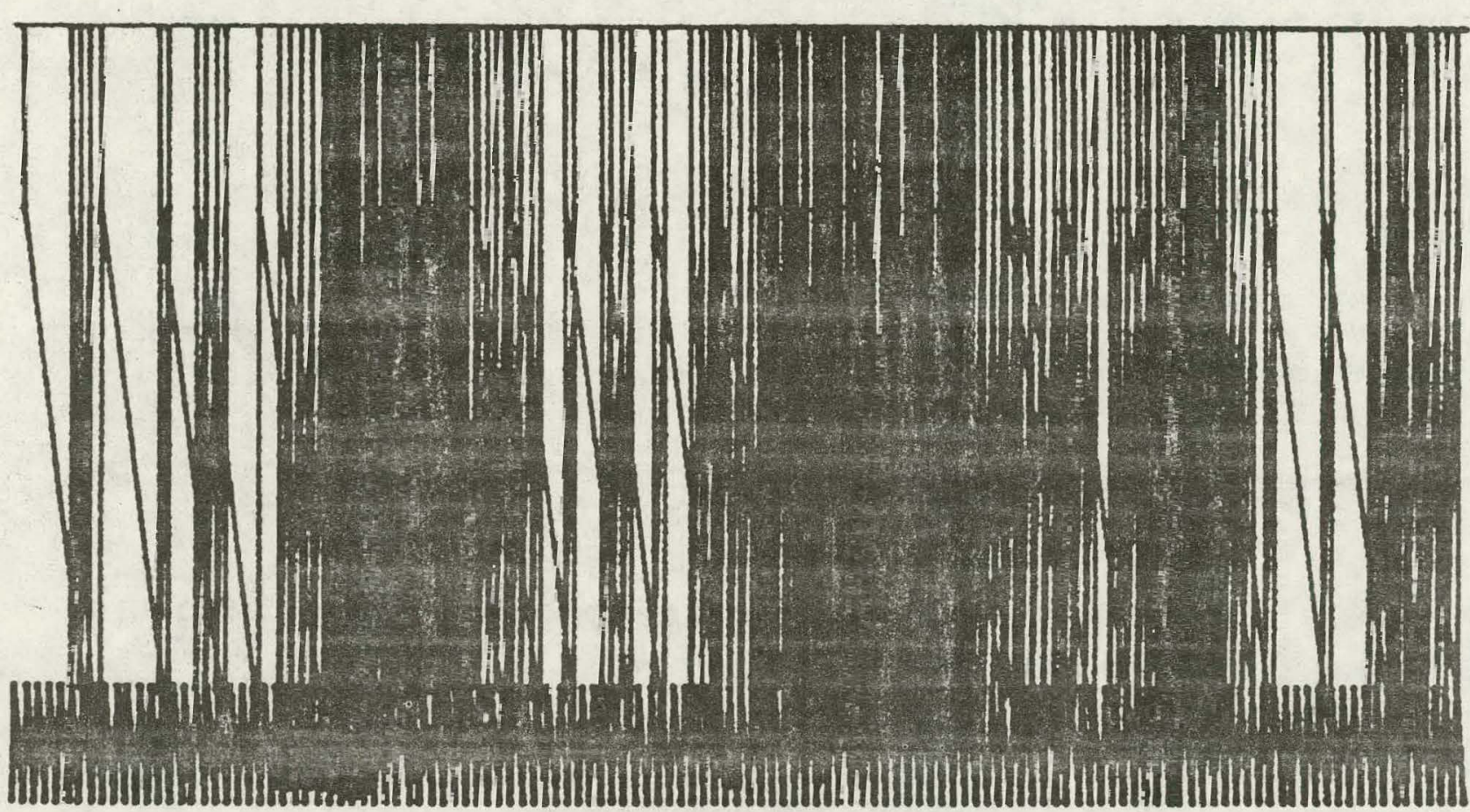

CONDUCTŨR

ENCLOSURE

Fig. 2-A-6a

Bouncing Path 
PATH OF THE 1-TH PARTICLE SIMULATION MODEL \#Z RUN \#13 ON JULY 20, 1980 CONDUCTOR TO UALLEY OF CORRUGATION=1.625 CORRUGATION FACTOR $=0.3$ CORRUGATIOH HEIGHT $=0.25$

CABLE LENGTH $=2 * 120$ CORRUGATIOHS

$X$-AXIS: BOUNCES FRUM 1 TO 672

Y-AXIS: AXIAL MOTION FROM -123.707178099 TO 3.28455729767

PARTICLE STARTS AT $Y=B$ FINISHES AT $Y=-123.707178099$

AFTER 672 BOUHCES

Electric force becomes dominating of $Y=1.25$

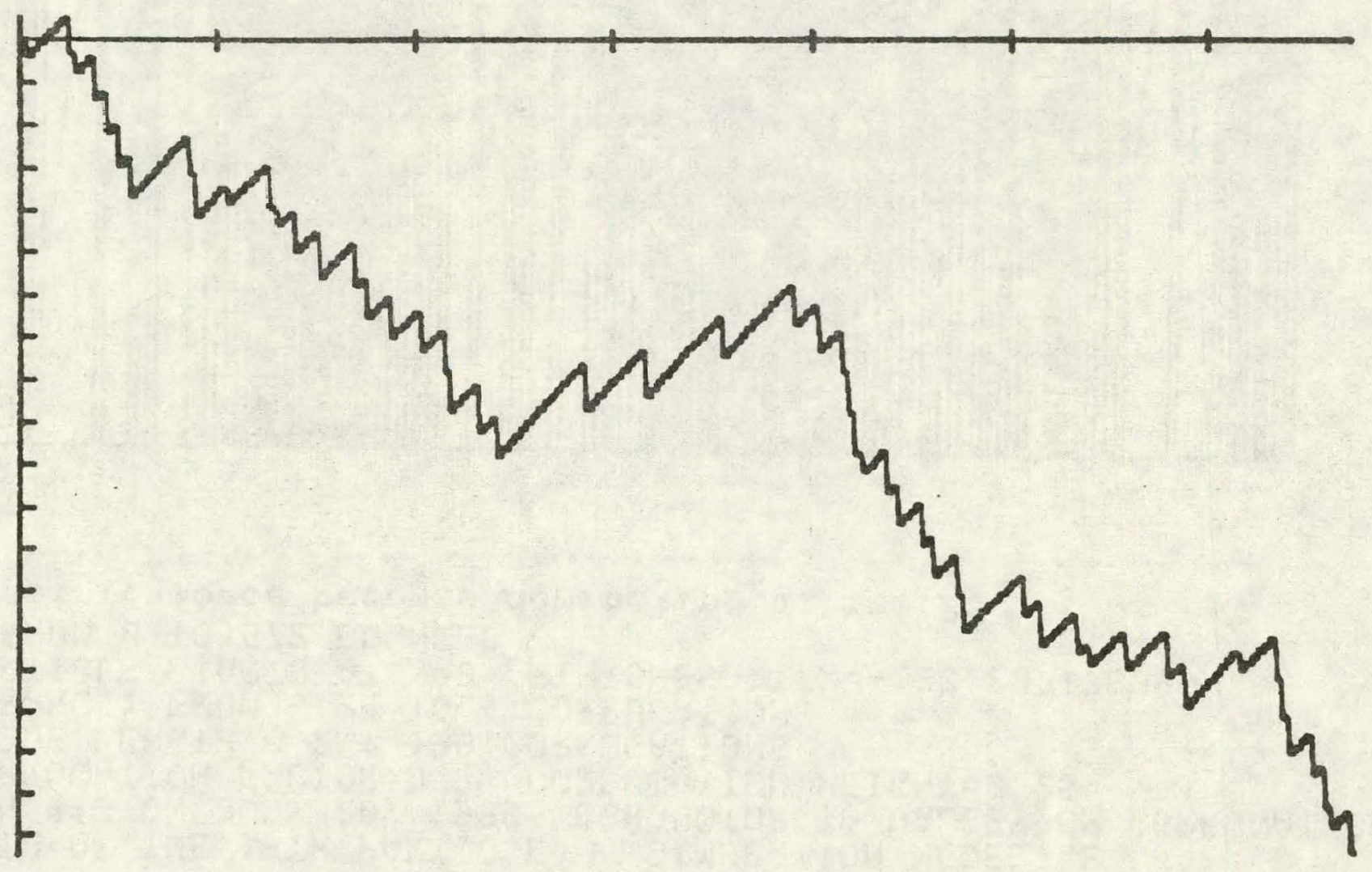

Fig $2-A-6 b$

Axial Displacement vs. Number of Deflections 
Table 2-A-1

Results of Simulation - Model \#1

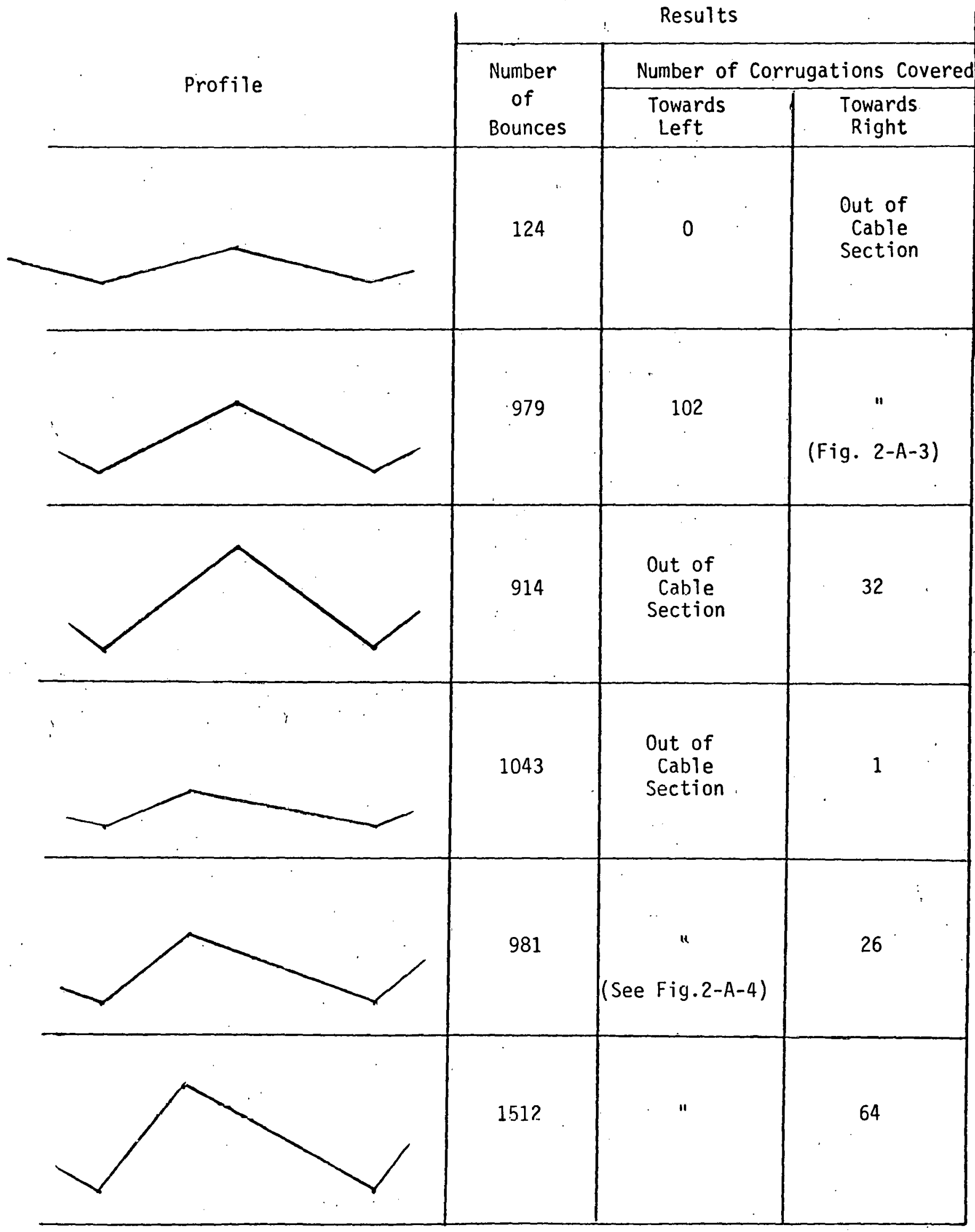


Table 2-A-2

Results of Simulation - Model \#2

$\frac{\text { left }}{\text { negative }}$

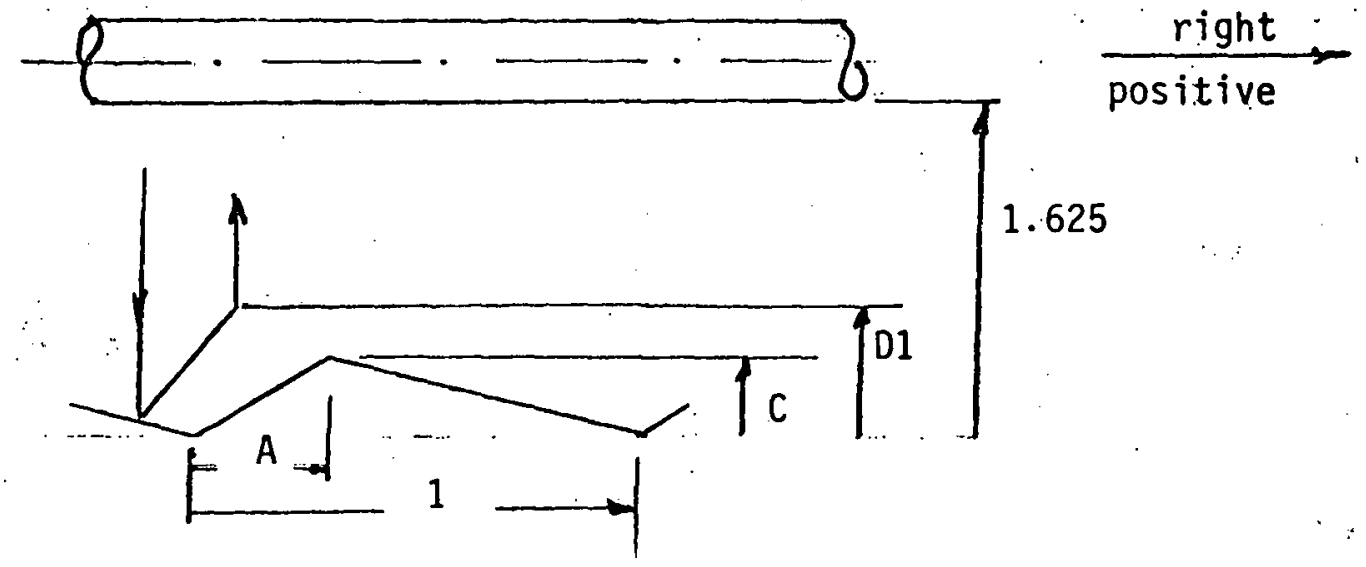

\begin{tabular}{|c|c|c|c|c|c|c|}
\hline \multirow{3}{*}{$A$} & \multirow{3}{*}{ C } & \multirow{3}{*}{$\mathrm{D} 1$} & \multicolumn{2}{|c|}{ Out of Cable Section } & \multirow{2}{*}{\multicolumn{2}{|c|}{$\begin{array}{l}\text { Remaining within the cable } \\
\text { Section. Corrugations } \\
\text { traveled in } N \text { reflections }\end{array}$}} \\
\hline & & & \multirow{2}{*}{ Towards } & \multirow{2}{*}{$\begin{array}{c}\text { No. of } \\
\text { Deflections }\end{array}$} & & \\
\hline & & & & & $N=1000$ & $N=2000$ \\
\hline \multirow[t]{9}{*}{0.5} & 0.125 & 0.325 & & & Same One & Same One \\
\hline & & 0.525 & & & Same One & Same One \\
\hline & & 0.725 & & & -3 to 1 & -3 to 4 \\
\hline & & 1.125 & & & -1 to 1 & -1 to 1 \\
\hline & 0.25 & 0.85 & & & -13 to 4 & -13 to 8 \\
\hline & & 1.05 & & & -3 to 7 & -4 to 9 \\
\hline & & 1.25 & (see Fir & $2-A-5$ & -48 to 6 & -72 to 32 \\
\hline & 0.375 & 0.975 & & & -25 to 26 & -25 to 46 \\
\hline & & 1.175 & & & -21 to 53 & -21 to 53 \\
\hline \multirow[t]{9}{*}{0.3} & 0.125 & 0.325 & & & Same One & Same One \\
\hline & & 0.515 & & & Same One & Same One \\
\hline & & 0.725 & & & -15 to 1 & -24 to 1 \\
\hline & & 0.925 & & . & -46 to $?$ & -96 to 2 \\
\hline & 0.25 & 0.45 & left & 1027 & & \\
\hline & & 0.65 & left & 792 & & \\
\hline & & 0.85 & Teft & 736 & & \\
\hline & & 1.05 & left & 791 & & \\
\hline & & 1.25 & left & 672 & (See & $2-A-6)$ \\
\hline
\end{tabular}


Gives mechanical design data of an aluminum HVDC conductor.

Interactive input; printout to terminal (FORTRAN, ATC DEC-10)

\section{Description and Formula}

$$
\begin{array}{cl}
\text { Inpit: } & \text { Conductor OD } \\
: & \text { Conductor ID } \\
& \text { Conductor length }
\end{array}
$$

Span $=$ Length $/ 2$

$$
I=.0491\left(O D^{4}-I D^{4}\right)
$$

Area $=\pi\left(O D^{2}-I D^{2}\right) / 4$

$w t / f t=$ area $\times 12 \times .0975$

Total $\omega t=\omega t / f t \times 1$ ength

Reaction at center $=1.25 \mathrm{WL}$

Shear

$\doteq .625 \mathrm{WL}$

Bending Moment

$=.125 \mathrm{WL}^{2}$

Max. def1.

$=.0054 \mathrm{WL}^{4} / \mathrm{EI}$

End reaction

$=.375$ WL

Center defi.

$=.0052 \mathrm{WL}^{4} / \mathrm{EI}$

$$
\begin{aligned}
\mathrm{B}=\text { Bending Stres } \mathrm{S} & =\mathrm{MC} / \mathrm{I}=\operatorname{AMAX}\left(\frac{\mathrm{OD}}{2}\right) / \mathrm{I} \\
\mathrm{S}=\text { Shear Stress } & =\text { Shear/Area } \\
\text { Max Stress } & =\text { Mohr's Circle Combination } \\
& =\frac{\mathrm{B}}{2}+\sqrt{\mathrm{S}^{2}+\left(\frac{\mathrm{B}}{2}\right)^{2}} \\
\text { Angle } \quad & \quad\left[\operatorname{Tan}^{-1}\left(\frac{2 \mathrm{~S}}{\mathrm{~B}}\right) / 2\right]\left[\left(\frac{180}{\pi}\right)\right] \\
\text { Therma1 Exp. } & =\mathrm{L} * 12 * 23.8\left(10^{-6}\right)
\end{aligned}
$$

(AOD)
(AID)
(ALEN)

(RMAX)

(VMAX)

(AMAX)

(DMAX)

(REMAX)

Variable Name

$$
\text { (REAX) }
$$




\section{. TYEE CONA - L.EC \\ APPENDIX 4.1}

00100100 WALTE(5,2)

002001 . FDFMAT(E)

00.300

2

Forínté HUIO

C. GAS

INSUHATE

113.

00400

00500

00600

00700

00800

00900

01000

01100

() 1200

FEEAI $(5,1)$ AOI

01300

01400

01500

01500

01700

0.1800

01900

02000

02100

02200

():300

02400

02500

02600

02700

02800

02900

03000

03100

03200

03300

03400

$-03500$

03600

03700

03800

03900

04000

04100

04200

04300

04400

04500

04600

04700

() 4800

04900

05000

05100

05200

05300

05400

05500

05600

05700

05800

05900

06000

06100

06200

06300

nLAnn

\section{3}

WFITE (E; 3$)$

FOFMAT $\left(8 X, X^{\prime}\right.$ II $\left.==^{\prime} \$\right)$

FEALI 5 ;I) AII

WFITE $(5,4)$

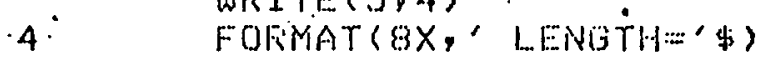

FEALI $(5,1)$ ALIEN

$A L=A L E N / 2:=1 E 7$

$A I=.0491 *(A 0 I * * 4-A I I * * A)$

AFEA $=3.1416 *(A O T * * 2 \cdots$.T [I**2) $/ 4$

$W=A F E A * 12 * .0975$

$W T=W * A L E N$

$A K F=1.25$

A $\mathrm{KV}=.625$

$A K \mathrm{HI}=.0054$

$A K X=.422$

$A K E=.375$

$A K C=.00 \% 2$

$A K M=125$

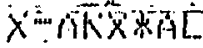

FMAX =AKF":WW*AL

UMAX $=A K U * W * A L$

AMAX $=A K M * W * A L * * 2$

IMMAX $=A K I I * W * A L * * 4 / E / A I * 1728$

FEMAX $=A K E * W * A L$

DCMAXWAKC*W*AL**A/E/AI*1728

ESTFES:-AMAX*AOLI/2/AT*12

SSTFES $=U M A X / A F E A$

$S 2=$ HSTFES/2

SMAX $=$ S2+SQRT (SSTFES $* * 2+5 \$ 5 S W R$.

AFHI $=A T A N(2 * S S: F E S /$ HSTFES $) / 2 * 180 / 3.1416$

THEALENTIT*2.5.8E-6

WFIT ITE $(5,5)$

5 FOFMAT(////,20X,' HURC Gas Insulated Conduction')

6 FOFMAT $(/ /, 5 X$, , IrFut: $0 \mathrm{~N}=(, F 8.2)$

WFITE $(5,7)$ AII

7 FOFMAT (ISX, III= , F8.2).

WFITE $(5,8)$ AL..EN

8 FOFMAT $\left(13 X_{y^{\prime}}\right.$ 'LENGTH $=$ ', F8.2)

WFTTE $(5,9)$

9 FOFMAT(//,5X, Ilata for 1350 Aluminum Coriductor:

WFITE $(5,10)$, AFEEA, FIMAX

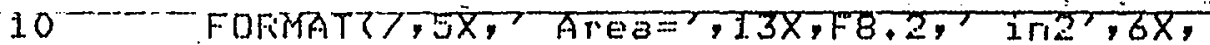

?' Ceriter Fieactior=',F8.2,' 1.bs!')

WFITE $(5,11) W$, FEMAX

11 - FOFMATTEX, WE7ft=, IXX,F6,

1' Frit Fifartion= 'F8,2,' 165 ')

WFITE (?, 12)WT.

12 - FOFMATCSX, TOEOT WE=, QX,F8,2, IGST

WFITE $(5,13)$ AI

13 FOFiMAT $\left(5 X,{ }^{\prime}\right.$ Moment of Inertia:',F8.2,' in, $4^{\prime}$ )

WFTTETS,14JUMAX

14 FOFMAT $\left(/, 5 X, x^{\prime}\right.$ Max Shear=',8X,F8,2,10X,' (at ceriter7usport)')

WFITE (5, 15) AMAX

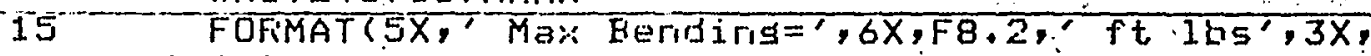

$1^{\prime}$ (at ceriter sisfifort)')

WFITE(5,20)SSTFES

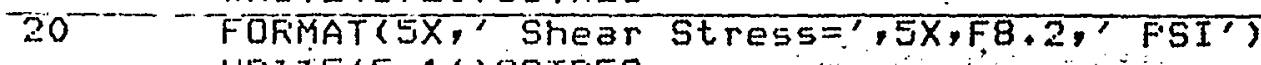

WRITE $(5,16)$ STRES

14

FnFimst(SX." Fandiria St.ross=', 3X,F8,2,'FSI'): 


\section{COND PRINTOUT (CONT'D.)}

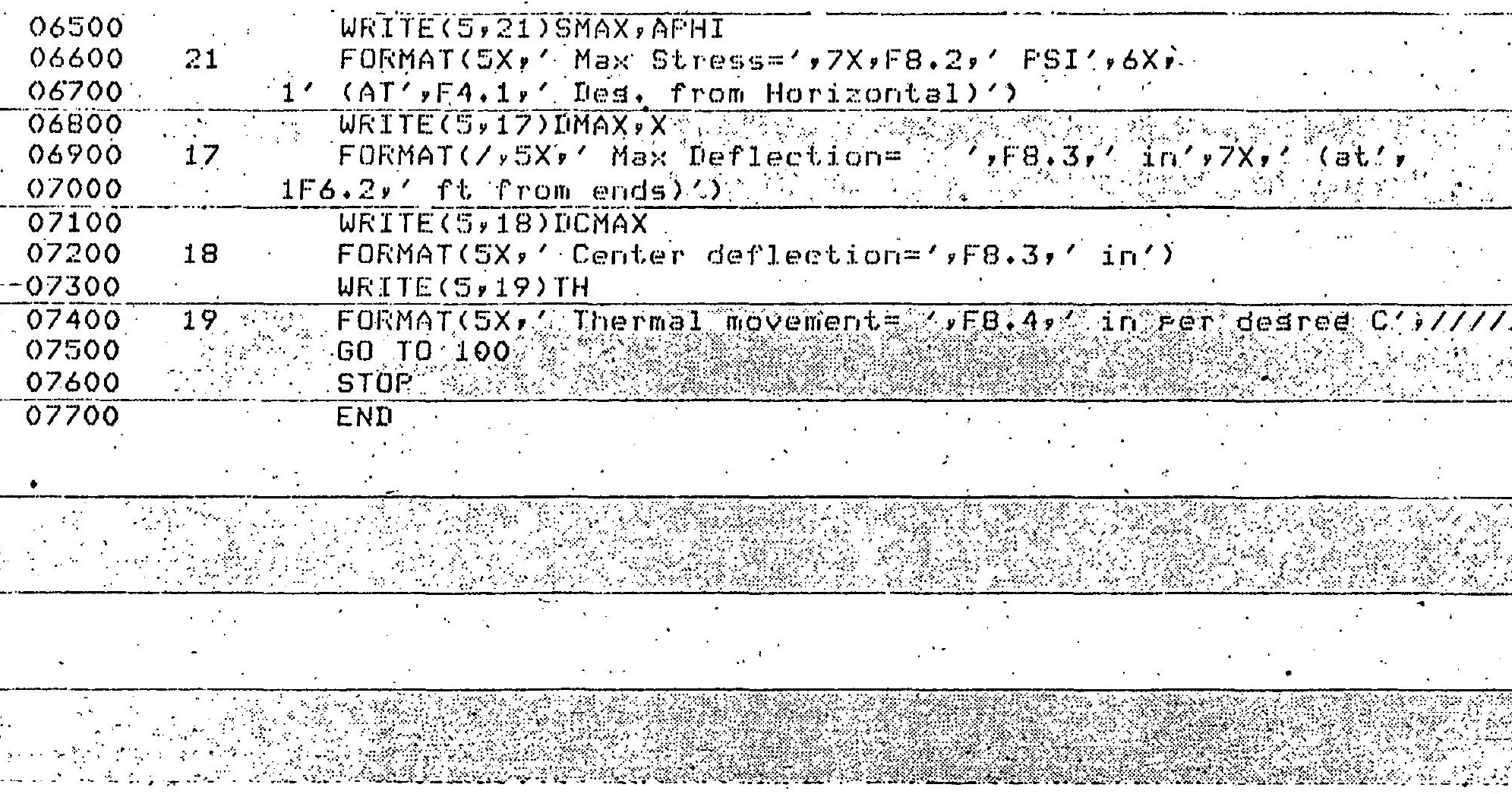


Hude Gas Irisulated conductor.

Trifut: $\quad 0 \mathrm{II}=\quad 0.00$

III $=\frac{0.00}{40.00}$

Liata: for 1350 Aluminum Corductor:

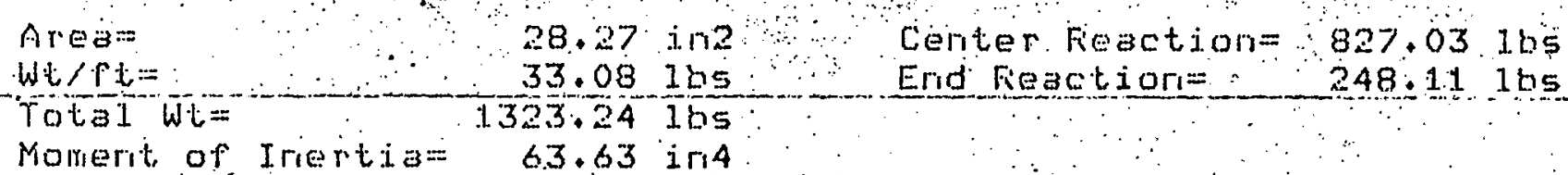

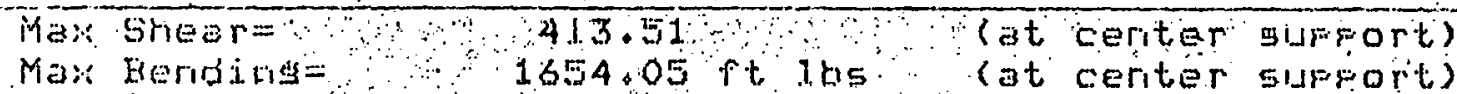

shearstress=. 14.63 Fi

Fendins Stress= 935.76 'pi

Mas Stress= $\quad 935.99$ Esi

(at 0.9 8teg. from horizunleil)

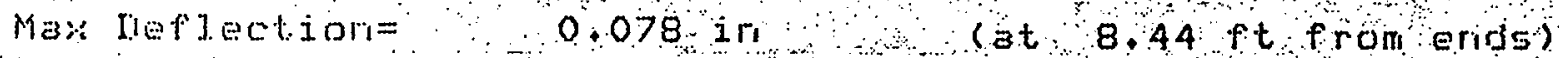

Center gef Iectione 0.075 In

Thermal movemerit $=0.0114$ in per destee $C$

HURC Gas Insinated Conructor

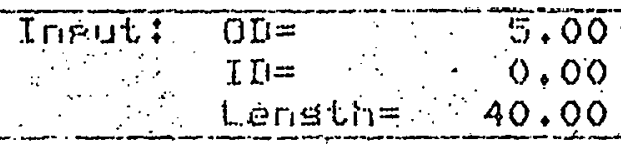

Ilata for 1350 Aluminum Conductors

Area $=$

$w t / r t=$

Total Wt:=

Moment of Iriertia=

Max shear $=$

Má Berrings=

Shear stress=

Beridinis stress=

Ma: Stress=

Max Lef]ection=

Ceriter seflection $=$

Ther rial: movemerit=
19.63 ind

23. 971 bs

$970+12183$

30.69 in 4

287.16

$1148.65 \mathrm{ft}$ ibs

$14.63 .85 i$

1122.91 F 1

$1123,10 \% 51$

0.112 in

0.108 in

0.0114 ir ger oesree C
Center Feaction $=574.32$ 165

Lrió Redation=

172.30 '14

(at center siperonts

(at ceriter suffort)

lat 0.7 desorrom horizoritels

(at 8.44 ft from ends) 
Wric Gas Insulated Conguctor.

InFut: on:m $\quad 9.00$

$\frac{0.00}{600}$

1. enisth $=60.00$

Mata for 1350 Aluminu Conductor:

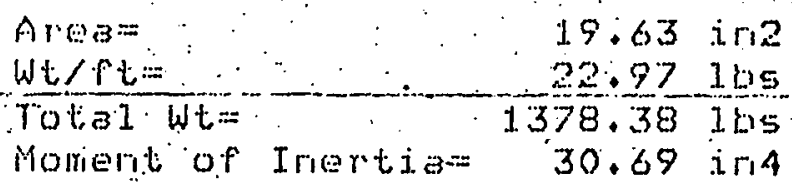

Ceriter Feaction= $861.491 \mathrm{bs}$ End Feectione 258.45165

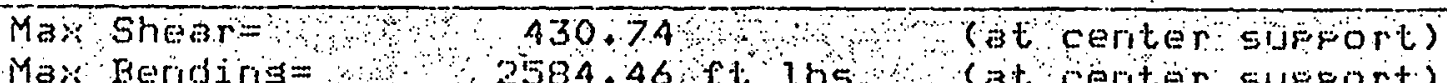

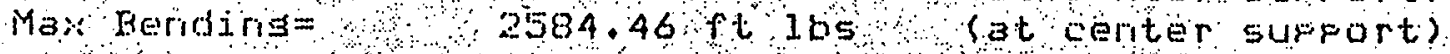

Shear stress $=\ldots \quad 21.94$ Fisi

Eendins Stress= . 2526.56 - $25 i$

Mas stress= 2526.75 Fsi

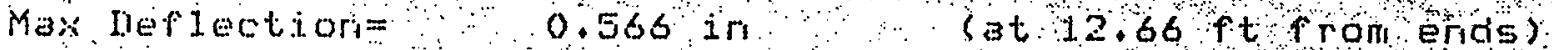

Center ger lection 0.545 in

Themal movement $=0.0171$ in per begree $\mathrm{C}$

Hunc Gas Irsulated Conductor

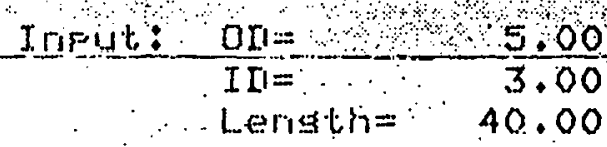

Data for 1350 Alumirum Condictor:

Area $=$

$12.57 \quad 112$

14.701 bs

Total $w=\quad 58811$ iss

Momerit of Inertio $=26.71$ in

Max Shear=

Mas Bending=

183.78

735.13 ft 1 is

(at ceriter sidfiort)

sriear stress=

$14.62=5 i$

Bendiris Stress=0 825.67 psi

Max Stress $=$

$825.93 \mathrm{Fsi}$

Center Fieaction=

End Fieaction=

367.57105

110.27165

$\therefore \therefore$

(at 0.5 deg, from horizortal)

$\therefore$.

Center deflection=

Thermal movemerit =

0.082 in

(at 1.0 des from horizorital)

0.079 in

(at 8.44 ft from erios)

0.0114 in fer desree $\mathrm{C}$ 


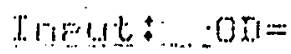

$T 21=$ 6.00

Leristin $=: 40,00$

Hure Gos trisulated Cordugtor

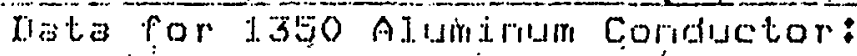

Area $=$

Wt $/ \mathrm{f} t=$

Total wt

Momert of Trentia=

Mä She $\sin =$

Mass Koriding=

Shear stress=

Beridirs stress=

Man Stress $=$

Mas rieflection=

Center deflection=

The rival irowement=
$15.71 \quad 112$

$18 \cdot 38 \cdot 105$

$735 \cdot 13$ 16s

$51,06,104$

229.73

$918.92+\mathrm{t}$ ils
Center Fezction= $459+46$ jos

End Feaction= 137.84 Ibs

1462651 647.84 .251 $648 \cdot 17, \% 5 i$

(at 1.3 deg. Prom horizontal)

(at ceriter susport)

(at-center supfort) (3t $8.44 f t$ from eriss) 
Writes mechanical design data of an Aluminum HVDC conductor to an ALPLOT file, for subsequent plotting. Interactive input; write to ALPLOT.EXT where EXT is supplied by user. (FORTRAN, ATC DEC-10), adapted from COND.LEC

Description and Formula

Input: ALDATA Extension

Wa11 thickness

(6" OD is assumed; enter a $3^{\prime \prime}$ thickness for solid)

Processing: (Same formulas as COND.LEC)

Runs lengths from 30 to 70 in steps of 1

Length (integer for DO loop)

Length (real for equations)

Span Length $=$ Length $/ 2$
Variable Name

(THICK)
Writes: $\quad: \quad: \cdot \because \cdot$ OD

Wa1l thickness

Length

Max. Stress

Max. Deflection

Center Reaction

Exp. Joint; Reaction*
(LENGTH)

(TLEN) .

(AOD)

(THICK)

(TLEN)

(SMAX)

(DMAX)

(RMAX)

(REXP)

* Consists of two end reactions plus wt. of exp. joint (50 lbs.) 
COND1.LEC

$00100-1$

00200

. 00300

$00408-2$

00500

00600

00650

00660

00700

00800

00900

00950

01000

01050

01060

01070

01100

01110

01200

01300

01400

01500

01550

01600

01700

01800

01900

02000

c. 02100

$-\frac{02200}{02300}$

( 02400

02500

02600

C. 02700

02800

02900

c. 03000

03100

03200

C 03300

03400

03500

03700

03775

03800

(.) 03900

07500

07600

(.) 07700

3

30

4
FOFMATAT (F) -

IOUMHE FFECISTON EX

WFITTE $(5,2)$

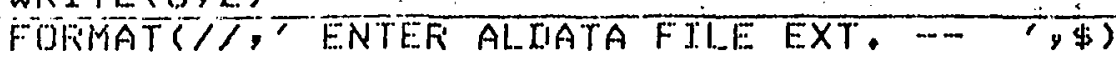

FEEALI $(5,3)$ EXT

FQFMAT $(A 3)$

ENCONE $(10,30, E X) E X T$

FOFIMAT ('ALIATA.', 'AB)

OPEN (UNI $T=1$, FILE=EX, ACCESS='SEROUT')

$A 0 \mathrm{I}=6.0$

WFI ITE $(5,4)$

FOFMAT (' ENTEF WALL THICKNESS - - ',

TEEAIIS, 1$)$ THICK

AID=AOII-2*THICK

INO 200 LENGTHk $30,70,1$

TLEN=ILELITH

$A L=T L E N / 2$

$E=1 E 7$.

$A I=.0491 *(A O I 1 * * 4-A I I 1 * * 4)$

$A F E A=3.1416 *(A O D * * 2-A I[1 * * 2) / 4$

$W=A F E A * 12 * .0975$

WT $=W * L E N G T H$

EXFWT $=50$

$A K K=1.25$

$A K V=.625$

$A K I=.0054$

$A K X=.422$

$A K E=.375$

$A K C=.0052$

$A K M=.125$

$X=A K X * A L$

FMAX:AKFFWWAL

UMAX $=A K \cup * W * A L$

$A M A X=A K M * W * A L * * 2$

IIMAX $=A K[I * W * A L * * A / E / A I * 1728$

FEEYAAX $=A K E X W * A L$

IICMAX $=A K C * W * A L * * 4 / E / A I * 1728$

BSTRES =AMAX *AOI $/ 2 / A I * 12$

SSTFES - VMAX/AFEA

S2=ESTFES $/ 2$

SMAX $=52+$ SQRT (SSTFES**2+S2**2)

AEHI =ATAN (2*SSTFESS/BSTFES)/2*180/3,14.16

FEXF: $=2$ 2*FEEMAX+EXF'WT

WFITE $(1,5)$ AOR, THTCK, TLEN, SMAX, LMAX, FMAX, REXP

FOFIMAT ( $4 F 10.1, F 10.4,2 F 10.1)$

CONT INUE

CLOSE (UNIT=1, FILE=EX,ACCESS='SEQOUT!)

GO TO 100

STOF:-

ENI 